\title{
Development of a Standard Fire Condition for a Large Compartment Floor Assembly
}

Ana Sauca, Chao Zhang, William Grosshandler, Lisa Choe, Mathew Bundy

This publication is available free of charge from: https://doi.org/10.6028/NIST.TN.2070

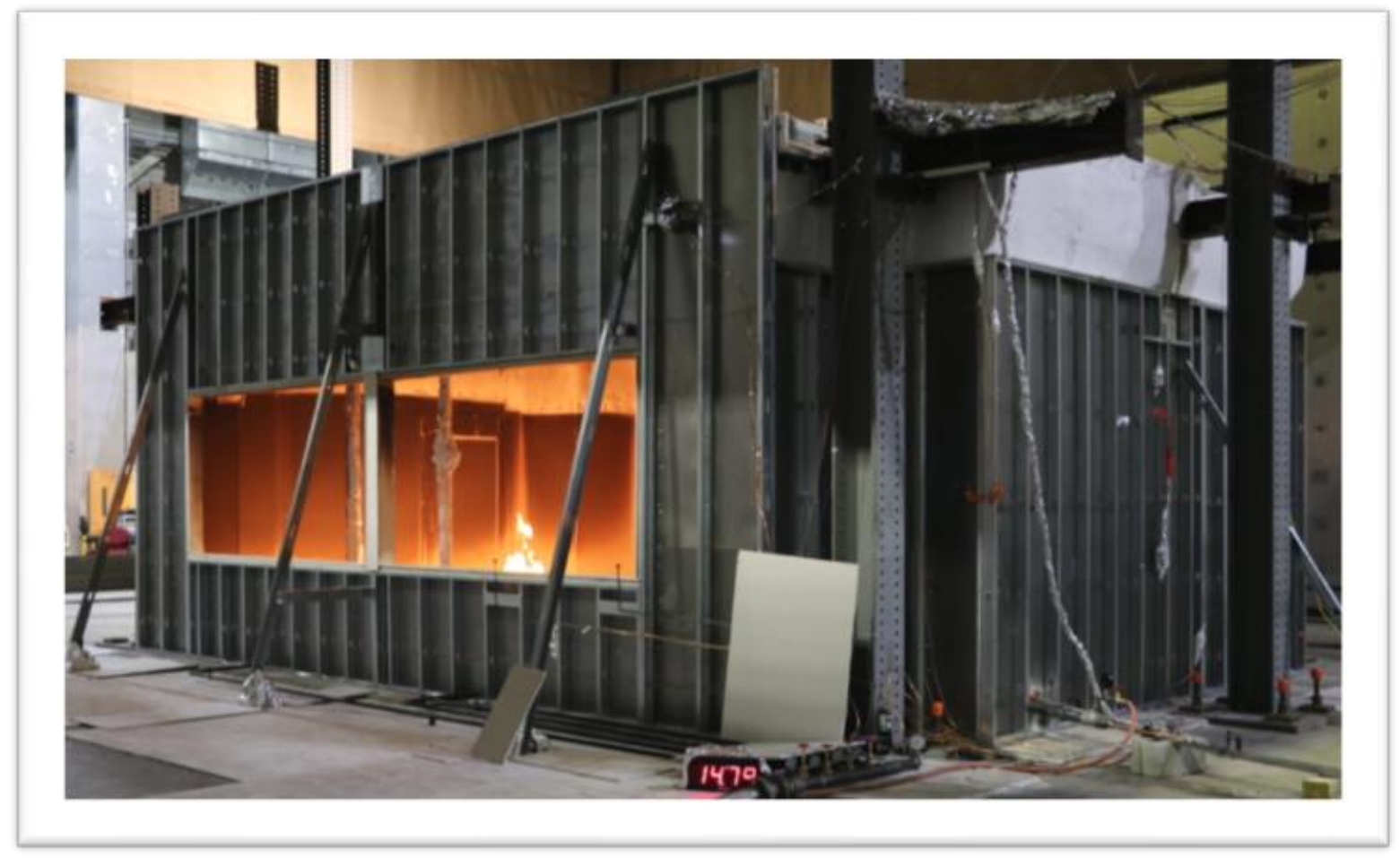


NIST Technical Note 2070

\title{
Development of a Standard Fire Condition for a Large Compartment Floor Assembly
}

\author{
Ana Sauca \\ Chao Zhang \\ William Grosshandler \\ Lisa Choe \\ Mathew Bundy \\ Fire Research Division \\ Engineering Laboratory
}

This publication is available free of charge from:

https://doi.org/10.6028/NIST.TN.2070

October 2019

INCLUDES UPDATES AS OF April 9, 2020; SEE APPENDIX E

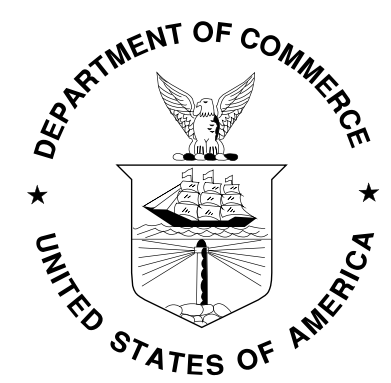

U.S. Department of Commerce

Wilbur L. Ross, Jr., Secretary

National Institute of Standards and Technology

Walter Copan, NIST Director and Undersecretary of Commerce for Standards and Technology 
The policy of the National Institute of Standards and Technology is to use metric units in all its published materials. Because this report is intended for the U.S. building construction industry, which uses inch-pound units, it is more practical and less confusing to use inch-pound units, in some cases, rather than metric units. However, in most cases, units might be presented in both metric and the inch-pound system.

Certain commercial entities, equipment, products, or materials are identified in this document in order to describe a procedure or concept adequately. Such identification is not intended to imply recommendation or endorsement by the National Institute of

Standards and Technology, nor is it intended to imply that the entities, products, materials, or equipment are necessarily the best available for the purpose.

National Institute of Standards and Technology Technical Note 2070

Natl. Inst. Stand. Technol. Tech. Note 2070, 63 pages (October 2019)

CODEN: NTNOEF

This publication is available free of charge from: https://doi.org/10.6028/NIST.TN.2070 


\section{ABStRACt}

This report presents the experimental investigation of a test fire in a large compartment of approximately $10 \mathrm{~m}$ wide, $7 \mathrm{~m}$ deep and $3.8 \mathrm{~m}$ high constructed in the National Fire Research Laboratory of the National Institute of Standards and Technology. The test fire condition, controlled by heat release rate of natural gas as a fuel, thermal boundary properties of the compartment, and ventilation, was designed to produce a uniform temperature condition in the upper layer of the compartment which followed the ASTM E119 time-temperature curve. Three fire tests were conducted with the same compartment and natural gas-fueled burners, including two repeated $15 \mathrm{~min}$ burn tests and one long test with heating duration of $75 \mathrm{~min}$ from ignition. Fire characteristics such as heat release rates, upper layer gas temperatures across the compartment and heat fluxes were measured. The measured average upper layer gas temperature was comparable with that prescribed in ASTM E119 standard. The maximum absolute difference towards the end of the long test was around $70{ }^{\circ} \mathrm{C}$. The upper layer gas temperature was uniform with a $2 \%$ coefficient of variation at the end of the test. The area under time-temperature curve, obtained by averaging the results from the readings, is within $2 \%$ of the corresponding area under the standard ASTM E119 time-temperature curve. The measured peak heat flux towards the end of the long test was $175 \mathrm{~kW} / \mathrm{m}^{2}$. The design procedure for the test fire, instrumentation and measurements, and the experimental results are presented.

Keywords: ASTM E119 time-temperature curve; Test fire; Experimental investigation; Large compartment; Design approach; Fire resistance 
This page intentionally left blank. 


\section{TABLE OF CONTENTS}

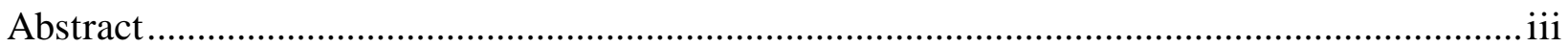

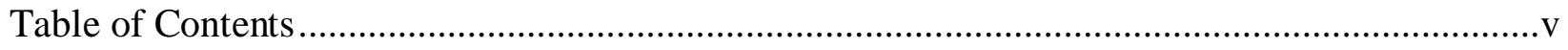

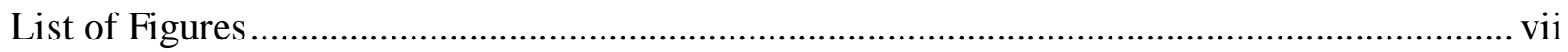

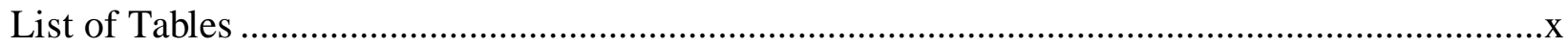

Chapter 1 Introduction................................................................................... 1

Chapter 2 Design of Test Fires ...................................................................

2.1 Fire Compartment ..........................................................................................

2.2 Natural Gas Burner ............................................................................................

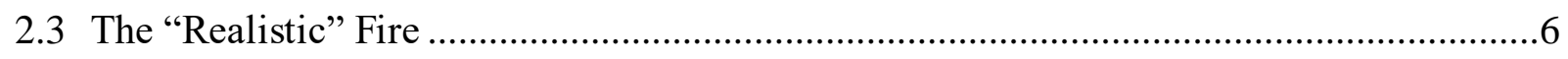

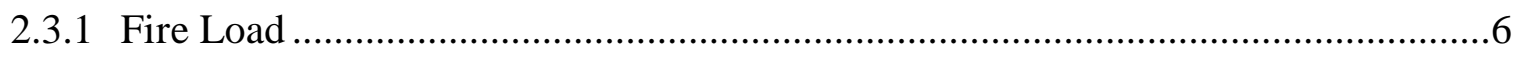

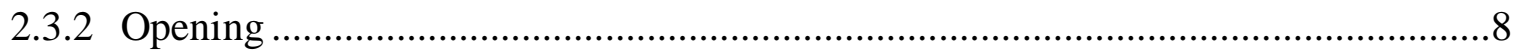

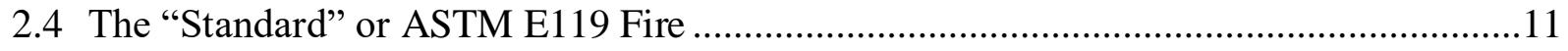

Chapter 3 Experimental Investigation............................................................... 13

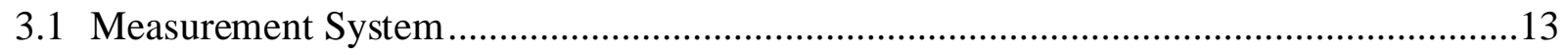

3.1.1 Burner Heat Release Rate....................................................................... 13

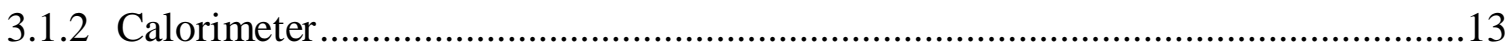

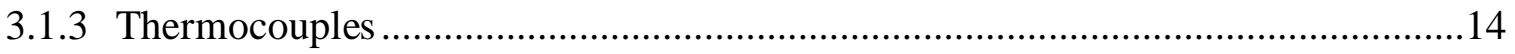

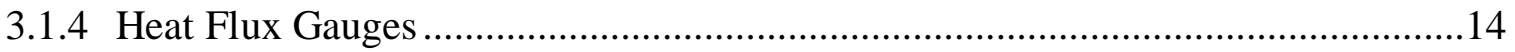

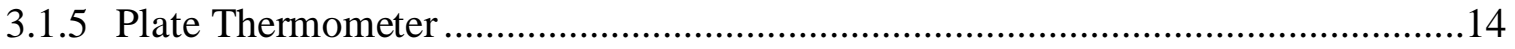

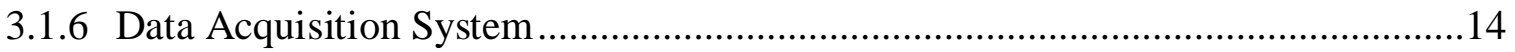

3.1.7 Uncertainty of Measurements …............................................................. 15

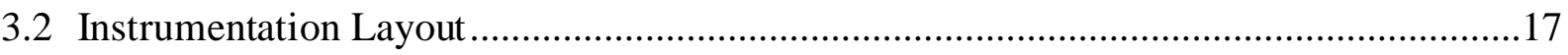


3.3 Test Results and Observations ............................................................................22

3.3.1 Heat Release Rate.................................................................................22

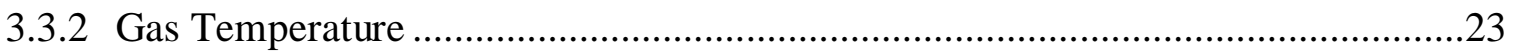

(i) Steel Sheathed Thermocouples ................................................................. 23

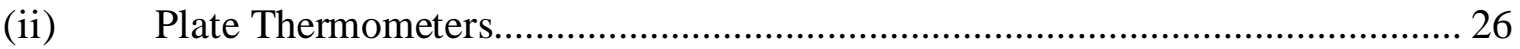

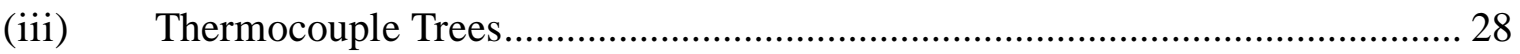

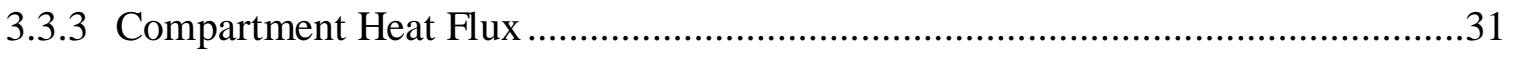

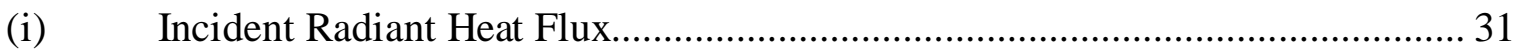

(ii) Measured Radiant and Convective Heat Flux .............................................. 33

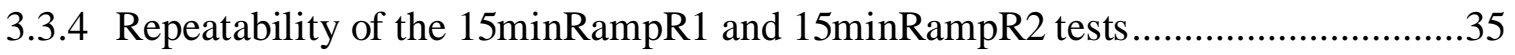

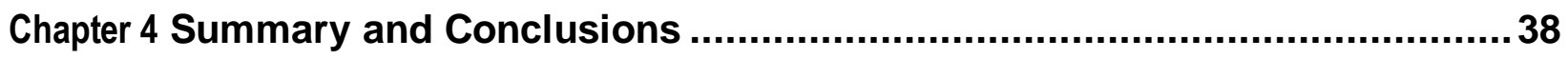

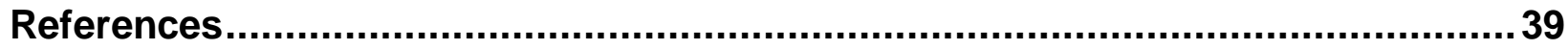

Appendix A: 15minRampR1 ........................................................................... 41

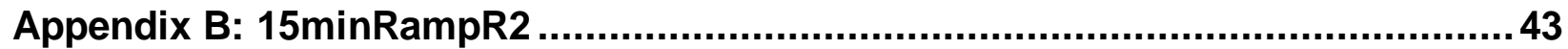

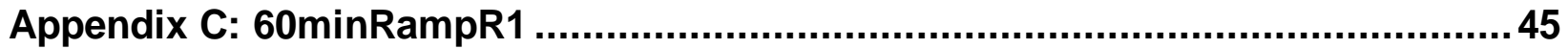

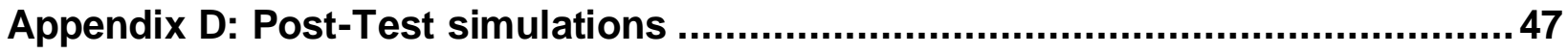

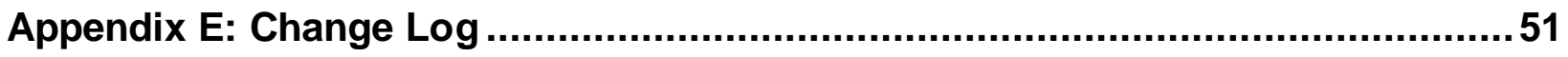




\section{LIST OF FIGURES}

Figure 1. (a) Test Structure-3D view (b) Steel frame layout-plan view........................................ 3

Figure 2. Measured internal dimensions of the fire compartment, imperial units. All dimensions

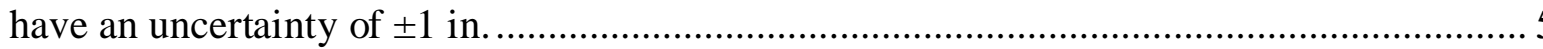

Figure 3. Detailed drawing of gas burner assembly, units in $\mathrm{cm}$. All dimensions have an uncertainty 6

Figure 4. Proposed HRR for the "realistic" fire and predicted gas temperature using the EC1 parametric fire model. Three other HRRs are also shown, which have the same growing phase as the proposed HRR. The areas below different HRR curves are the same. 42.55 $\mathrm{kW} / \mathrm{min}$ — steady stage of $15 \mathrm{~min} ; 57.14 \mathrm{~kW} / \mathrm{min}$ — steady stage of $45 \mathrm{~min} ; 86.96 \mathrm{~kW} / \mathrm{min}$ steady stage of $75 \mathrm{~min} ; 117.65 \mathrm{~kW} / \mathrm{min}$ - steady stage of $90 \mathrm{~min}$.

Figure 5. Field fire model simulated flame behaviors for various opening and burners configurations. The main opening in the south wall (to the right) is $6 \mathrm{~m}$ wide and $1.5 \mathrm{~m}$ high and remains constant in size for all of the geometries examined, although height of the window sill is varied. The size and location of the opening on the opposite (north) wall, and the number and distribution of the burners are varied.

Figure 6. FDS simulated temperature distributions for the compartment with proposed $H R R$, opening, and burners (Units in ${ }^{\circ} \mathrm{C}$ ). The results are for fire at $1 \mathrm{~h}$ after burning. (Left) 0.305 $\mathrm{m}$ below the ceiling; (Right) $2 \mathrm{~m}$ away from widow center

Figure 7. FDS predicted gas temperatures for the compartment with proposed $H R R$, opening, and burners. Max, Ave and Min $T_{g}$ are maximum, average, and minimum values of 35 thermocouples located $0.305 \mathrm{~m}$ below the ceiling.

Figure 8. Proposed HRR for "standard" test fire and FDS predicted average gas temperatures.. 11

Figure 9. Thermocouple devices used to calculate the average gas temperatures by FDS. All the devices are located $0.305 \mathrm{~m}$ below the ceiling. The circled five devices (TCC1 to TCC5) are used in the calculation. (a) view from the bottom of the compartment; (b) plan view. ........ 12

Figure 10. Instrumentation layout, imperial units. All dimensions have an uncertainty of \pm 1 in. 17

Figure 11. (a) The burner and (b) the position of the burners in the compartment...................... 18

Figure 12. (a) Ceiling thermocouples; (b) thermocouple trees; (c) north opening thermocouples;

(d) south opening thermocouples.

Figure 13. Thermocouple Tree Details. All dimensions have an uncertainty of \pm 1 in................. 20

Figure 14. Plate thermometer in the (a) east side and (b) center of the compartment. 
Figure 15. The heat flux gauges mounted in the south-east of the compartment..................... 21

Figure 16. Measured burner and calorimeter HRRs. ..................................................... 23

Figure 17. Measured average upper layer gas temperature for the tests................................ 24

Figure 18 Measured upper layer gas temperatures by 12 thermocouples for (a) 15minRampR1,

(b) 15minRampR2, and (c) 60minRampR1.

Figure 19. Temperatures measured using the plate thermometers for (a) 15minRampR1, (b) 15minRampR2, and (c) 60minRampR1. 28

Figure 20. Trees temperatures for (a) 15minRampR1, (b) 15minRampR2, and (c) 60minRampR1 30

Figure 21. Temperature profile at the location of Tree 1 and Tree $2 .$. 31

Figure 22. Incident fluxes for (a) 15minRampR1, (b) 15minRampR2, and (c) 60minRampR1.. 33

Figure 23. Measured heat fluxes for (a) 15minRampR1, (b) 15minRampR2, and (c)

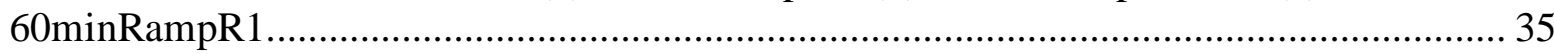

Figure 24. Reproducibility of the average upper layer gas temperature ................................. 36

Figure 25. Reproducibility of the heat release rate (HRR) of the burner................................. 36

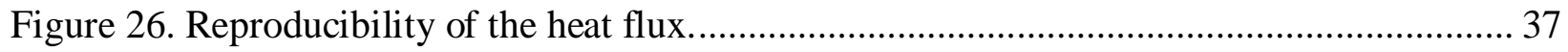

Figure 27. Gardon gauges temperature for 15 minRampR1 test. ............................................ 41

Figure 28. Openings temperature for $15 \mathrm{minRampR1} \mathrm{test.................................................} 42$

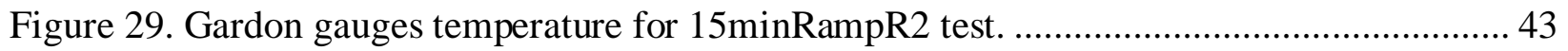

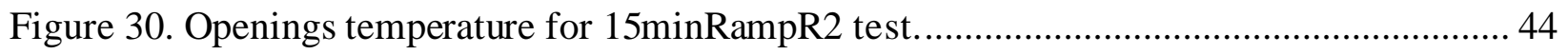

Figure 31. Gardon gauges temperature for $60 \mathrm{minRampR} 1$ test. ........................................ 45

Figure 32. Openings temperature for $60 \mathrm{minRampR1}$ test............................................... 46

Figure 33. 15minRampR1. (a)-(1) are TC1-TC12. Bold red line - test data; black line - FDS data 48

Figure 34. 15minRampR2. (a)-(1) are TC1-TC12. Bold red line - test data; black line - FDS data

Figure 35. 60minRampR1. (a)-(1) are TC1-TC12. Bold red line - test data; black line - FDS data 
This page intentionally left blank. 


\section{LIST OF TABLES}

Table 1. Key geometric and thermal parameters. ........................................................... 7

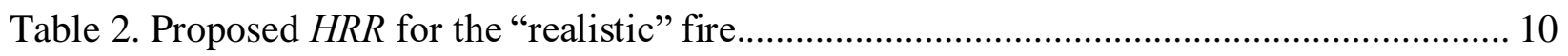

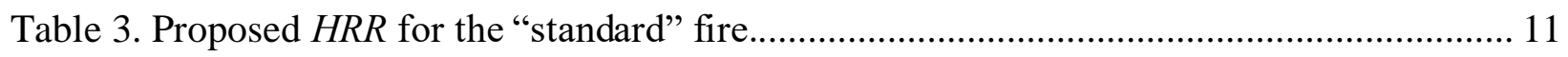

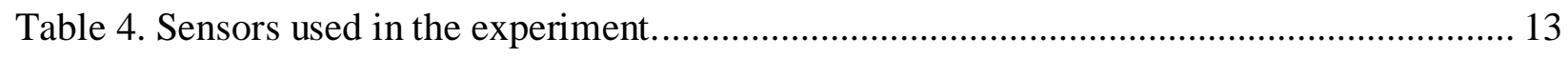

Table 5. Uncertainty in the experimental data............................................................ 16

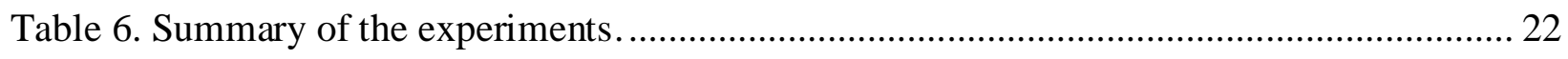


This page intentionally left blank. 


\section{Chapter 1 \\ INTRODUCTION}

Fire safety design of steel-framed buildings in the United States is based on prescriptive fireresistance ratings of individual load-bearing elements which require a certain amount of insulation coating. Adequacy of insulating materials and associated installation details must be certified by standard fire testing, e.g., ASTM E119 (2018). In standard fire testing, a custom-built gas furnace is used to heat a small-scale composite floor assembly by following the gas temperature-time curve prescribed in the ASTM E119 standard. The span length of the test assembly seldom exceeds $6 \mathrm{~m}$ due to the size limitations of available furnaces. Further, the test assembly does not incorporate realistic structural connections. The ends of a test assembly are either simply supported as allowing free thermal expansion and rotation during the fire exposure or fully fixed at the test frames of which stiffness is generally not available in public. In real building fires, the actual fire resistance of composite floor assemblies can be largely influenced by the restraint and stiffness provided by adjoining structural frames and connections as witnessed in the Cardington test series (British Steel, 1999; Wald et al., 2006).

While there have been some experimental studies conducted to assess the fire resistance of composite steel frames over the last few decades, most of them were conducted in Europe. The Cardington fire test program and other follow-up tests (e.g., Bailey and Toh, 2007; Vassart and Zhao, 2011) highlighted the inability of isolated floor assemblies used for standard fire testing to predict the actual fire resistance of composite floor assemblies in a steel framed building. With the inclusion of tensile membrane action, composite floor assemblies supported by primary structural steel frames can withstand significant fire loading without collapse, thus secondary (filler) floor beams can remain unprotected. The load-carrying capacity of the composite floor systems observed in those tests was highly influenced by the detailing of the structural steel connections and the reinforcement within the composite slabs. Specifically, the use of flexible end-plate connections and high reinforcement ratios in the composite slabs, more common in European practice, produced significantly larger capacities that those predicted using standard fire test methods.

Although methods for high-fidelity modeling of structures subjected to fire have improved, they still require validation against the experimental data. To date, there is no data to describe the actual fire performance of large-scale composite steel frames designed in compliance with U.S. building codes and specifications. Experimental studies to investigate this performance must incorporate span lengths and floor beams commonly used in the U.S. practice. This cannot be achieved using 
current testing methods with furnaces. If the structural redundancy of a given multistory building against fire attack is unknown, fire ratings mandated in building codes can result in costly passive fire protection systems. Additionally, the use of certain shear connections that cannot resist thermal restraint forces can render the fire protection coating insufficient to prevent fire-induced failure, for example, the investigation of the World Trade Center 7 collapse (McAllister et al., 2012).

Motivated by such research needs, NIST launched a multi-year research project to measure the behavior and design limit states (governing failure modes) of full-scale composite floor systems subjected to fire. As part of this research project, a two-story steel-framed building is being constructed at the National Fire Research Laboratory (Bundy et al., 2016). As shown in Figure 1 the test structure is two bays by three bays in plan, covers a nominal area of $18 \mathrm{~m} \times 11 \mathrm{~m}$, and has an overall height of $7.2 \mathrm{~m}$. The fire test bay is $6.1 \mathrm{~m}$ by $9.1 \mathrm{~m}$ in plan and $3.8 \mathrm{~m}$ in height. The structural frames were designed to represent gravity frames commonly used in office buildings in the United States.

The test fires will be confined within a single compartment, allowing flame leakage through openings with restricted sizes and locations. The first test fire or the "standard" fire will be controlled to provide uniform average gas temperatures that follow the ASTM E119 timetemperature curve to study the embedded safety factor of the composite floor systems designed using prescriptive approaches. The second test fire or the "realistic" fire is intended to represent an extreme but plausible condition, one that has the potential to threaten the structure. The results of the fire test will elucidate the failure modes of the floor system in a realistically restrained structural steel frame and will be used for validation of numerical models.

This report presents parameters used for designing the fire loading used for the experimental study of composite floor systems subject to compartment fires. Three fire tests were carried out at the NFRL, which were designed to produce a uniform temperature condition in the upper layer of the compartment which followed the ASTM E119 time-temperature curve. 


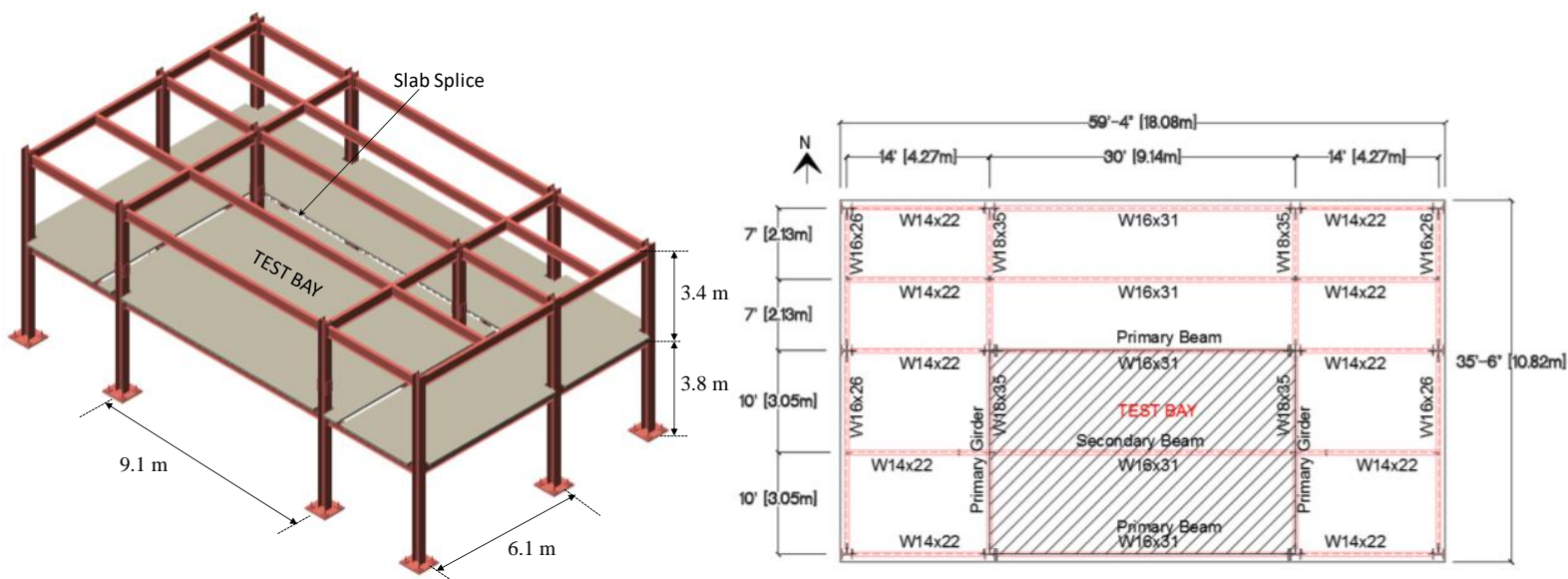

Figure 1. (a) Test Structure-3D view (b) Steel frame layout-plan view. 


\section{Chapter 2 \\ DESIGN OF TEST FIRES}

The behavior of the two-story steel-framed building is analyzed under two fire scenarios confined within a single compartment, allowing flame leakage through openings with restricted sizes and locations.

The "realistic" fire is intended to represent an extreme but plausible condition, one that has the potential to threaten the structure. The "standard" fire will be controlled to provide uniform average gas temperatures that follow the ASTM E119 time-temperature curve to study the embedded safety factor of the composite floor systems designed using prescriptive approaches.

This chapter presents more details about the design procedure of the two fires. Nevertheless, prior the two-story steel-framed building tests, only the "standard" fire test is experimentally simulated in a build in compartment, to check the designed parameters, and the details of the work are the main topic of this report.

\subsection{FIRE COMPARTMENT}

For this experimental series, the fires were confined to a compartment of about $10 \mathrm{~m}$ (width) $\times$ $7 \mathrm{~m}$ (depth) $\times 3.8 \mathrm{~m}$ (height), as shown in Figure 2 .

The compartment walls were made of stiffened sheet steel (18 gauge) protected by three layers of $16 \mathrm{~mm}$ thick gypsum boards (4 hours fire rating); the compartment ceiling slab was made of stiffened sheet steel (20 gauge) protected by two layers of $25.4 \mathrm{~mm}$ thick ceramic blanket (Kaowool). Two layers of $16 \mathrm{~mm}$ cement boards were placed on the floor. 


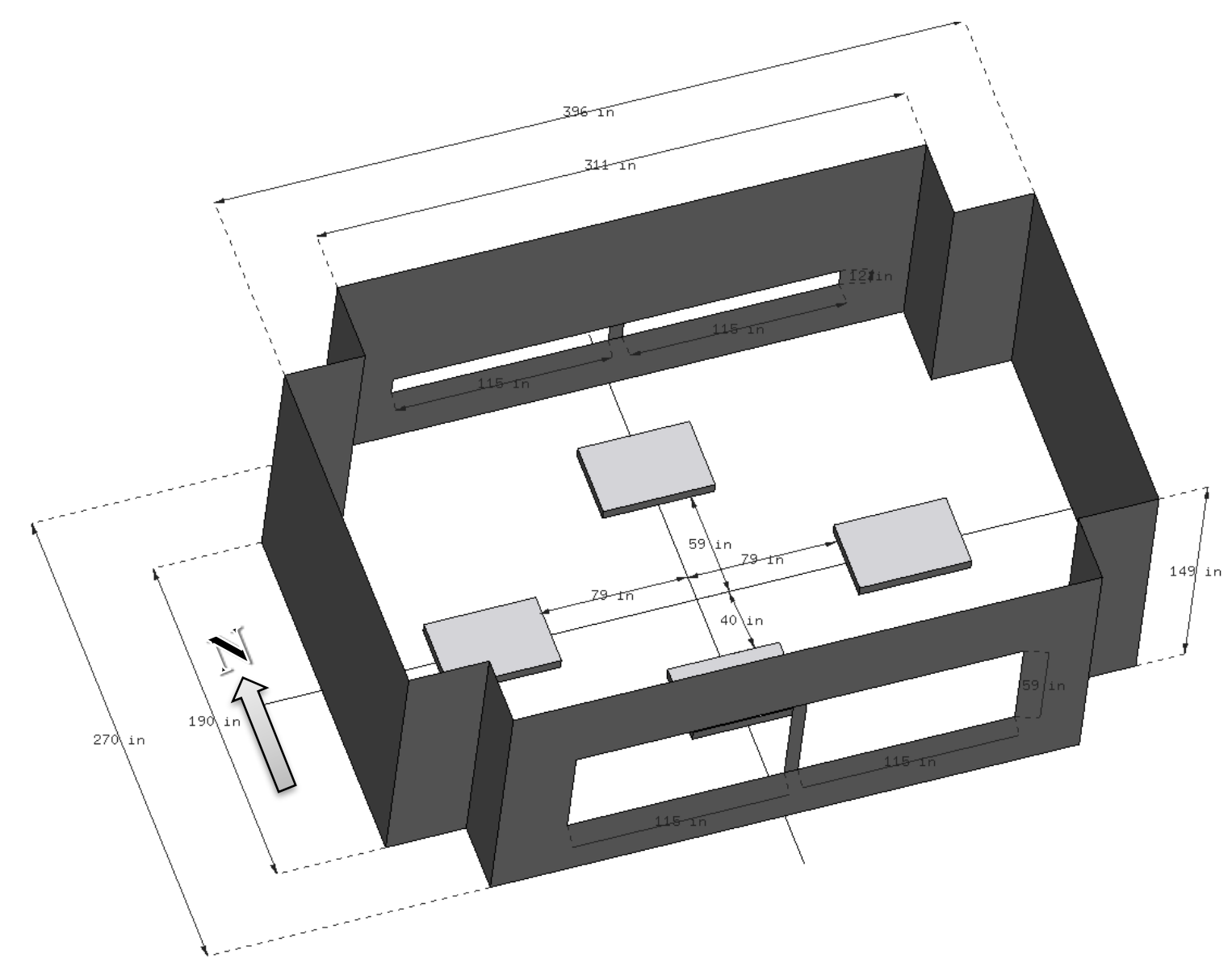

Figure 2. Measured internal dimensions of the fire compartment, imperial units. All dimensions have an uncertainty of \pm 1 in.

\subsection{NATURAL GAS BURNER}

The fires were fueled by four natural gas burners located as shown in Figure 2. Natural gas is used since:

- a gaseous fuel allows independent and instantaneous control of $H R R$ during an experiment;

- the NFRL has extensive experience with high accuracy flow rate measurements and independent means of $H R R$ calculation when using natural gas;

- the major constituent of natural gas $(\mathrm{CH} 4)$ has the lowest tendency to soot of any hydrocarbon, providing the best environment for optical measurements of displacement;

- natural gas fires are well suited for simulation; and

- natural gas provides a baseline for comparison to future solid fuel fires. 

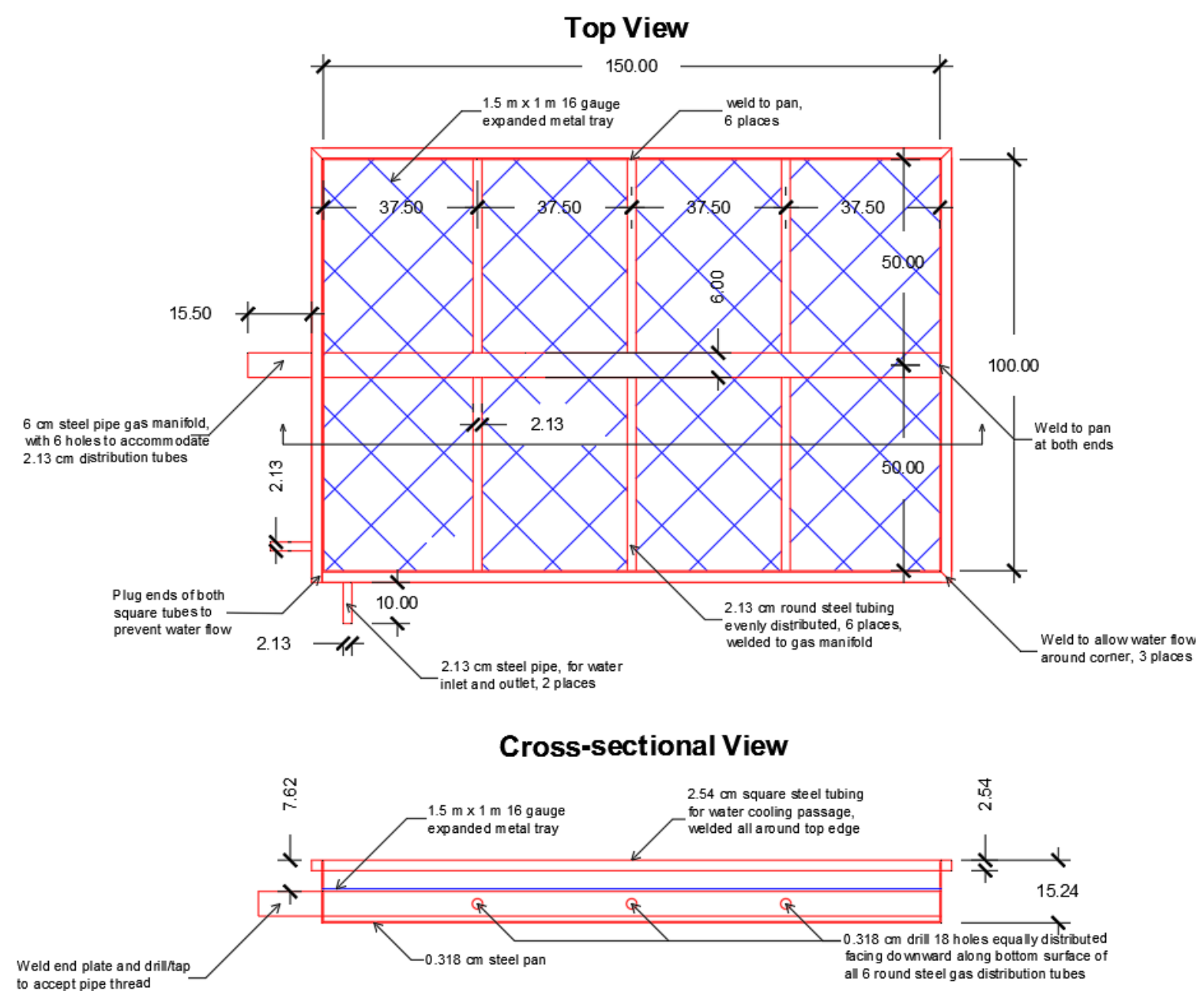

Figure 3. Detailed drawing of gas burner assembly, units in $\mathrm{cm}$. All dimensions have an uncertainty of $\pm 0.5 \mathrm{~cm}$.

Each burner was a steel box, with internal dimensions of $1 \mathrm{~m} \times 1.50 \mathrm{~m}$ in plan and $15 \mathrm{~cm}$ deep. The fuel inlet tube was located at the bottom of the burner box, below a fiber blanket. Steel mesh screens were used above the blanket to keep it in place. A detailed drawing of the burner design is shown in Figure 3.

\subsection{THE "REALISTIC" FIRE}

\subsubsection{Fire Load}

The heat release rate for the "realistic" fire is based upon knowledge gained in previous full-scale experiments, one conducted at NIST using three workstations as the fuel (Hamins et al., 2008), and another at Cardington using wood pallets for fuel (BRE, 2004). Table 1 gives key fire parameters for the previous NIST and the Cardington fire tests. $W, D$ and $H$ are width, depth and height of the compartment, respectively; $W_{\mathrm{o}}, H_{\mathrm{o}}$ are width and height of the opening, respectively; $V$ is volume of compartment; $A_{f}, A_{o}$ and $A_{t}$ are areas of floor, opening and internal compartment 
boundaries (including openings), respectively; $F_{\mathrm{o}}=A_{o} H_{o}{ }^{1 / 2} \mathrm{~A}_{\mathrm{t}}^{-1}$ is opening factor; $q_{f}$ is fire load density (per unit floor area); and $T_{g}$ is gas temperature.

Table 1. Key geometric and thermal parameters.

\begin{tabular}{|c|c|c|c|}
\hline Parameter & $\begin{array}{c}\text { NIST } 2008 \\
\text { (Hamins et al., 2008) }\end{array}$ & $\begin{array}{c}\text { Cardington } 2003 \\
\text { (BRE, 2004) }\end{array}$ & $\begin{array}{r}\text { This Study } \\
\text { (proposed) }\end{array}$ \\
\hline$W \times D \times H$ & $7 \mathrm{~m} \times 10.7 \mathrm{~m} \times 3.4 \mathrm{~m}$ & $11.0 \mathrm{~m} \times 7.0 \mathrm{~m} \times 4.1 \mathrm{~m}$ & $7 \mathrm{~m} \times 10 \mathrm{~m} \times 3.8 \mathrm{~m}$ \\
\hline$W_{o} \times H_{o}$ & $2.25 \mathrm{~m} \times 2.12 \mathrm{~m}$ & $9.0 \mathrm{~m} \times 1.27 \mathrm{~m}$ & $6.0 \mathrm{~m} \times 1.5 \mathrm{~m}$ \\
\hline$A_{f}$ & $74.9 \mathrm{~m}^{2}$ & $77.0 \mathrm{~m}^{2}$ & $70.0 \mathrm{~m}^{2}$ \\
\hline$A_{t}$ & $270.2 \mathrm{~m}^{2}$ & $301.6 \mathrm{~m}^{2}$ & $268.2 \mathrm{~m}^{2}$ \\
\hline$V$ & $254.7 \mathrm{~m}^{3}$ & $315.7 \mathrm{~m}^{3}$ & $263.9 \mathrm{~m}^{3}$ \\
\hline$A_{o}$ & $4.84 \mathrm{~m}^{2}$ & $11.43 \mathrm{~m}^{2}$ & $9.0 \mathrm{~m}^{2}$ \\
\hline$V$ & $254.7 \mathrm{~m}^{3}$ & $315.7 \mathrm{~m}^{3}$ & $263.9 \mathrm{~m}^{3}$ \\
\hline$A_{o} / V$ & $0.019 / \mathrm{m}$ & $0.036 / \mathrm{m}$ & $0.034 / \mathrm{m}$ \\
\hline$A_{o} H_{o}{ }^{1 / 2}$ & $7.09 \mathrm{~m}^{5 / 2}$ & $12.88 \mathrm{~m}^{5 / 2}$ & $11.0 \mathrm{~m}^{5 / 2}$ \\
\hline$F_{o}$ & $0.026 \mathrm{~m}^{1 / 2}$ & $0.043 \mathrm{~m}^{1 / 2}$ & $0.041 \mathrm{~m}^{1 / 2}$ \\
\hline fuel package & $\begin{array}{c}3 \text { workstations }+40 \mathrm{~L} \\
\text { of jet fuel }\end{array}$ & wood cribs & $\begin{array}{l}4 \text { natural gas burners, } \\
1 \mathrm{~m} \times 1.5 \mathrm{~m} \text { each }\end{array}$ \\
\hline$q_{f}$ & $400 \mathrm{MJ} / \mathrm{m}^{2}$ & $700 \mathrm{MJ} / \mathrm{m}^{2}$ & $1200 \mathrm{MJ} / \mathrm{m}^{2}$ \\
\hline peak HRR & $\sim 10,000 \mathrm{~kW}$ & unknown & $\sim 10,000 \mathrm{~kW}$ \\
\hline peak HRR/vol. & $40.5 \mathrm{~kW} / \mathrm{m}^{3}$ & unknown & $37.9 \mathrm{~kW} / \mathrm{m}^{3}$ \\
\hline peak $T_{g}$ & $\sim 1050^{\circ} \mathrm{C}$ & $\sim 1070^{\circ} \mathrm{C}$ & $\sim 1000^{\circ} \mathrm{C}$ \\
\hline fire duration & $67 \mathrm{~min}$ & $200 \mathrm{~min}$ & $240 \min$ \\
\hline
\end{tabular}

Note: The proposed openings in this study include a slit, which is not shown here and will be discussed later.

Surveys have found that the fuel loads in commercial and public spaces vary greatly with the designated purpose of the space (Vassart, 2014). A standard office contains in the range of 420 to $655 \mathrm{MJ} / \mathrm{m}^{2}$ of combustible material; a shopping center is in the range of 600 to $936 \mathrm{MJ} / \mathrm{m}^{2}$; and a library can have fuel loads up to $2340 \mathrm{MJ} / \mathrm{m}^{2}$. Since the current experiments are intended to represent an extreme fire condition to attain significant structural failure, the assumed fuel load was about $1200 \mathrm{MJ} / \mathrm{m}^{2}$ for a two-hour or possibly longer fire exposure to simulate uncontrolled burning of building contents.

The right-hand vertical scale of Figure 4 shows the proposed $H R R$ for the "realistic" fire, which linearly ramps up to $10,000 \mathrm{~kW}$ in $15 \mathrm{~min}$, is held steady until $105 \mathrm{~min}$, and then is reduced linearly to zero over the next $85 \mathrm{~min}$. The peak intensity of the fire on a volumetric basis is 37.9 $\mathrm{kW} / \mathrm{m}^{3}$, close to that in the previous NIST studies (Hamins et al., 2008). The proposed HRR assumes no structural failure. In case the structure fails, the decaying phase starts at the failure 
moment and the decaying duration is calculated based on energy equivalence that the area below the new $H R R$ curve is equal to that of the proposed $H R R$ curve.

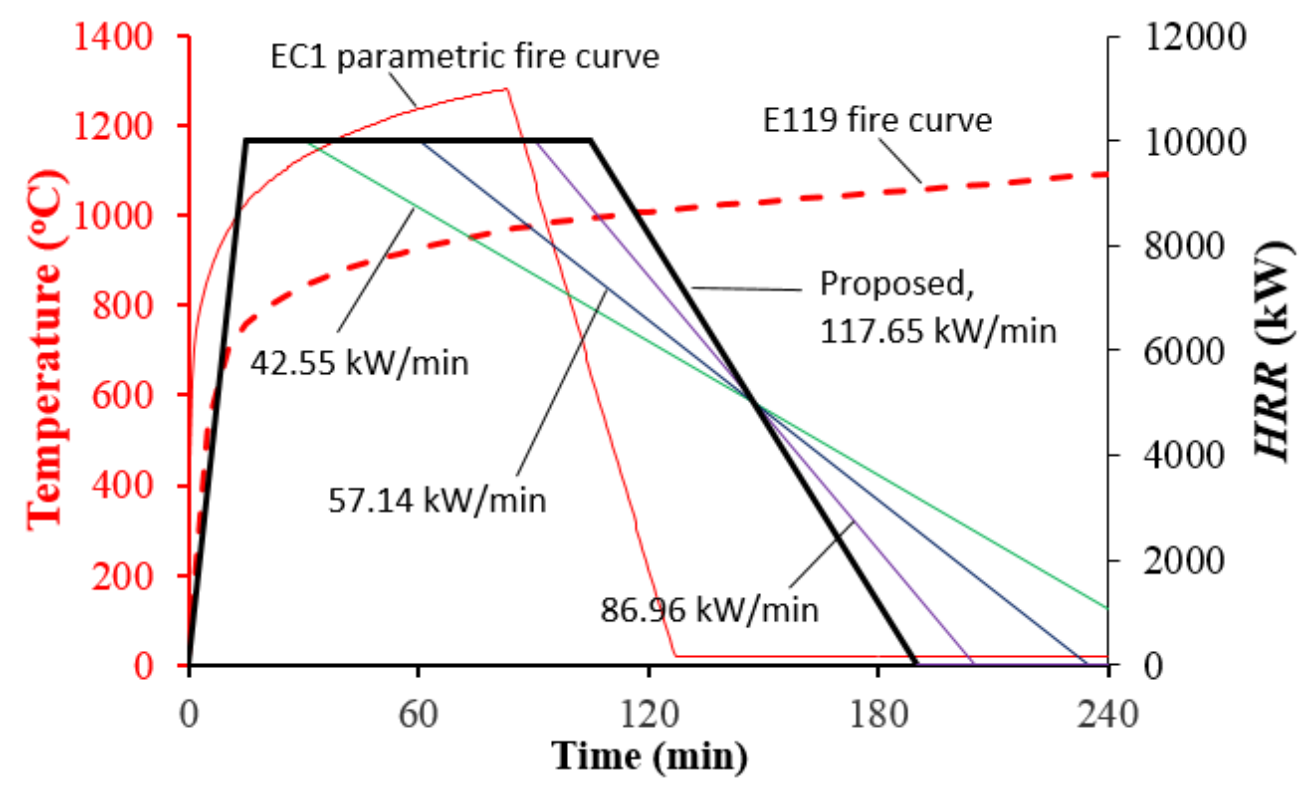

Figure 4. Proposed HRR for the "realistic" fire and predicted gas temperature using the EC1 parametric fire model. Three other HRRs are also shown, which have the same growing phase as the proposed HRR. The areas below different HRR curves are the same. $42.55 \mathrm{~kW} / \mathrm{min}$ - steady stage of $15 \mathrm{~min} ; 57.14 \mathrm{~kW} / \mathrm{min}-$ steady stage of $45 \mathrm{~min} ; 86.96 \mathrm{~kW} / \mathrm{min}$ - steady stage of $75 \mathrm{~min} ; 117.65 \mathrm{~kW} / \mathrm{min}$ - steady stage of $90 \mathrm{~min}$.

\subsubsection{Opening}

Table 1 also gives the proposed opening for the "realistic" fire based on calculations by empirical and zone fire models. When scaled with the room volume, the proposed opening area, i.e., $0.034 / \mathrm{m}$, is similar to that in the Cardington fire (Table 1). The left-hand vertical scale of Figure 4 shows the predicted gas temperature using the EC1 parametric fire model (BSI, 2002). The predicted peak gas temperature is $1269^{\circ} \mathrm{C}$. Calculations using the zone model CFAST (Peacock et al., 2017) also show that the opening factor is sufficient to substantially exceed the minimum target temperature of $1000{ }^{\circ} \mathrm{C}$.

Numerical simulations using the field fire model FDS (McGrattan et al., 2018) are run to identify the distribution of openings and burners that confine the majority of the heat release within the compartment. For the compartments with opening factor of $0.041 \mathrm{~m}^{1 / 2}$ and greater, the FDS simulations show that the fires are over-ventilated, and the heat release is confined primarily within the compartment. Figure 5 shows how the position and size of the north vent significantly affects the simulated flame behavior. For compartment with the main opening on the south wall (6.0 $\mathrm{m}$ wide, $1.5 \mathrm{~m}$ high and sill $1 \mathrm{~m}$ above the floor), a slit on the north wall (6 m wide, $0.3 \mathrm{~m}$ 
high and sill $1 \mathrm{~m}$ above the floor), and four burners distributed as indicated in Figure 2, the air flow is almost entirely inward through the opening on the north wall.

Using symmetry, only half of the compartment is modeled, and the "MIRROR" boundary condition is used in the symmetry plane. Uniform grids of $0.1 \mathrm{~m}$ are used in the XYZ directions. Note that the steel members (steel beams supporting the compartment ceiling slab as shown in Figure 1) are omitted in the FDS models.
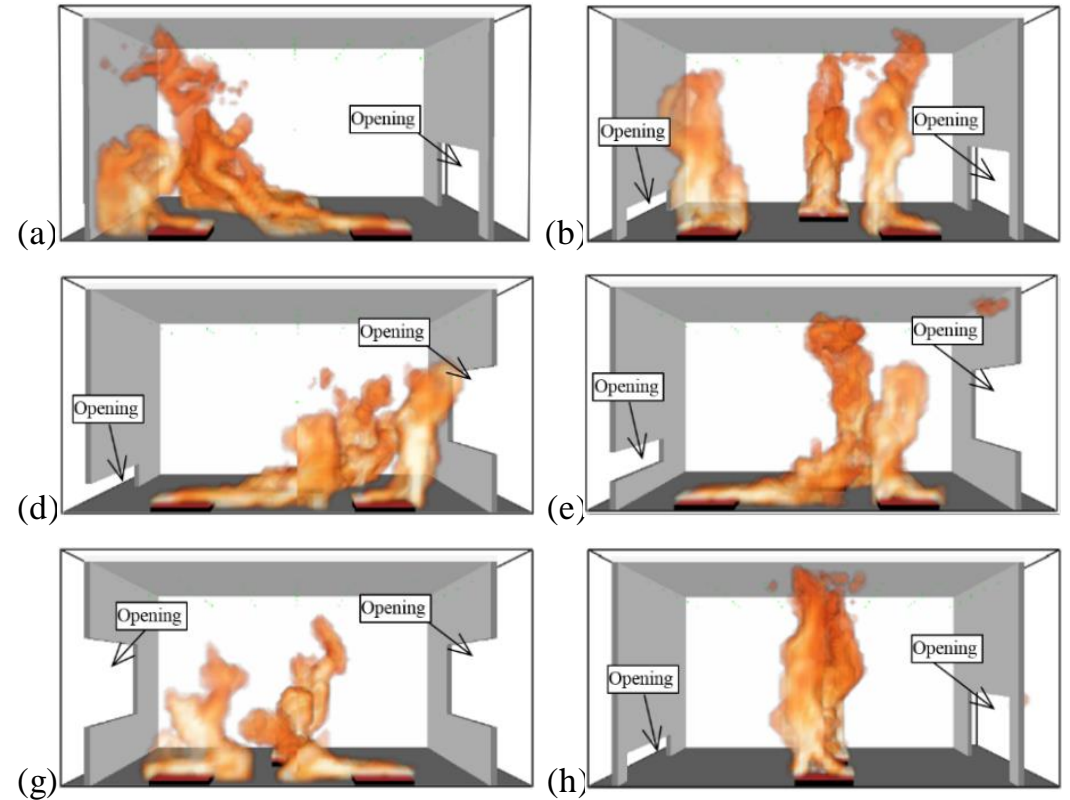
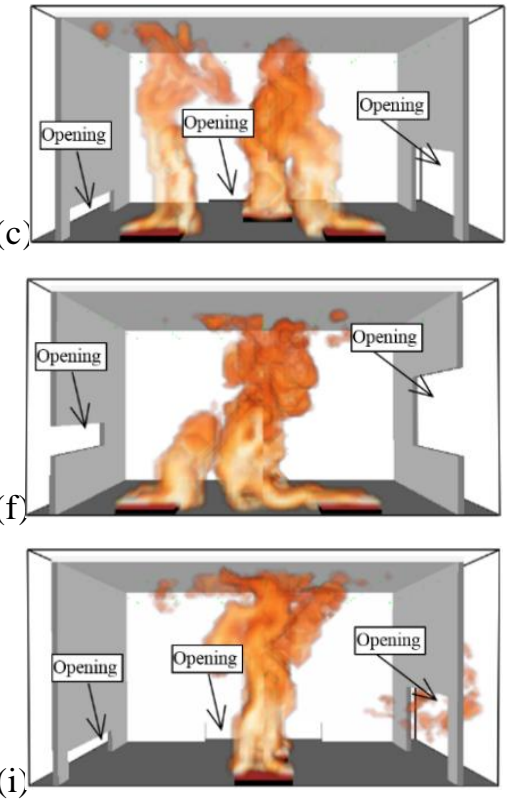

Figure 5. Field fire model simulated flame behaviors for various opening and burners configurations. The main opening in the south wall (to the right) is $6 \mathrm{~m}$ wide and $1.5 \mathrm{~m}$ high and remains constant in size for all of the geometries examined, although height of the window sill is varied. The size and location of the opening on the opposite (north) wall, and the number and distribution of the burners are varied.

Figure 6 shows the FDS predicted temperature distributions for the compartment with the proposed HRR (produced by four distributed burners as shown in Figure 2) and a main opening on the south wall ( $6.0 \mathrm{~m}$ wide, $1.5 \mathrm{~m}$ high, and $1 \mathrm{~m}$ high above the floor) and an opening on the opposite north wall ( $6 \mathrm{~m}$ width, $0.3 \mathrm{~m}$ high and $1 \mathrm{~m}$ above the floor). The horizontal temperature distribution in the gas layer about $0.305 \mathrm{~m}$ below the ceiling is quite uniform. Figure 7 shows the FDS predicted gas temperature-time curves. The maximum gas temperature reaches $1000^{\circ} \mathrm{C}$ with the standard deviation among 35 temperature detectors located $0.305 \mathrm{~m}$ below the ceiling of $50{ }^{\circ} \mathrm{C}$. 

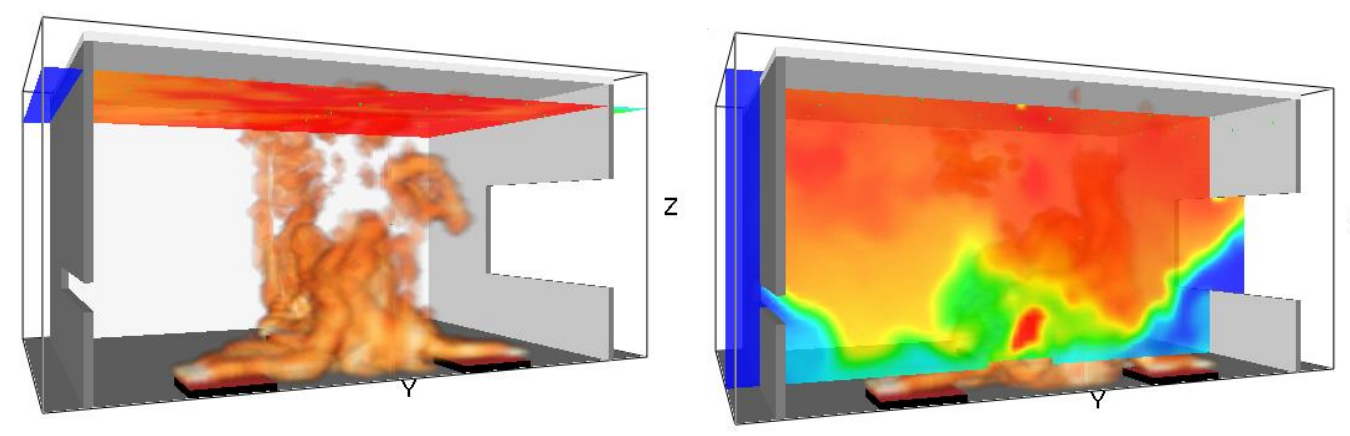

$$
\begin{aligned}
& 1000 \\
& 902 \\
& 804 \\
& 706 \\
& 608 \\
& 510 \\
& 412 \\
& 314 \\
& 216 \\
& 118 \\
& 20.0
\end{aligned}
$$

Figure 6. FDS simulated temperature distributions for the compartment with proposed $H R R$, opening, and burners (Units in ${ }^{\circ} \mathrm{C}$ ). The results are for fire at $1 \mathrm{~h}$ after burning. (Left) $0.305 \mathrm{~m}$ below the ceiling; (Right) 2 m away from widow center.

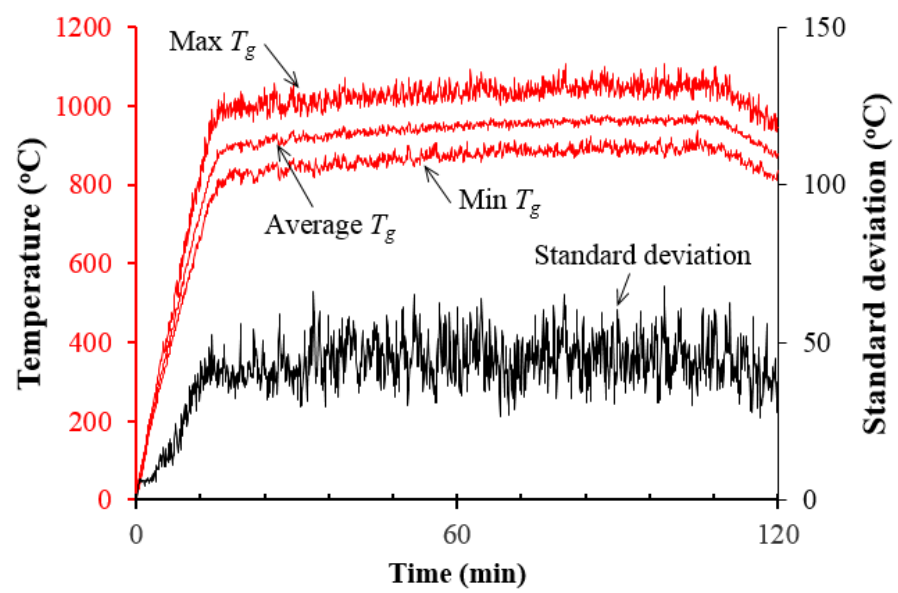

Figure 7. FDS predicted gas temperatures for the compartment with proposed $H R R$, opening, and burners. Max, Ave and Min $T_{g}$ are maximum, average, and minimum values of 35 thermocouples located $0.305 \mathrm{~m}$ below the ceiling.

In summary, the proposed "realistic" fire has the heat release rate shown in Table 2, has four distributed natural gas burners as shown in Figure 2, and has a main opening on the south wall (6 $\mathrm{m}$ width, $1.5 \mathrm{~m}$ high and $1 \mathrm{~m}$ above the floor) and a slit on the north wall (6 $\mathrm{m}$ width, $0.3 \mathrm{~m}$ high and $1 \mathrm{~m}$ above the floor).

Table 2. Proposed $H R R$ for the "realistic" fire.

\begin{tabular}{|c|c|}
\hline Time (min) & HRR (MW) \\
\hline 0 & 0 \\
\hline 15 & 10 \\
\hline 105 & 10 \\
\hline 190 & 0 \\
\hline 240 & 0 \\
\hline
\end{tabular}




\subsection{THE "STANDARD" OR ASTM E119 FIRE}

Using the same ventilation as proposed for the "realistic" fire, the most appropriate $H R R$ for the "standard" or ASTM E119 fire was determined through a trial and error process. Table 3 gives the proposed HRR for the "standard" or ASTM E119 fire. Figure 8 shows the average gas temperatures predicted by FDS using the proposed $H R R$. The gas temperatures are taken as the average recorded values of five thermocouple devices located $0.305 \mathrm{~m}$ below the ceiling. Figure 9 shows the locations of the devices. Note that because symmetry is used in the FDS simulation, the average of five thermocouple devices in the half model is equal to the average of ten thermocouple devices in the whole model. In the ASTM E119 standard (ASTM, 2018), at least nine thermocouples placed $0.305 \mathrm{~m}$ from the exposed face at the beginning of the test should be used to average the furnace temperature for floor tests. The FDS simulations show that test fire two is capable of approximating the E119 time-temperature curve.

Table 3. Proposed $H R R$ for the "standard" fire.

\begin{tabular}{|c|c|}
\hline Time (min) & HRR (MW) \\
\hline 0 & 0 \\
\hline 5 & 6.0 \\
\hline 10 & 8.0 \\
\hline 30 & 9.0 \\
\hline 60 & 10.0 \\
\hline 120 & 11.4 \\
\hline 240 & 11.4 \\
\hline
\end{tabular}

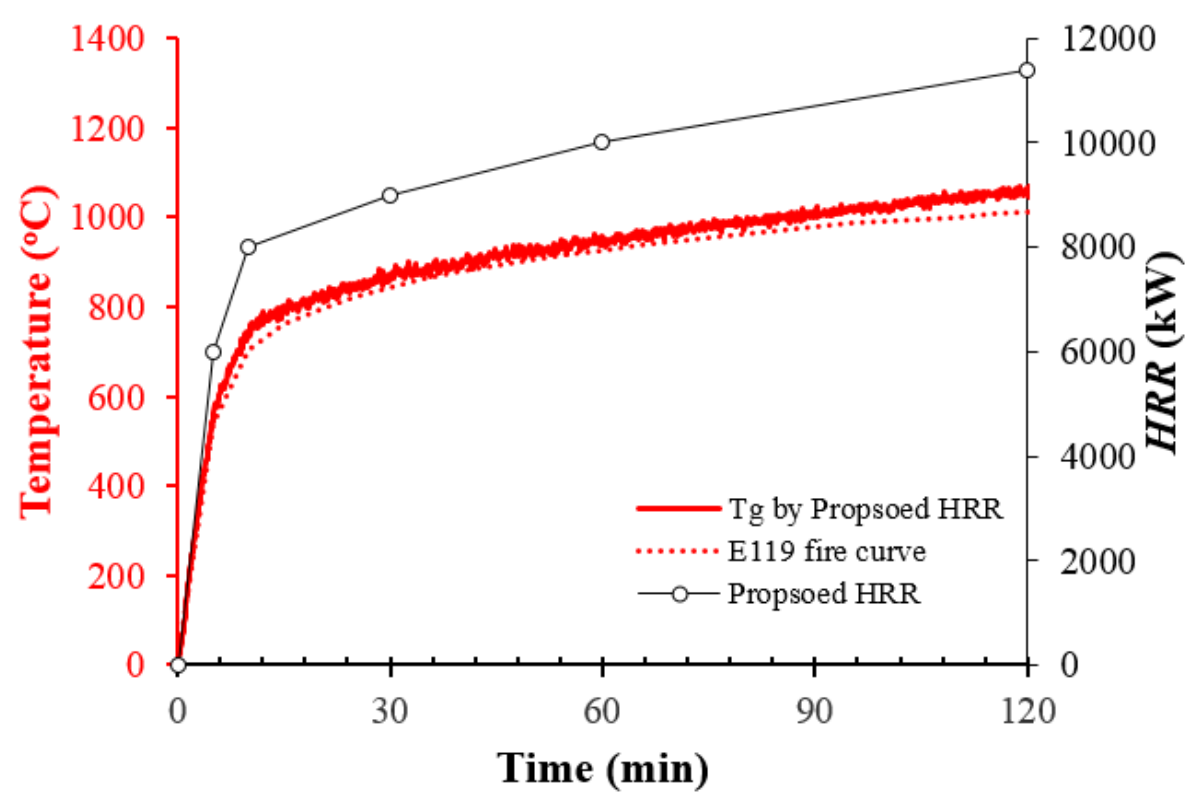

Figure 8. Proposed HRR for "standard" test fire and FDS predicted average gas temperatures. 


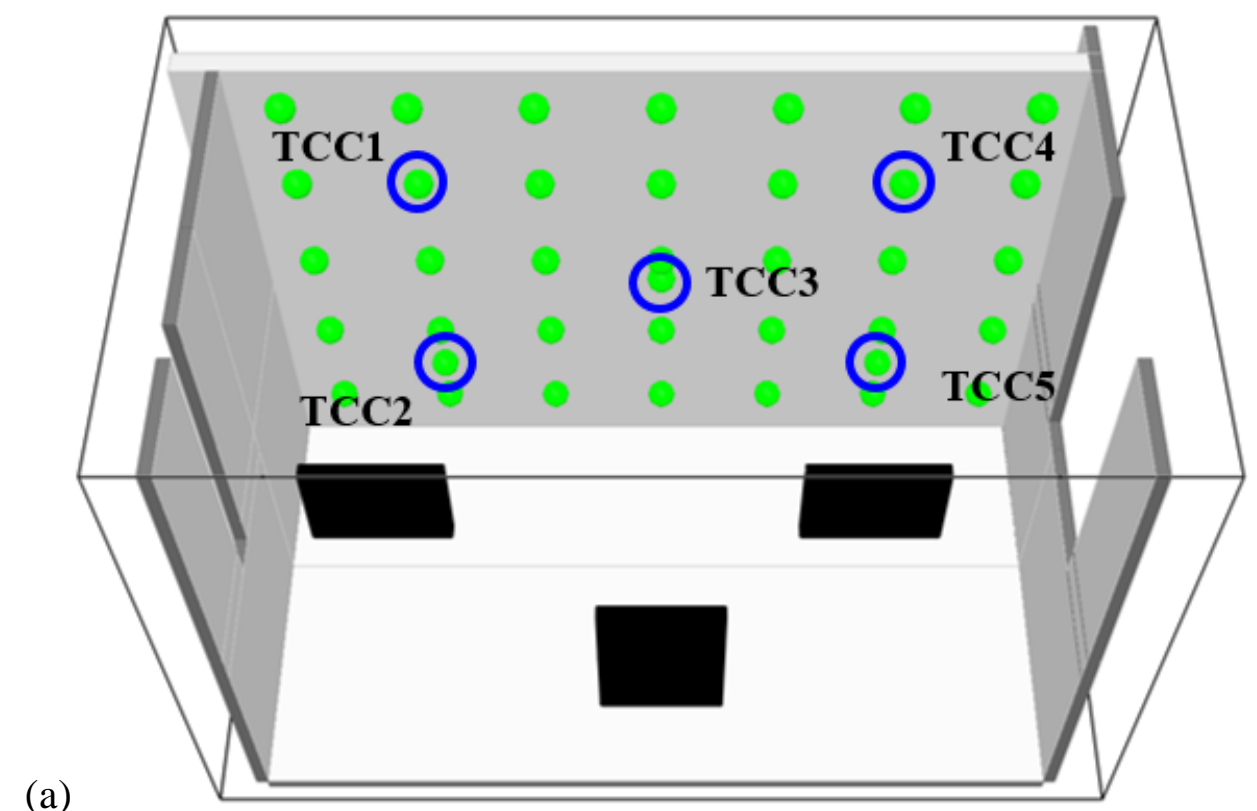

(a)

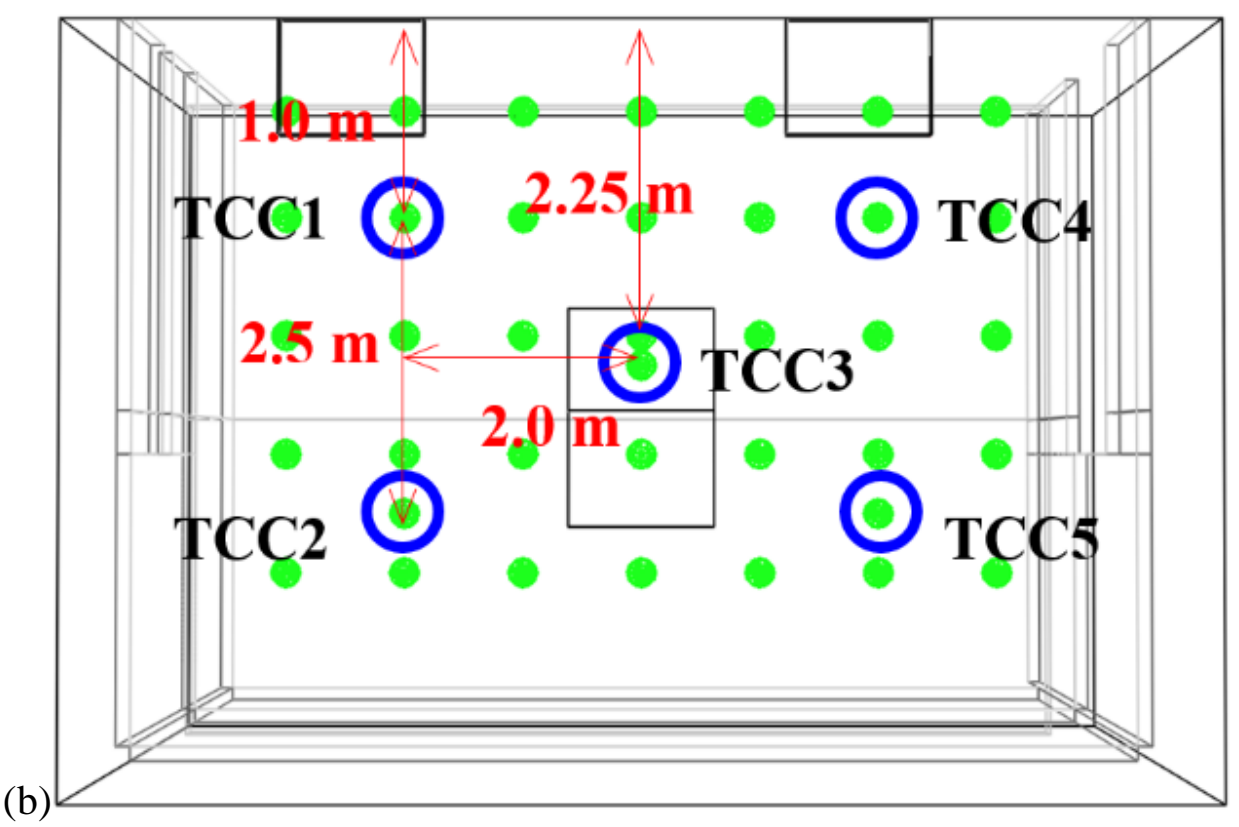

Figure 9. Thermocouple devices used to calculate the average gas temperatures by FDS. All the devices are located $0.305 \mathrm{~m}$ below the ceiling. The circled five devices (TCC1 to TCC5) are used in the calculation. (a) view from the bottom of the compartment; (b) plan view. 


\section{Chapter 3 \\ EXPERIMENTAL INVESTIGATION}

\subsection{MEASUREMENT SYSTEM}

The sensors used in the experiment are described in Table 4 and a more detailed description for the heat release rate measurements, instrumentation, data acquisition systems, and the estimated uncertainty of measurements are presented as follows.

Table 4. Sensors used in the experiment.

\begin{tabular}{cccc}
\hline Sensor Description & Manufacturer & Model & Full Scale Value \\
\hline Inconel thermocouples & & TJ36-CAXL-14U-24 & $1335^{\circ} \mathrm{C}$ \\
Opening thermocouples & Omega & GG-K-24 & $1250^{\circ} \mathrm{C}$ \\
Tree thermocouple & & XT-K-20-SLE & $1250^{\circ} \mathrm{C}$ \\
Gardon gauge & Medtherm & GTW-15SB-6-60-40- \\
Plate thermometer & Pentronic & $484 \mathrm{~K}$ & \\
\hline
\end{tabular}

\subsubsection{Burner Heat Release Rate}

The heat release rate of the burner was determined using the measured mass flow and the composition of the natural gas. The gas flow was controlled using a computer controller pneumatic valve. The gas mass flow rate was measured using a positive displacement rotary flow meter, pressure gauge and thermistor. The energy value of the natural gas was determined from historical average values of gas composition from gas chromatograph measurements in previous years. The gas composition was not measured for these experiments. Details of the gas fuel delivery and measurement system are presented in detail by Bryant et al. (2004).

\subsubsection{Calorimeter}

The NFRL fire laboratory oxygen consumption fire calorimeter measures the heat release rate. The calorimeter consisted of a $15 \mathrm{~m}$ square canopy style smoke collection hood, a $2.42 \mathrm{~m}$ diameter exhaust duct instrumented for mass flow measurements and a gas sampling system for measuring exhaust gas composition. The smoke collection hood was located $12.5 \mathrm{~m}$ above the test floor and was equipped with $6 \mathrm{~m}$ retractable side curtains. 


\subsubsection{Thermocouples}

The upper layer gas temperatures in the compartment were measured with Inconel type $\mathrm{K}$ thermocouples, $6 \mathrm{~mm}$ diameter, with grounded junction (Omega model TJ36-CAXL-14U-24). No correction for radiation on the bead was performed. The measurement range is up to $1335^{\circ} \mathrm{C}$.

Thermocouple trees with Nextel insulated wire, K-type, 20-gauge, bare-bead thermocouples (Model XT-K-20-SLE) were used to measure the vertical gas temperature profile in the compartment. The thermocouple trees were wrapped with thermal ceramic fiber blanket with the tips of the thermocouples projecting from the blanket.

All the other thermocouples were glass insulated wire, K-type, 24-gauge, bare-bead thermocouples (Model GG-K-24). The measurement range was of $-200{ }^{\circ} \mathrm{C}$ to $1250{ }^{\circ} \mathrm{C}$. These thermocouples were created in-house (purchased in spools, cut to length and the bead welded).

\subsubsection{Heat Flux Gauges}

Heat flux gauges (Gardon Model 64-20-18) were placed at three locations in the compartment (see Section Instrumentation layout for more details). The gauges were placed in steel pipes of $25 \mathrm{~mm}$ inside diameter and were water cooled. The water temperature was not monitored during the test.

\subsubsection{Plate Thermometer}

Pentronic plate thermometers (PT) were placed at three locations, as presented in the following section, i.e., Instrumentation layout, and were used to measure the adiabatic surface temperature. They consisted of a glass-sheathed, K-type, 24-gauge, Omega thermocouple (Model GG-K-24) welded to an Inconel plate with dimensions of $100 \mathrm{~mm} \times 100 \mathrm{~mm} \times 0.7 \mathrm{~mm}$ and insulating material on the back. To mount the plate thermocouple a metal bracket was used such as the plate was parallel with the ceiling or the wall. The bracket and sensor wiring were not thermally insulated and deformed during the fire test. The nominal range of the plate thermometer was $1200{ }^{\circ} \mathrm{C}$.

Omega glass-sheathed, K-type, 24 gauges, thermocouples (Model GG-K-24) were used to measure the gas temperature near the plate thermocouple.

\subsubsection{Data Acquisition System}

Measurements from the test were acquired using National Instruments cDAQ-9188 data acquisition (DAQ) chassis populated with the following Input/Output-Modules: NI-9213 (thermocouples) and NI-9205 for sensors with voltage outputs. An in-house software developed in LabVIEW ${ }^{\text {TM }}$ was 
used to allocate channels and control the data acquisition. During the tests, data were recorded at $1 \mathrm{~Hz}$ along with the standard deviations from the averaging process.

\subsubsection{Uncertainty of Measurements}

This report presents the raw data from various measurements of heat release, heat flux and temperature. Refer to Table 5 for the measurement uncertainties estimated for various components. For each measurand, Type A and/or Type B uncertainties, combined standard uncertainties, and total expanded uncertainties were estimated, as defined in Taylor and Kuyatt (Taylor \& Kuyatt 1994). Type A uncertainty was evaluated using statistical methods and Type B uncertainty was estimated by other means such as the information available in manufacturer's specifications, from past-experience, or engineering judgement. The combined standard uncertainty was estimated by combining the individual uncertainties using "root-sum-of-squares". The expanded uncertainty was then computed by multiplying the combined uncertainty by a coverage factor of 2 corresponding to an approximately $95 \%$ confidence interval. All uncertainties are assumed to be symmetric $( \pm)$.

The following definitions are used:

Precision: Uncertainty in the ability of the measurement instrument to resolve information from the sensor (Type B).

Zero, calibration, linearity: Uncertainties from known sources of error and derived from instrument specifications (Type B).

Installation: Uncertainty due to installation and estimated based on engineering judgment (Type B). Random error: Uncertainty due to random, unpredictable variations in the measurement process during a typical steady-state period and derived using the standard deviation of the residuals from the mean value of the measurements (Type A).

Repeatability error: Uncertainty when measuring the same point multiple times during a typical steady-state period.

The estimation of uncertainties of the heat release rate measurement was done using a natural gas burner reference fire (Bryant et al. 2004). The heat release rate of the reference fire had a measurement combined standard uncertainty of less than $\pm 1 \%$. Calorimeter verification tests were performed on 2 separate days at heat release rate values of $1 \mathrm{MW}, 5 \mathrm{MW}, 10 \mathrm{MW}, 15 \mathrm{MW}$ and $20 \mathrm{MW}$. The maximum relative difference between the measured heat release rate and reference fire was less than $4.5 \%$. The relative standard deviation of the heat release rate varied from $6.5 \%$ at $1 \mathrm{MW}$ to $3 \%$ at $20 \mathrm{MW}$ for a steady reference fire over a period of $180 \mathrm{~s}$. The combined standard relative uncertainty for the heat release rate measurements was determined to be $7.4 \%$ for this set 
of experiments. This uncertainty estimate is valid for near steady state fires. Transient events $(<30 \mathrm{~s})$ have larger uncertainty due to the effect of system response time. Additional time delays and smearing of heat release rate data related to transport of the combustion gases out of the test compartment are not quantified in this report.

Table 5. Uncertainty in the experimental data.

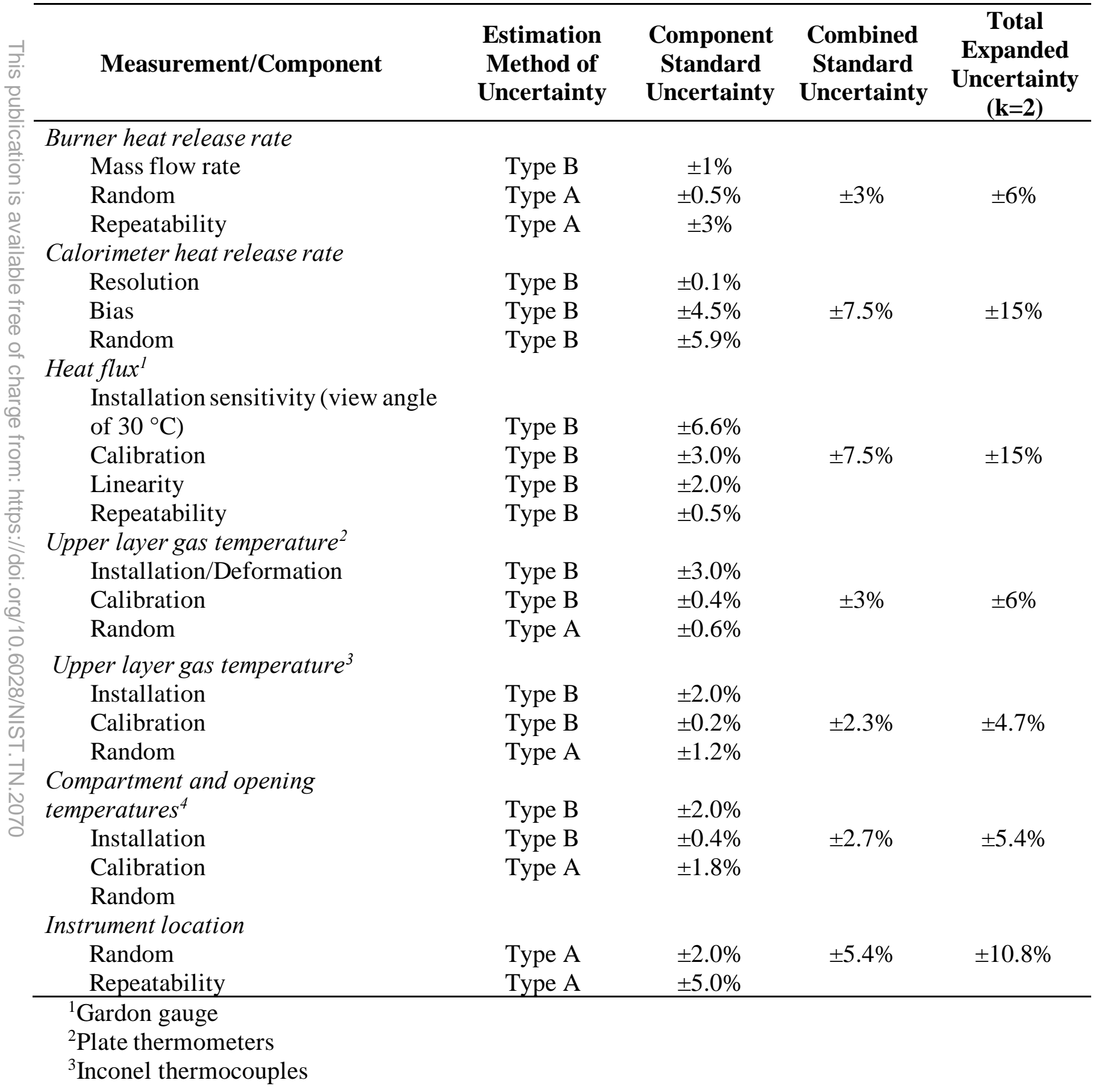




\subsection{INSTRUMENTATION LAYOUT}

This section describes the instrumentation layout.

Figure 10 presents the plan view of the compartment along with the position of the instruments.

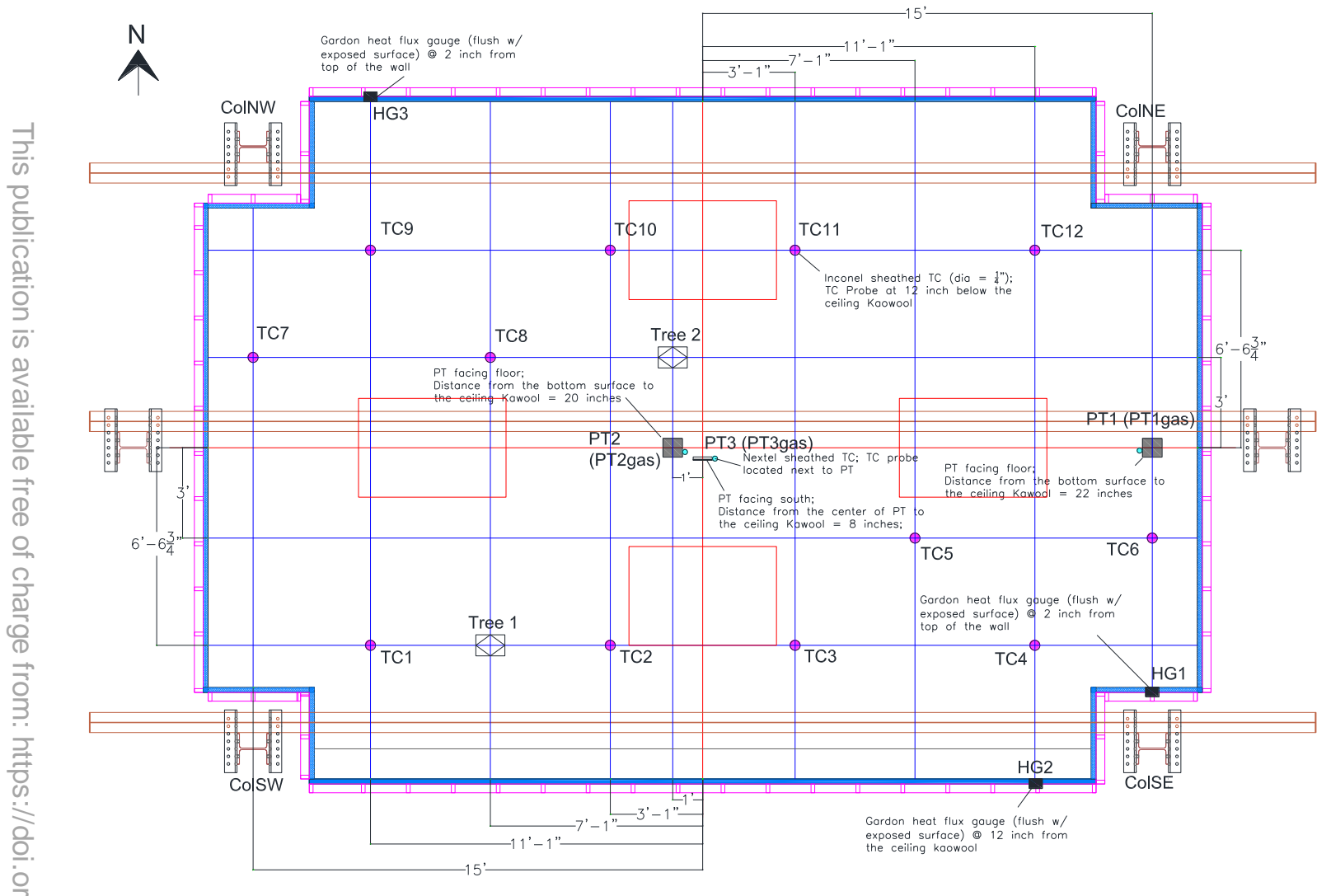

Figure 10. Instrumentation layout, imperial units. All dimensions have an uncertainty of \pm 1 in.

The burners were placed at four locations inside the test compartment (Figure 10 and Figure 11):

- Two burners were placed at $2 \mathrm{~m}$ west and east from the center of the compartment, while the other two were placed at $1.5 \mathrm{~m}$ north and $1 \mathrm{~m}$ south from the center of the compartment. 


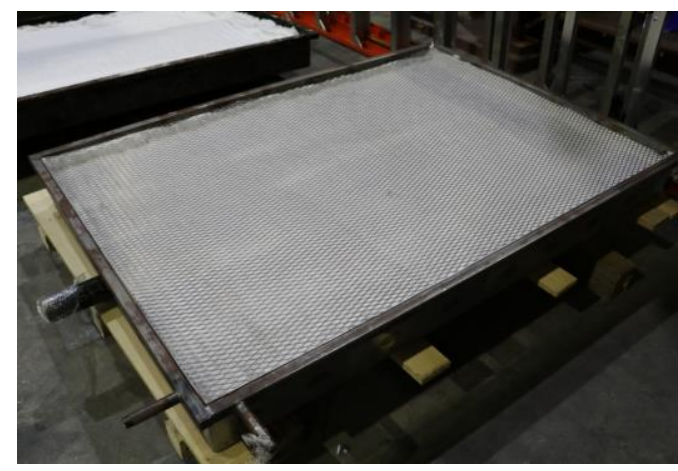

(a)

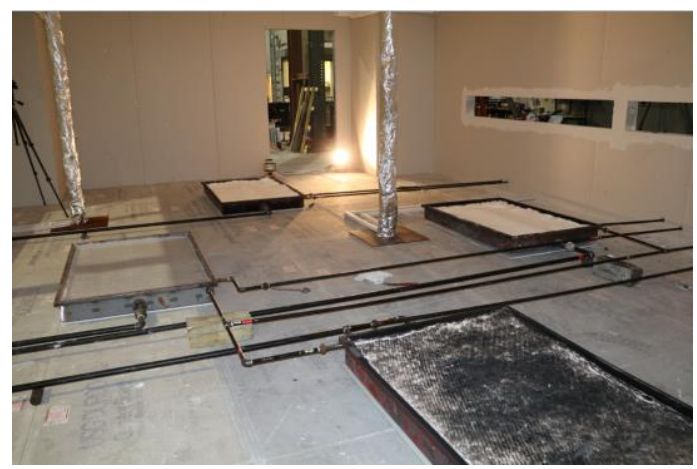

(b)

Figure 11. (a) The burner and (b) the position of the burners in the compartment.

Temperatures were measured at several locations as presented in Figure 10 and described below:

- Twelve of stainless-steel sheathed thermocouples were placed $30.5 \mathrm{~cm}$ below the ceiling (Figure 12a) as per ASTM E119-18 (ASTM, 2018).

- Two trees using glass-sheathed thermocouples were installed in the compartment (Figure 12b). Each tree incorporated four thermocouples at $101.6 \mathrm{~cm}, 175.9 \mathrm{~cm}, 250.2 \mathrm{~cm}$ and $297.2 \mathrm{~cm}$ above floor. The position of the trees in the compartment can be seen in Figure 10.

- Four of glass-sheathed thermocouples were used to measure the temperature at the top of each opening (Figure 12c-d).

- One Inconel thermocouple was used to measure the temperature close to the two bidirectional velocity probes installed on the south wall.

- Three glass-sheathed thermocouples were used to measure the temperature close to the plate thermometers.

- Three glass-sheathed thermocouples were used to measure the temperature close to the Gardon gauges.

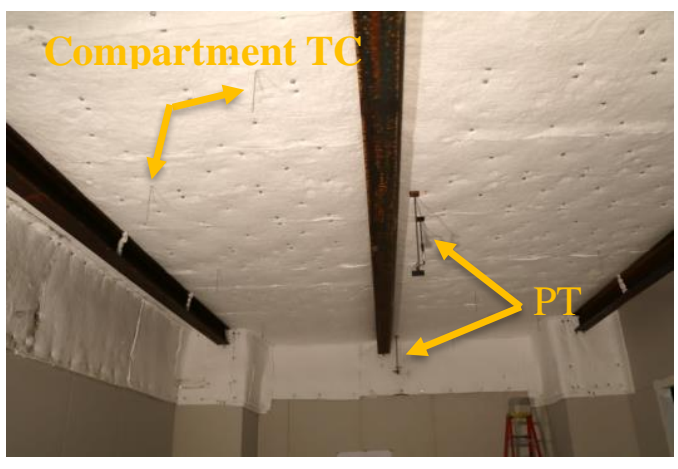

(a)

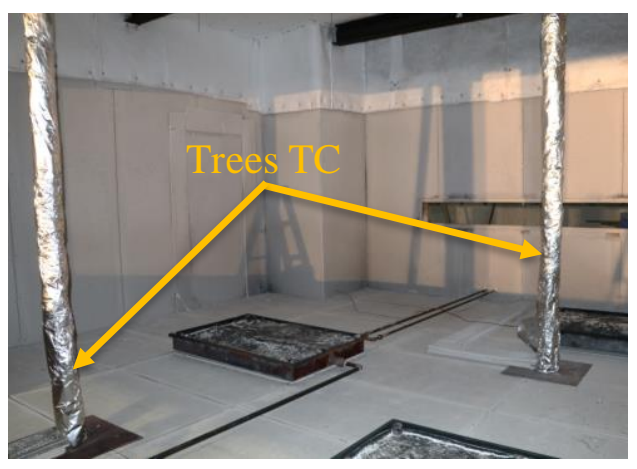

(b) 


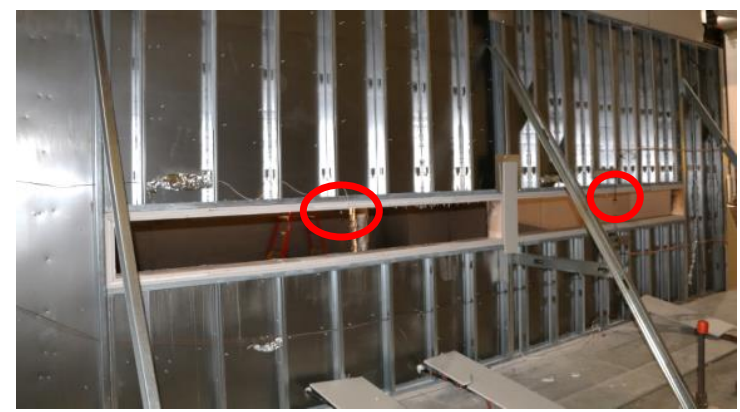

(c)

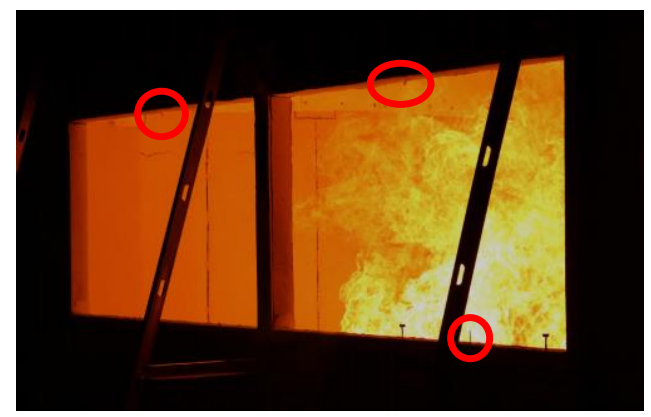

(d)

Figure 12. (a) Ceiling thermocouples; (b) thermocouple trees; (c) north opening thermocouples; (d) south opening thermocouples.

Thermocouple trees measured the vertical distribution of temperatures inside the compartment and were placed in two locations: Tree 1 was placed near the south opening while Tree 2 near the center of the compartment. Each tree comprises four thermocouples as shown in Figure 13. 


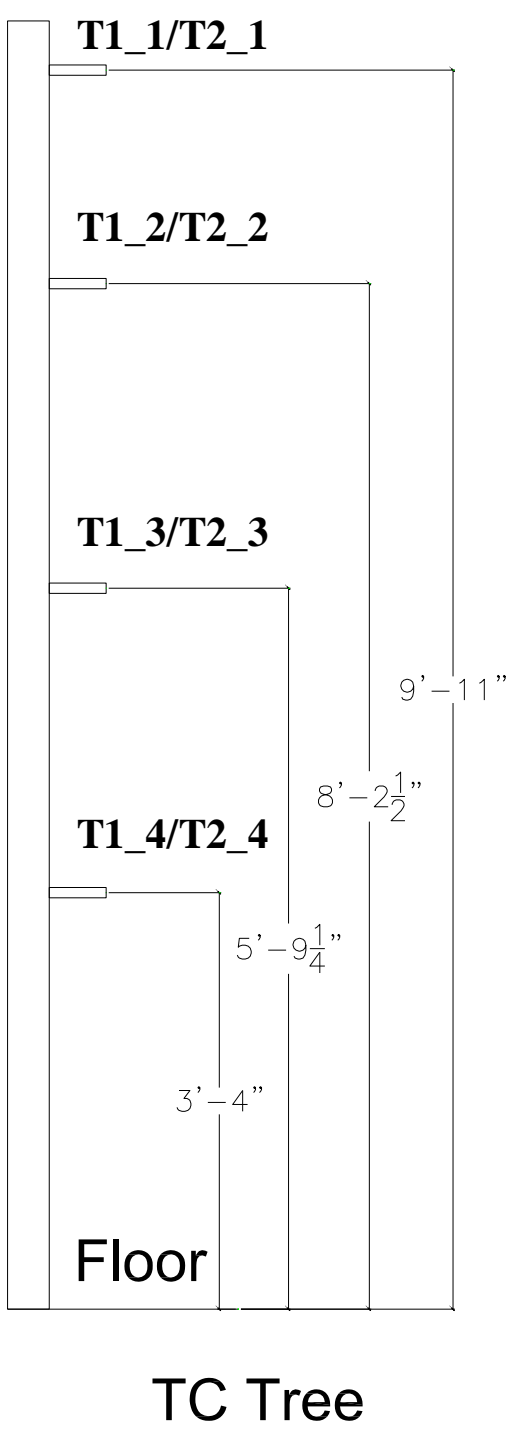

Figure 13. Thermocouple Tree Details. All dimensions have an uncertainty of \pm 1 in

$$
(1 \mathrm{in}=2.54 \mathrm{~cm}) \text {. }
$$

The plate thermometers (PT) were placed at three locations, as presented in Figure 14 and described below:

- In the east side of the compartment at $4.6 \mathrm{~m}$ from the centerline (Figure 14a). The PT was facing the floor and the distance from the bottom surface of the PT to the bottom of the ceiling (the thermal blanket) was $55.9 \mathrm{~cm}$.

- In the center west of the compartment at $0.3 \mathrm{~m}$ from the centerline (Figure 14b). The PT is facing the floor and the distance from the bottom surface of the PT to the bottom of the ceiling (the thermal blanket) was $50.8 \mathrm{~cm}$. 
- In the center of the compartment, facing south (Figure 14b). The distance from the center of the PT to the bottom of the ceiling (the thermal blanket) was $20.3 \mathrm{~cm}$.

The steel rods used for mounting PTs were not fire protected, and they suffered deformations during the tests (no measurements of the deformed position were made).

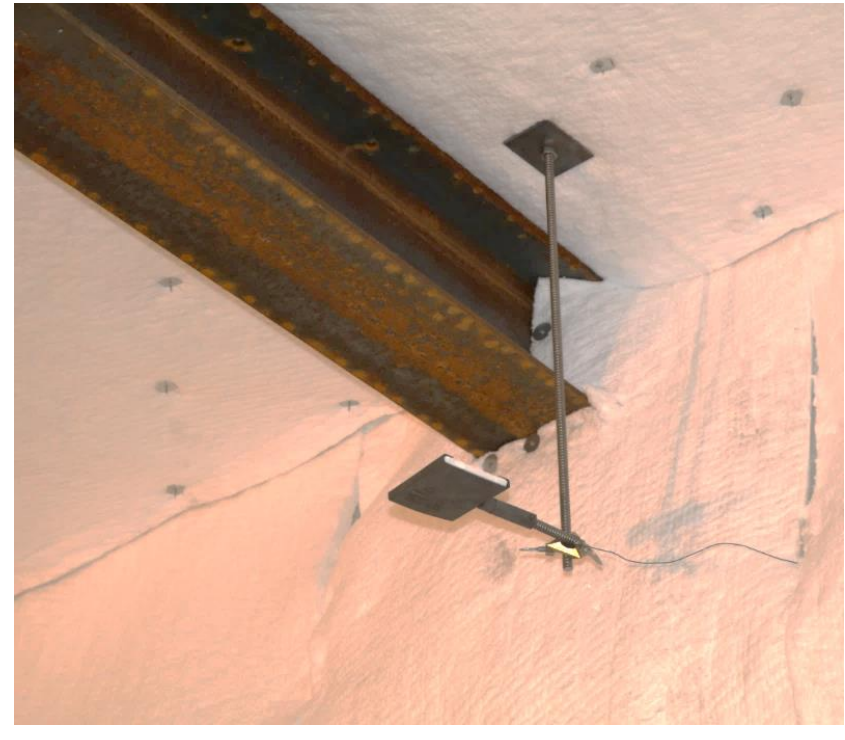

(a)

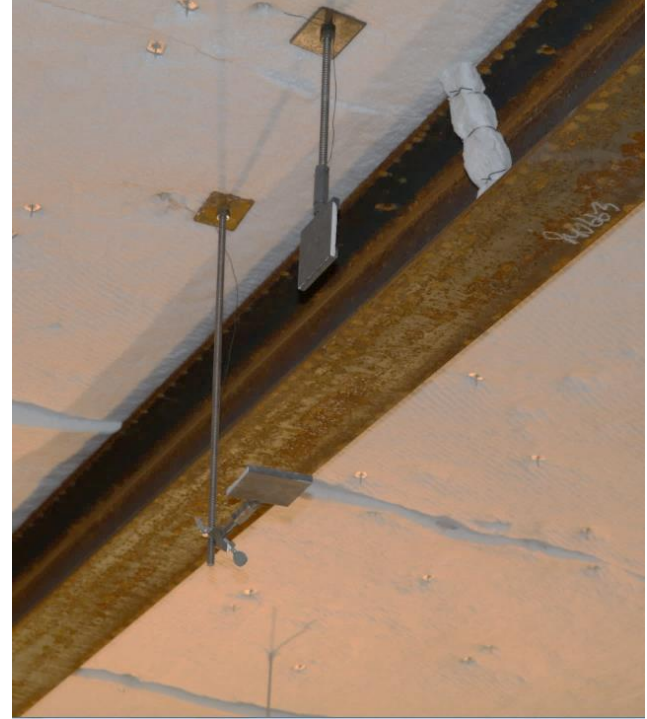

(b)

Figure 14. Plate thermometer in the (a) east side and (b) center of the compartment.

The heat flux gauges were placed at three locations, as presented in Figure 15:

- On the South East column enclosure wall at $5.1 \mathrm{~cm}$ from the top of the wall compartment.

- On the south wall, at $337.8 \mathrm{~cm}$ East from the centerline and $30.5 \mathrm{~cm}$ from the ceiling.

- On the North wall close to the North West column at $5.1 \mathrm{~cm}$ from the top of the wall compartment.

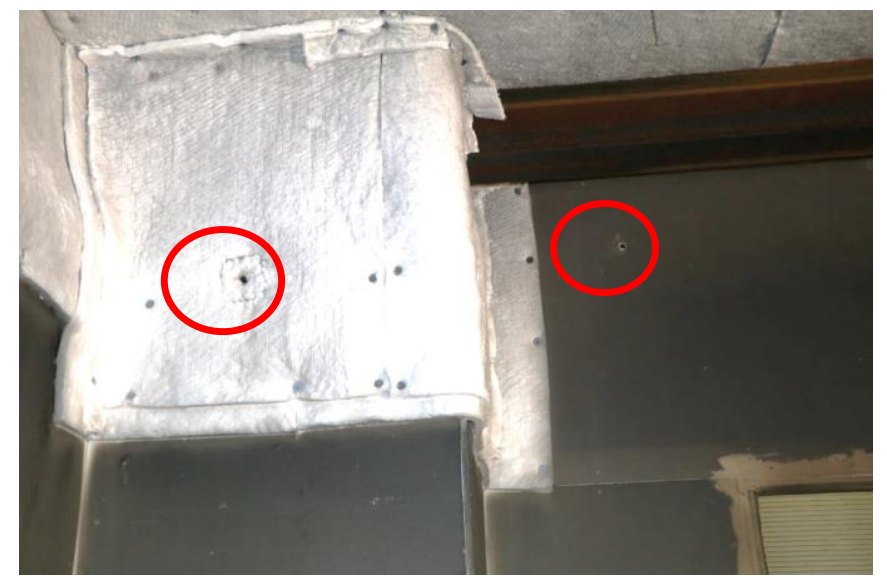

Figure 15. The heat flux gauges mounted in the south-east of the compartment. 


\subsection{TEST RESULTS AND OBSERVATIONS}

Three experiments have been performed as described in Table 6 .

Table 6. Summary of the experiments.

\begin{tabular}{|c|c|c|}
\hline Test ID & Date & Duration (min) \\
\hline 15minRampR1 & $12 / 19 / 2018$ & 15 \\
\hline 15minRampR2 & $12 / 19 / 2018$ & 15 \\
\hline 60minRampR1 & $12 / 20 / 2018$ & 75 \\
\hline
\end{tabular}

Prior to the $60 \mathrm{~min}$ fire test, i.e. $60 \mathrm{minRampR}$, two $15 \mathrm{~min}$ test were performed, i.e., $15 \mathrm{minRampR} 1$ and $15 \mathrm{minRampR} 2$. The same compartment and the same instrumentation layout were kept for all the tests. The two 15 min burn tests did not induce modifications of the compartment, except that the gypsum paper was burned during the first 15 min burn test.

The following procedure was used for each test:

- Start data acquisition and instrumentation system;

- Ignite the gas burner with the pilot flame;

- Control the heat release rate (HRR) of the burners until the test is terminated;

- Examine debris and restart the next test.

\subsubsection{Heat Release Rate}

Figure 16 shows the burner heat release rate (HRR) during the three tests, compared with the proposed HRR. The measured peak HRR for the 15 min burn tests was around 7.5 MW on average and $10 \mathrm{MW}$ around $75 \mathrm{~min}$ for the longer burn test. The measured HRR is slightly different than the proposed HRR. The differences at $5 \mathrm{~min}, 10 \mathrm{~min}, 30 \mathrm{~min}$ and $60 \mathrm{~min}$ are 24\%, 14\%, 5\% and $3 \%$, respectively. 


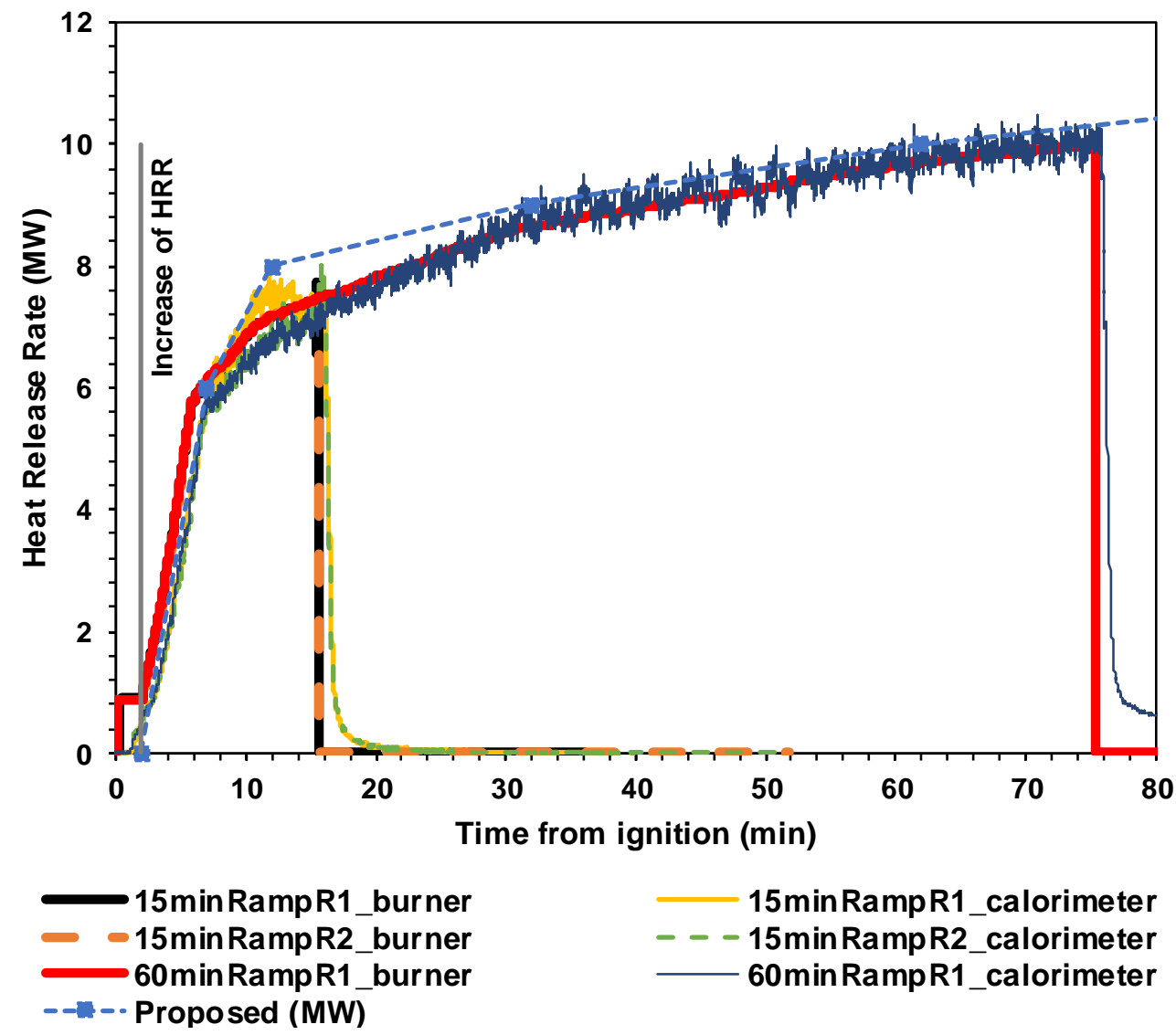

Figure 16. Measured burner and calorimeter HRRs.

\subsubsection{Gas Temperature}

\section{(i) Steel Sheathed Thermocouples}

Figure 17 shows the upper layer gas temperatures measured using 12 thermocouples below the ceiling for the three tests. The ASTM E119 curve is also presented for comparison purpose. In the first $25 \mathrm{~min}$ of the test, the measured average temperature of the upper layer gas is slightly lower than the one predicted by ASTM E119. The difference error at the 5 min time is around $14 \%$ but starts decreasing as heating continued. For example, at 10 min the difference decreases to $6 \%$ for the $15 \mathrm{minRampR} 1$ test and approximately $9 \%$ for both $15 \mathrm{minRampR} 2$ and $60 \mathrm{minRampR} 1$ tests. Around $25 \mathrm{~min}$, the measured upper layer gas temperature becomes slightly greater than that of the ASTM E119 curve towards the end of the test. The maximum difference before extinguishment of the fire was approximately $7 \%$. The area under time-temperature curve, obtained by averaging the results from the readings, is within $2 \%$ of the corresponding area under the standard ASTM E119 time-temperature curve. The standard requires a difference within 7,5\% for tests over $1 \mathrm{~h}$ and not more than $2 \mathrm{~h}$. 


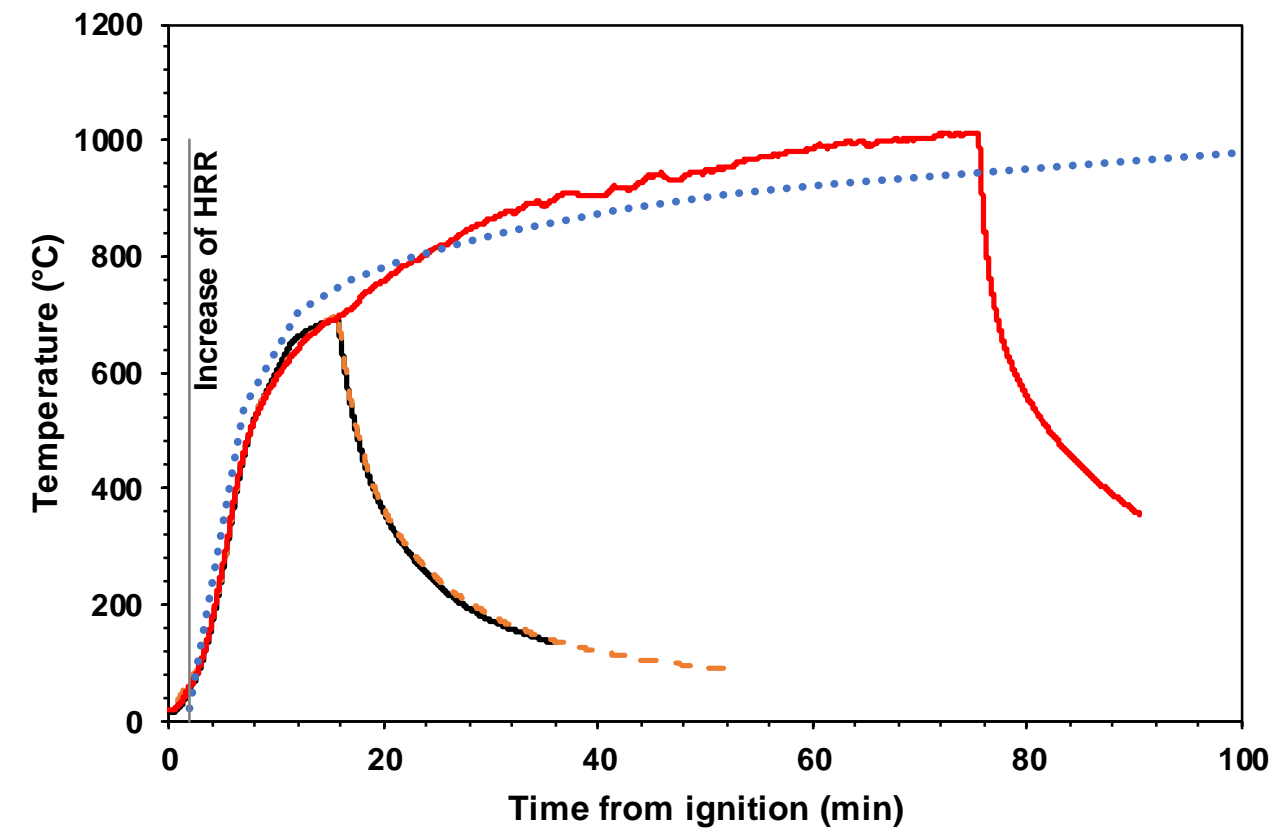

15minRampR1 - - -15minRampR2 — 60minRampR1 ..... ASTM E119

Figure 17. Measured average upper layer gas temperature for the tests.

Figure 18 shows the time-temperature curves measured using individual thermocouples, along with the average temperatures and standard deviations. The maximum standard deviation is below $40{ }^{\circ} \mathrm{C}$ for all the three tests. The upper layer gas temperature was uniform. The coefficient of variation was $2 \%$ at the end of the long test. 

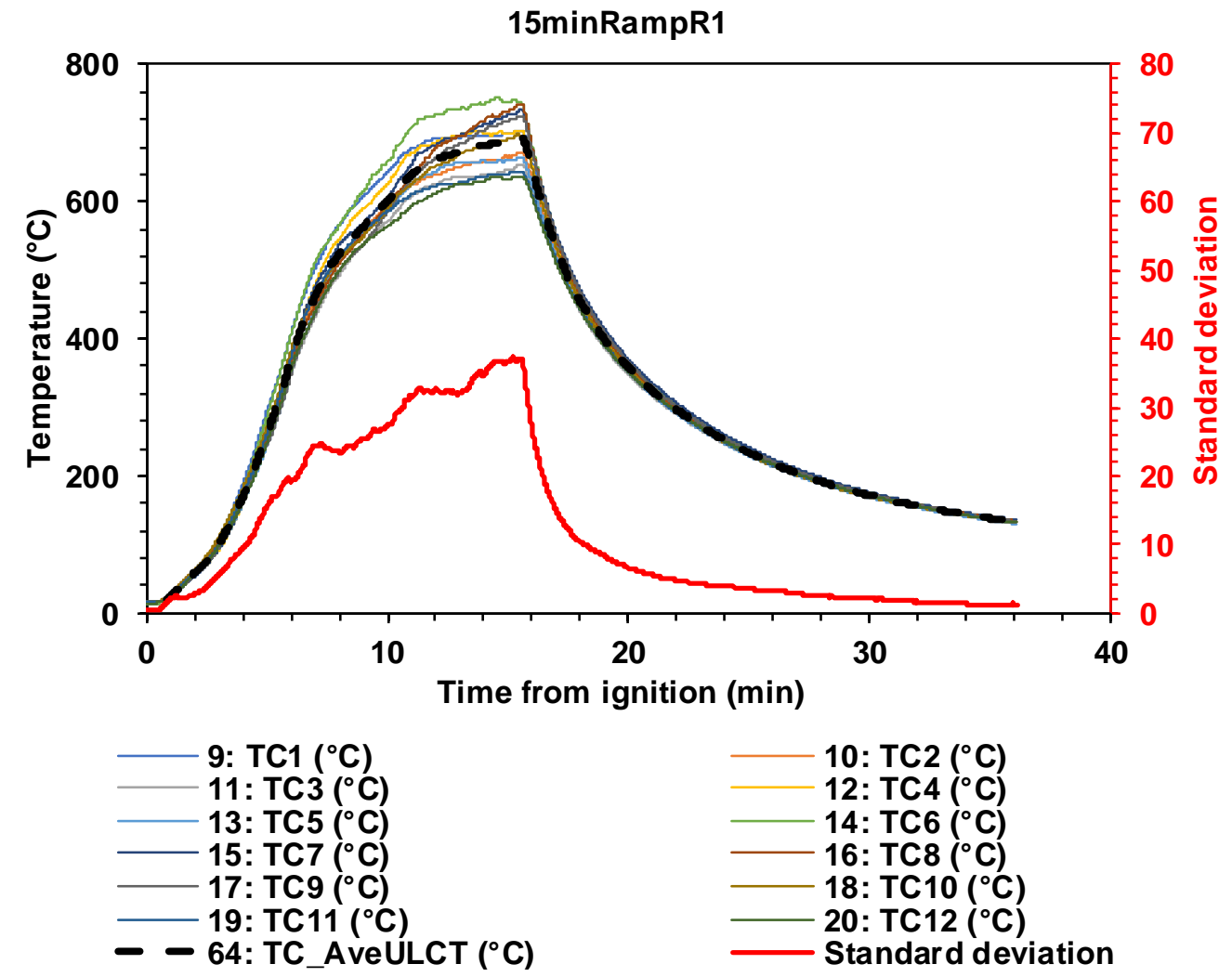

(a)

15minRampR2
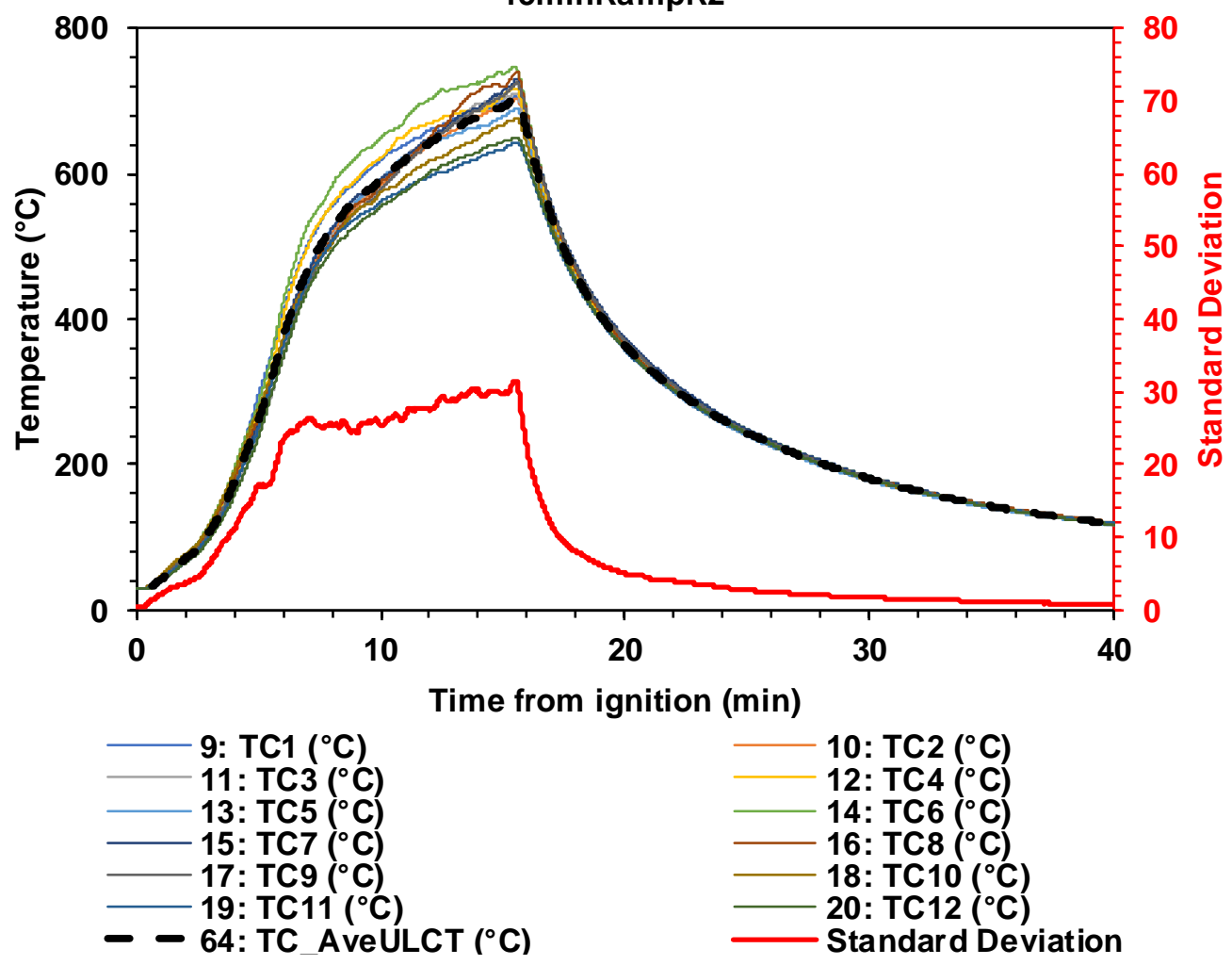


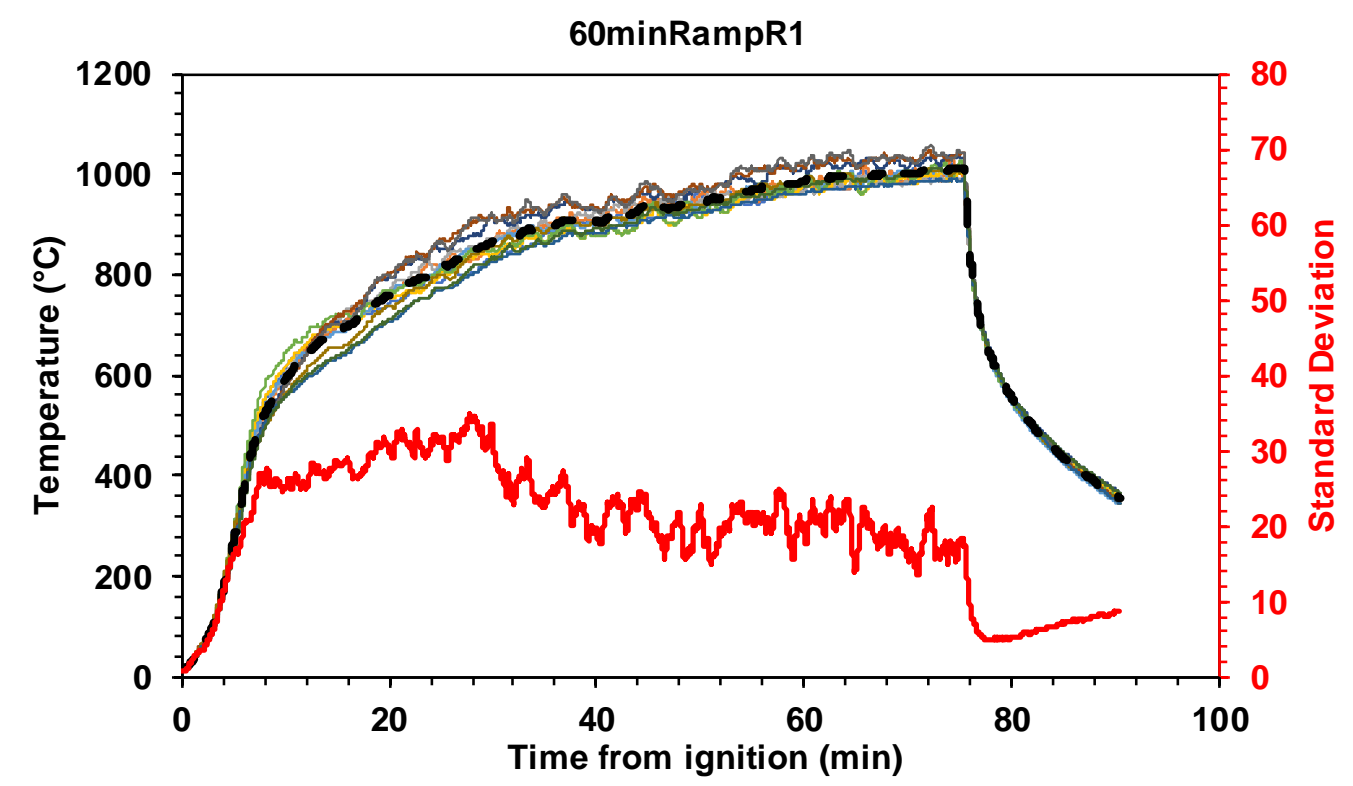

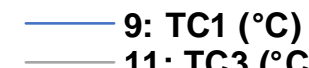
11: TC3 $\left({ }^{\circ} \mathrm{C}\right)$
13: $\operatorname{TC5}\left({ }^{\circ} \mathrm{C}\right)$
17: TC9 $\left({ }^{\circ} \mathrm{C}\right)$
19: $\operatorname{TC} 11\left({ }^{\circ} \mathrm{C}\right)$
(c)
- 64: TC_AveULCT $\left({ }^{\circ} \mathrm{C}\right)$

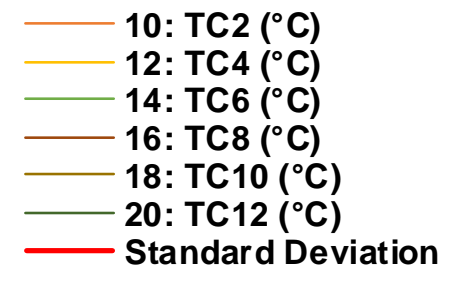

Figure 18 Measured upper layer gas temperatures by 12 thermocouples for (a) 15minRampR1, (b) 15 minRampR2, and (c) 60minRampR1.

\section{(ii) Plate Thermometers}

Figure 24 presents the measured temperatures by plate thermometers (PT1, PT2, PT3), for 15minRamR1, 15minRampR2 and 60minRampR1, respectively.

The measured peak temperatures during 15minRampR1 are presented in Figure 19(a) and were around $700{ }^{\circ} \mathrm{C}(\mathrm{PT} 1), 650{ }^{\circ} \mathrm{C}(\mathrm{PT} 2)$ and $620{ }^{\circ} \mathrm{C}$ (PT3) respectively. The peak mean value was approximately $650{ }^{\circ} \mathrm{C}$ and the maximum standard deviation was $40{ }^{\circ} \mathrm{C}$. The measured peak temperatures during $15 \mathrm{minRampR} 2$ are presented in Figure $19(\mathrm{~b})$ and were: approximately $700{ }^{\circ} \mathrm{C}$ (PT1), $670{ }^{\circ} \mathrm{C}(\mathrm{PT} 2)$ and $670{ }^{\circ} \mathrm{C}(\mathrm{PT} 3)$ respectively. The peak mean value was $680{ }^{\circ} \mathrm{C}$ and the maximum standard deviation was $30^{\circ} \mathrm{C}$. The measured peak temperatures during $60 \mathrm{minRampR} 1$ are presented in Figure 19 (c) and were: approximately $1020{ }^{\circ} \mathrm{C}(\mathrm{PT} 1), 1000{ }^{\circ} \mathrm{C}(\mathrm{PT} 2)$ and $990{ }^{\circ} \mathrm{C}$ (PT3) respectively. The peak mean value was $1000^{\circ} \mathrm{C}$ and the maximum standard deviation was around $25^{\circ} \mathrm{C}$. Same figure presents the measured gas temperature by glass-sheathed thermocouples (PT1_G, PT2-G, PT3-G) at the location of the plate thermometers. The gas temperatures were higher than the temperatures measured using the plate thermometer, excepting the gas temperature measured at the location of the plate thermometer PT3. 


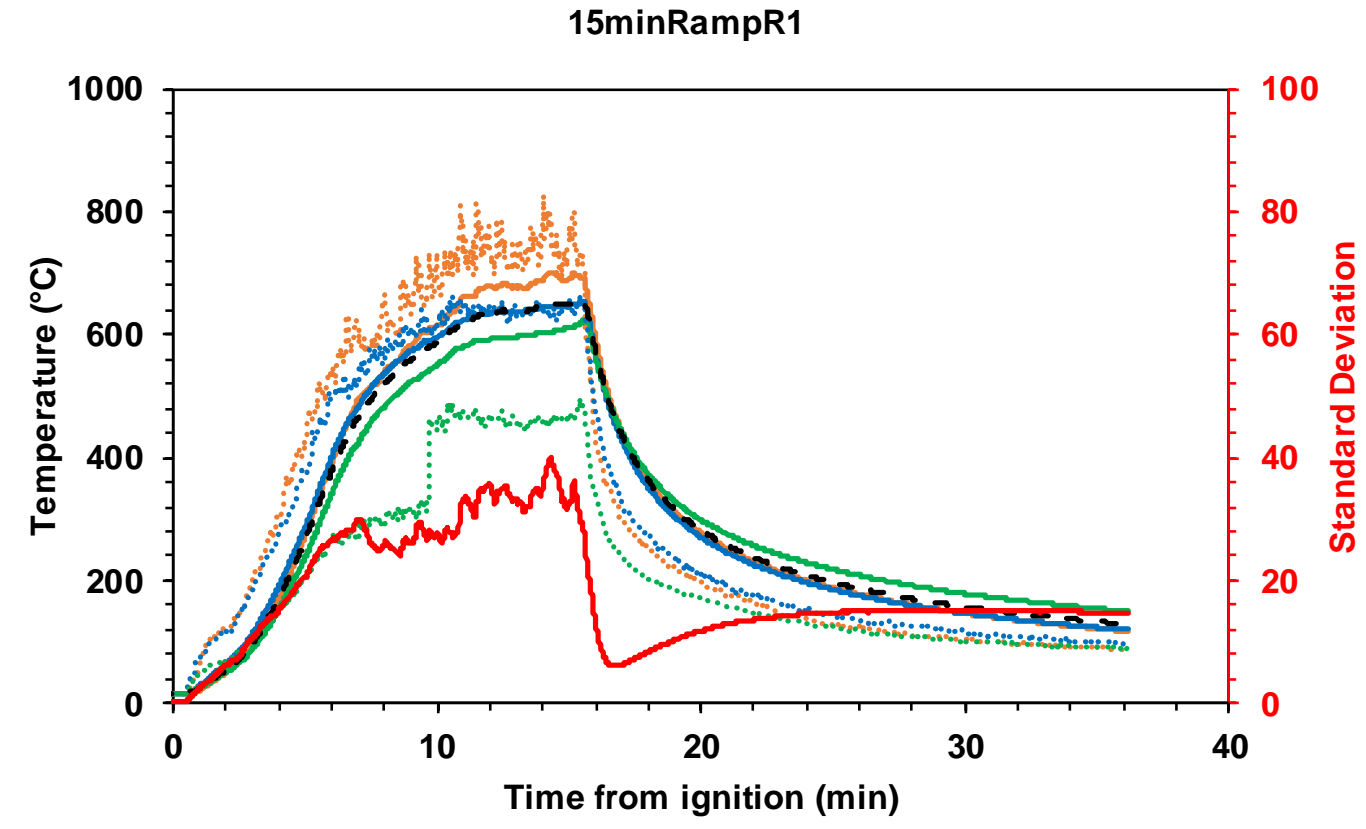
29: PT1 ( $\left.{ }^{\circ} \mathrm{C}\right)$
31: РT3 $\left({ }^{\circ} \mathrm{C}\right)$
….... 33: PT2_G ( $\left.{ }^{\circ} \mathrm{C}\right)$
(a)
- - -69: TC_AveULPT $\left({ }^{\circ} \mathrm{C}\right)$
30: PT2 $\left({ }^{\circ} \mathrm{C}\right)$
32: PT1_G $\left({ }^{\circ} \mathrm{C}\right)$
34: PT3_G ( $\left.{ }^{\circ} \mathrm{C}\right)$
Standard Deviation PT

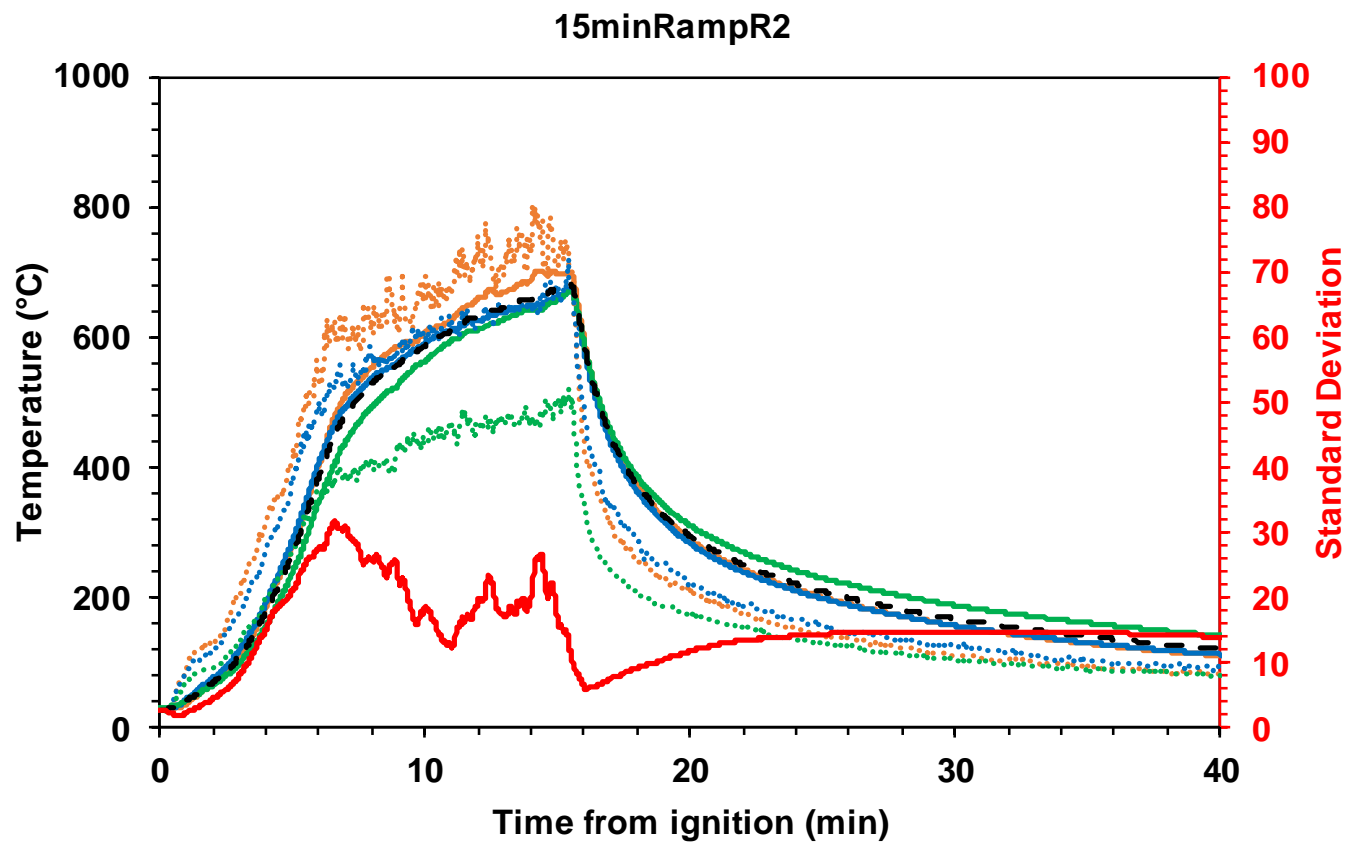
29: PT1 $\left({ }^{\circ} \mathrm{C}\right)$
31: РT3 $\left({ }^{\circ} \mathrm{C}\right)$
....... 33: PT2_G $\left({ }^{\circ} \mathrm{C}\right)$
- - 69: TC_AveULPT $\left({ }^{\circ} \mathrm{C}\right)$

(b)

30: PT2 $\left({ }^{\circ} \mathrm{C}\right)$

32: PT1 G $\left({ }^{\circ} \mathrm{C}\right)$

34: PT3_G $\left({ }^{\circ} \mathrm{C}\right)$

Standard Deviation 


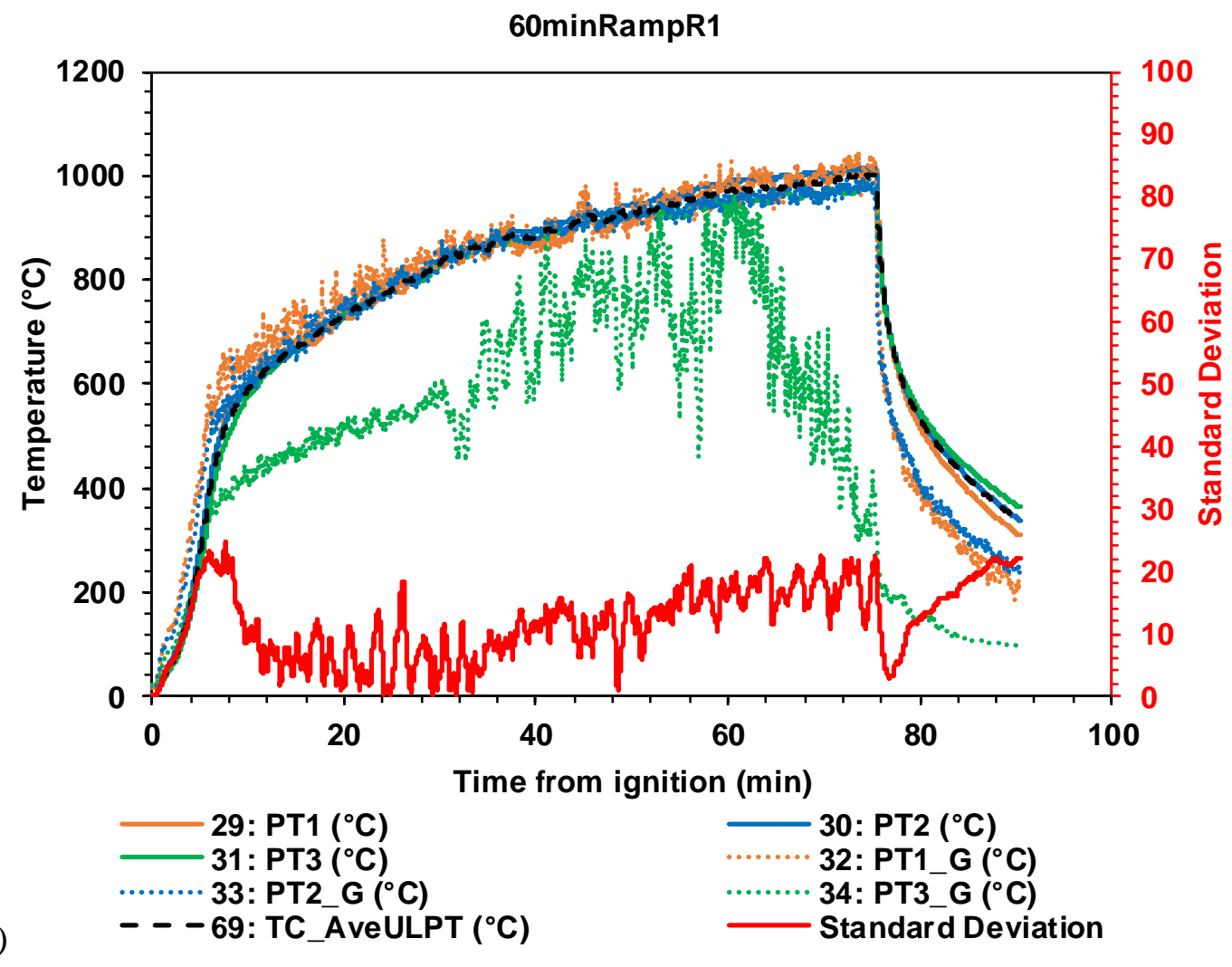

Figure 19. Temperatures measured using the plate thermometers for (a) $15 \mathrm{minRampR1,(b)} \mathrm{15minRampR2,}$ and (c) 60minRampR1.

\section{(iii) Thermocouple Trees}

Figure 20 presents the vertical distribution of temperatures inside the compartment measured by thermocouple trees (see Figure 13 for tree details). The temperatures measured at the location of Tree 1 were higher than the one measured at the location of Tree 2.

During 15 minRampR2 test, a peak temperature of $700{ }^{\circ} \mathrm{C}$ was measured by T1_1. During 60minRampR1 test, the measured peak temperature by T1_1 was around $1000{ }^{\circ} \mathrm{C}$. 

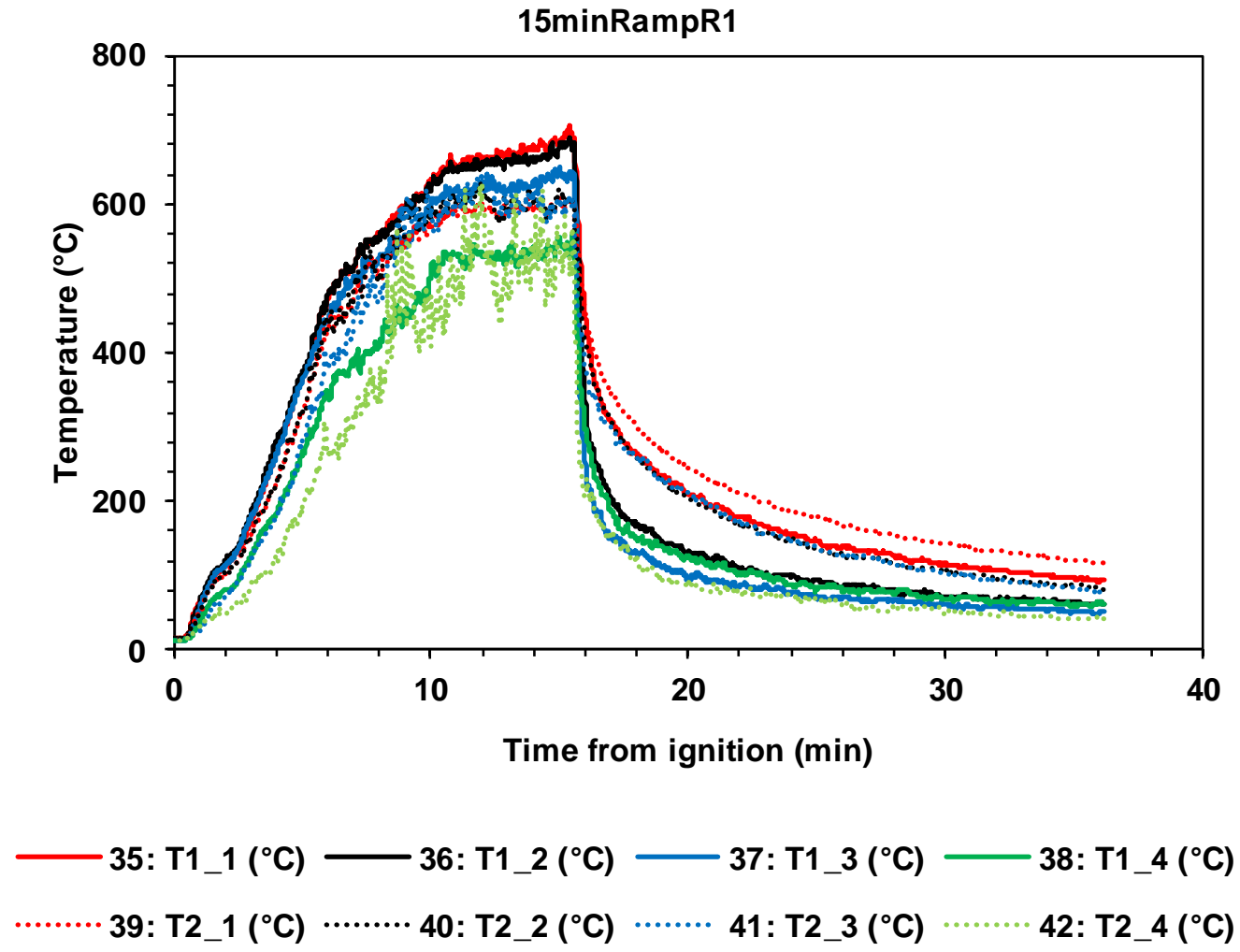

(a)

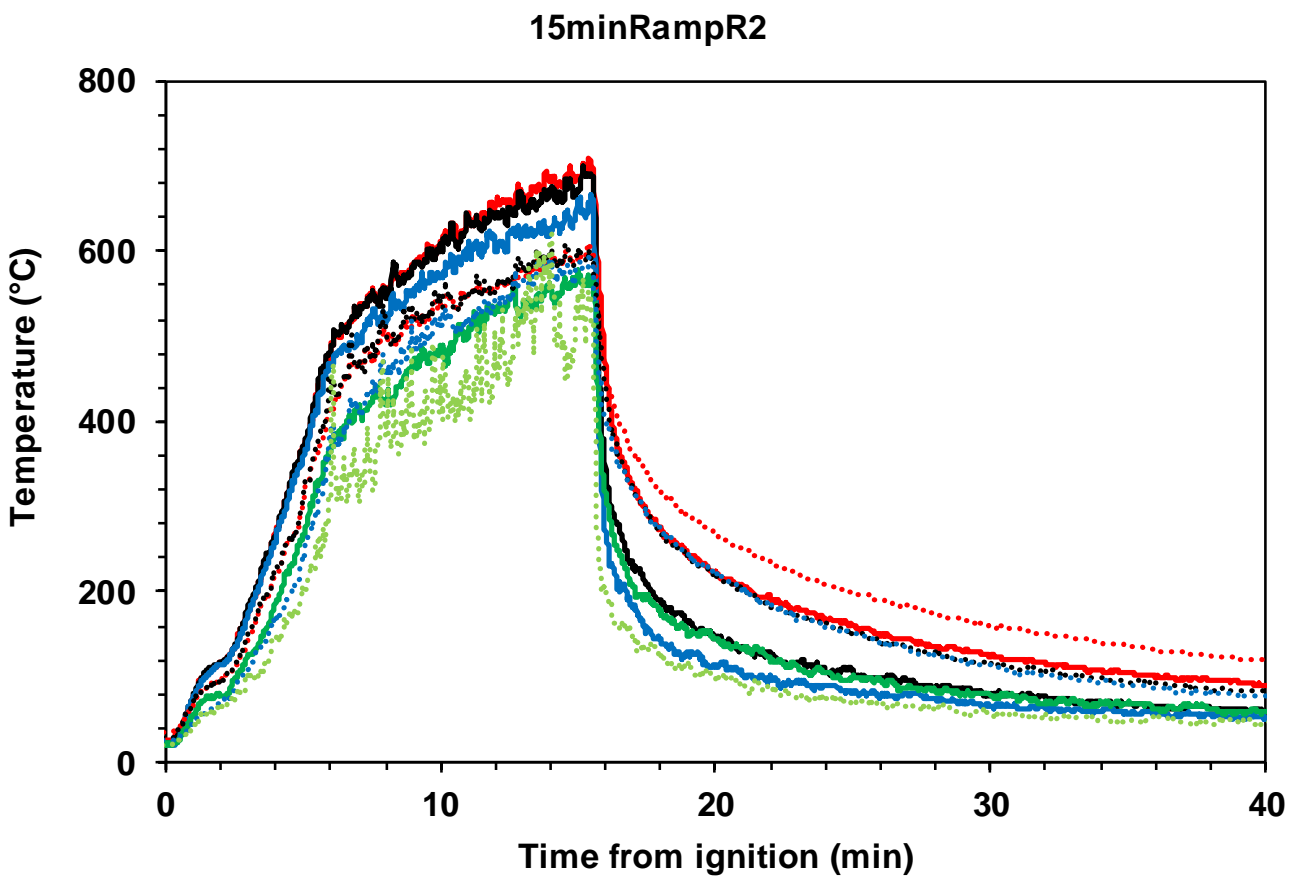
-35: T1_1 $\left({ }^{\circ} \mathrm{C}\right)$
36: T1_2 ( $\left.{ }^{\circ} \mathrm{C}\right)$
37: T1_3 $\left({ }^{\circ} \mathrm{C}\right)$
38: T1_4 $\left({ }^{\circ} \mathrm{C}\right)$
39: T2_1 ( $\left.{ }^{\circ} \mathrm{C}\right)$
40: T2_2 ( $\left.{ }^{\circ} \mathrm{C}\right)$
41: T2_3 $\left({ }^{\circ} \mathrm{C}\right)$
42: T2_4 ( $\left.{ }^{\circ} \mathrm{C}\right)$

(b) 


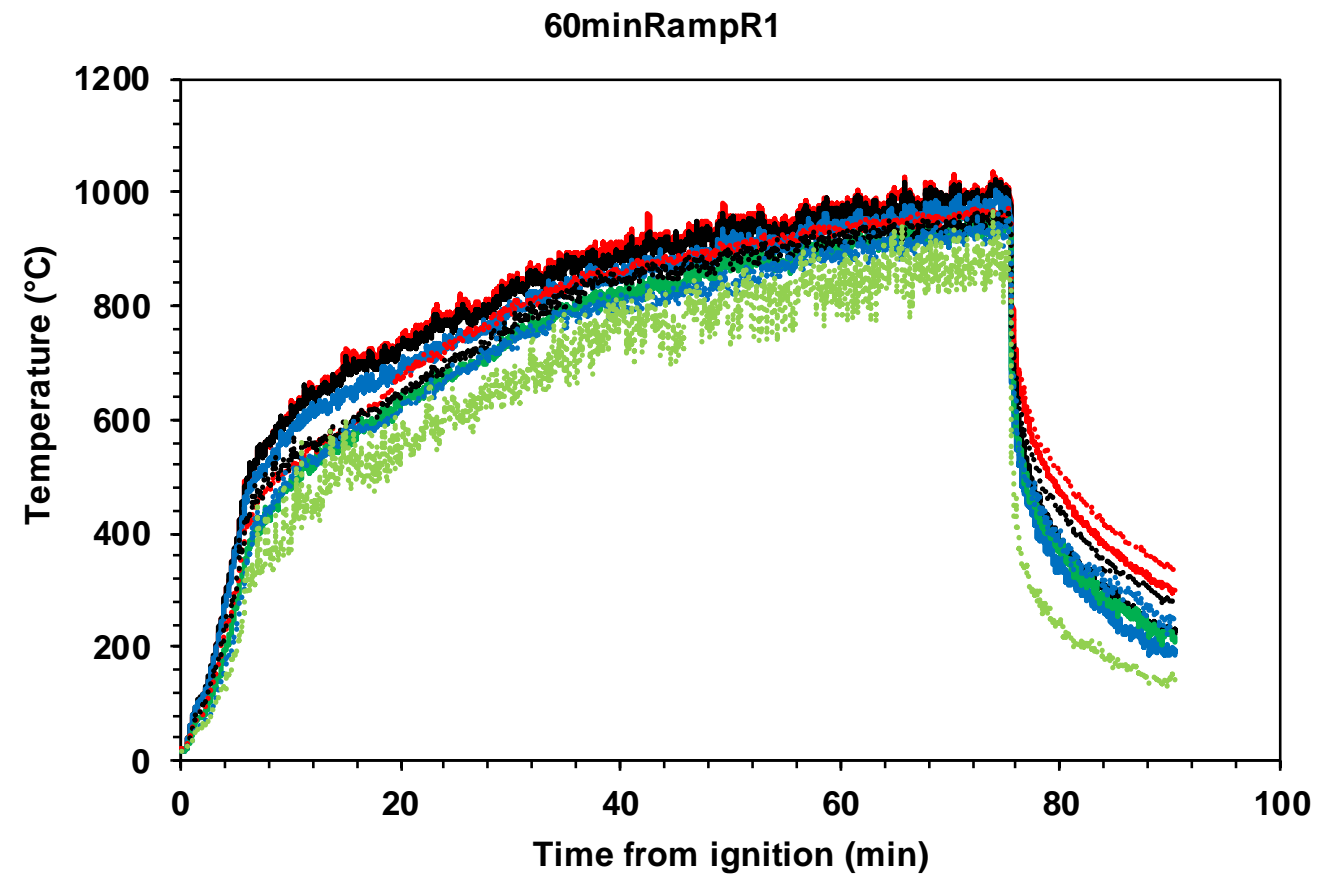
(c)
35: T1_1 ( $\left.{ }^{\circ} \mathrm{C}\right)$
$\cdots \cdots . . . .39:$ T2_1 ( $\left.{ }^{\circ} \mathrm{C}\right)$
36: T1_2 ( $\left.{ }^{\circ} \mathrm{C}\right)$
37: T1_3 $\left({ }^{\circ} \mathrm{C}\right)$
38: T1_4 ( $\left.{ }^{\circ} \mathrm{C}\right)$
40: T2_2 ( $\left.{ }^{\circ} \mathrm{C}\right)$
41: T2_3 $\left({ }^{\circ} \mathrm{C}\right)$
42: $\mathrm{T}_{2} 4\left({ }^{\circ} \mathrm{C}\right)$

Figure 20. Trees temperatures for (a) 15minRampR1, (b) 15minRampR2, and (c) 60minRampR1.

The vertical distribution of temperatures at the location of Tree 1 and Tree 2 is presented in Figure 21, for 5, 10, 20, 30, and $60 \mathrm{~min}$. Higher temperatures were registered at the location of Tree 1. Towards the end of the test, the vertical distribution of temperatures tends to become more uniform 


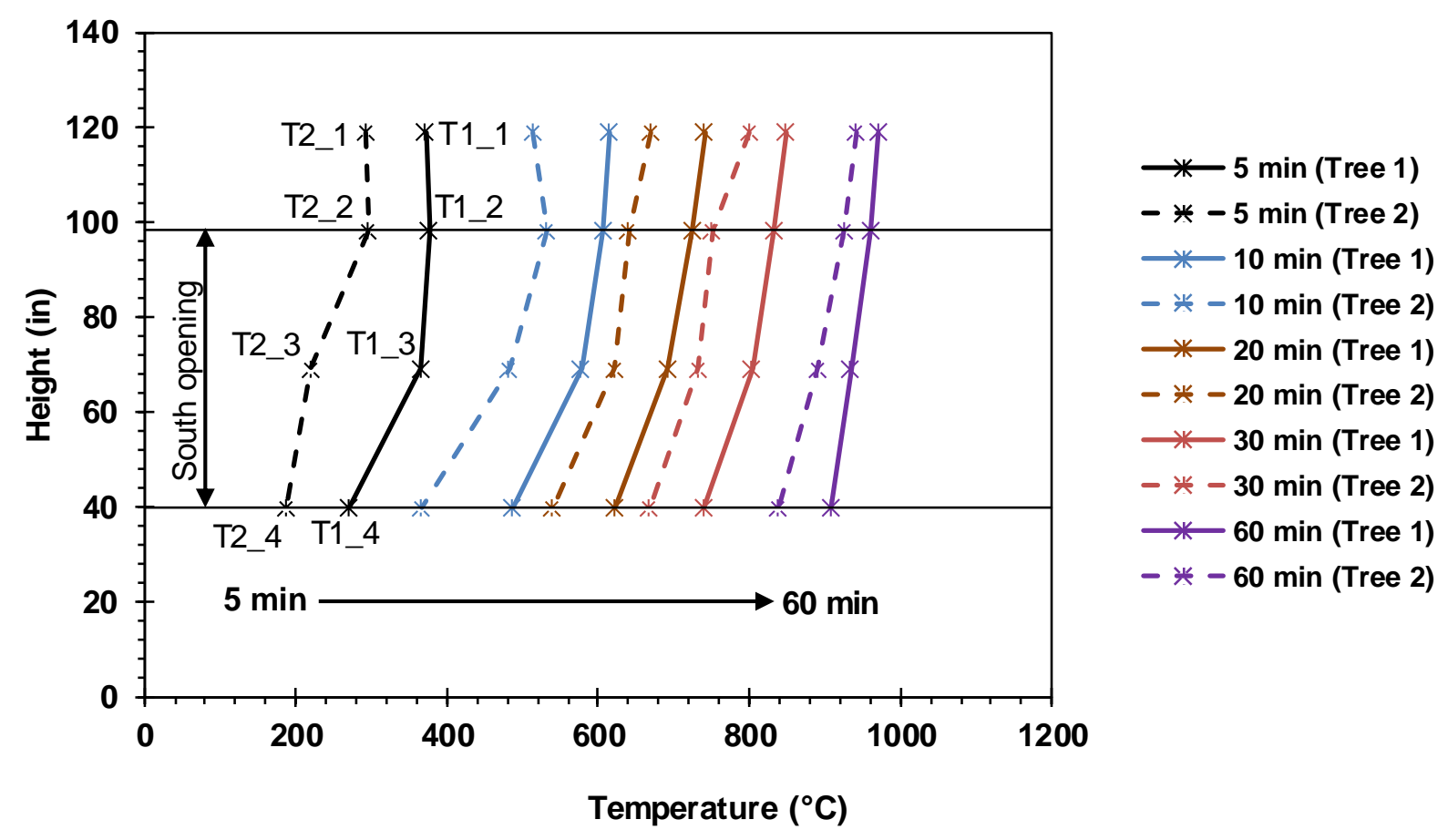

Figure 21. Temperature profile at the location of Tree 1 and Tree 2

\subsubsection{Compartment Heat Flux}

\section{(i) Incident Radiant Heat Flux}

To calculate the incident radiant heat flux using the plate thermometers, gas temperature directly adjacent to each probe was measured using bare-bead thermocouples (Model GG-K-24).

The measured temperature of the plate thermometer $\left(T_{\mathrm{PT}}\right.$, in $\left.\mathrm{K}\right)$ and the gas temperature near the plate thermometer $\left(T_{\text {gas }}\right.$, in $\left.\mathrm{K}\right)$ are used to compute the incident radiant heat flux at step $i\left(\left[\dot{q}_{\text {inc }}{ }^{\prime \prime}\right]^{i}\right.$, in $\mathrm{W} / \mathrm{m}^{2}$ ) as follows (Häggkvist et al. 2013):

$$
\left[\dot{q}_{i n c}^{\prime \prime}\right]^{i}=\sigma\left[T_{P T}^{4}\right]^{i}+\frac{\left(h+K_{P T}\right)\left(\left[T_{P T}\right]^{i}-\left[T_{g a s}\right]^{i}\right)}{\varepsilon_{P T}}+\frac{C_{P T} \frac{\left[T_{P T}\right]^{i+1}-\left[T_{P T}\right]^{i-1}}{[t]^{i+1}-[t]^{i-1}}}{\varepsilon_{P T}}
$$

where the time $(t)$ is in seconds, the Stefan Boltzmann constant $(\sigma)$ is $5.6704 \mathrm{E}-8 \mathrm{~W} / \mathrm{m}^{2} / \mathrm{K}^{4}$, the convection coefficient $\left(h_{\mathrm{c}}\right)$ is taken to be $10 \mathrm{~W} / \mathrm{m}^{2} / \mathrm{K}$, the heat transfer coefficient due to heat losses of the plate thermocouples $\left(K_{\mathrm{PT}}\right)$ is taken to be $8 \mathrm{~W} / \mathrm{m}^{2} / \mathrm{K}$ (Häggkvist et al. 2013), the lumped heat capacity of the plate thermocouples $\left(C_{\mathrm{PT}}\right)$ is taken to be $4200 \mathrm{~J} / \mathrm{m}^{2} / \mathrm{K}$ (Häggkvist et al. 2013), and 
the emissivity of the plate thermocouple $\left(\varepsilon_{\mathrm{PT}}\right)$ is taken to be 0.9 . The emissivity was suggested by the inventor of the plate thermocouple based on experience.

Figure 22 presents the incident fluxes for the three tests. The peak values for $15 \mathrm{minRampR} 1$, $15 \mathrm{minRampR} 2$ and $60 \mathrm{minRampR} 1$ were approximately $50 \mathrm{~kW} / \mathrm{m}^{2}, 50 \mathrm{~kW} / \mathrm{m}^{2}$, and $160 \mathrm{~kW} / \mathrm{m}^{2}$. The maximum standard deviations for $15 \mathrm{minRampR} 1,15 \mathrm{minRampR} 2$ and $60 \mathrm{minRampR} 1$ were $8 \mathrm{~kW} / \mathrm{m} 2,6 \mathrm{~kW} / \mathrm{m}^{2}$ and $10 \mathrm{~kW} / \mathrm{m}^{2}$.

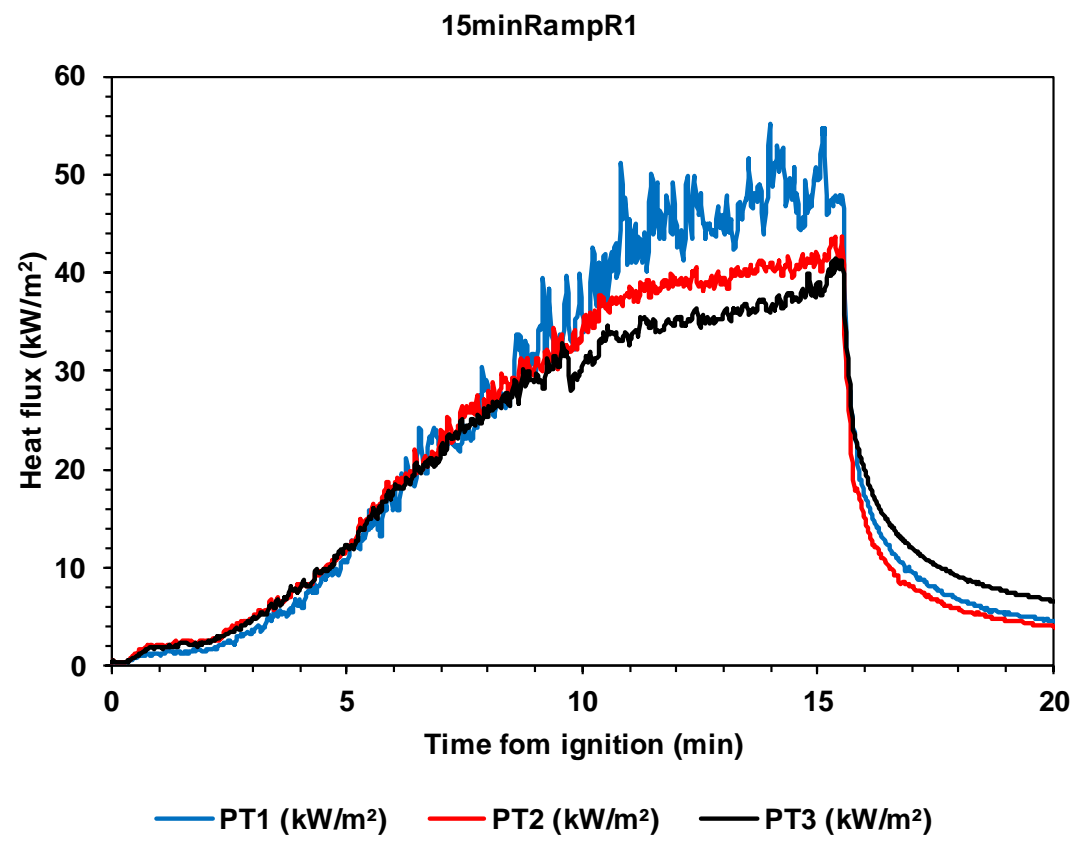




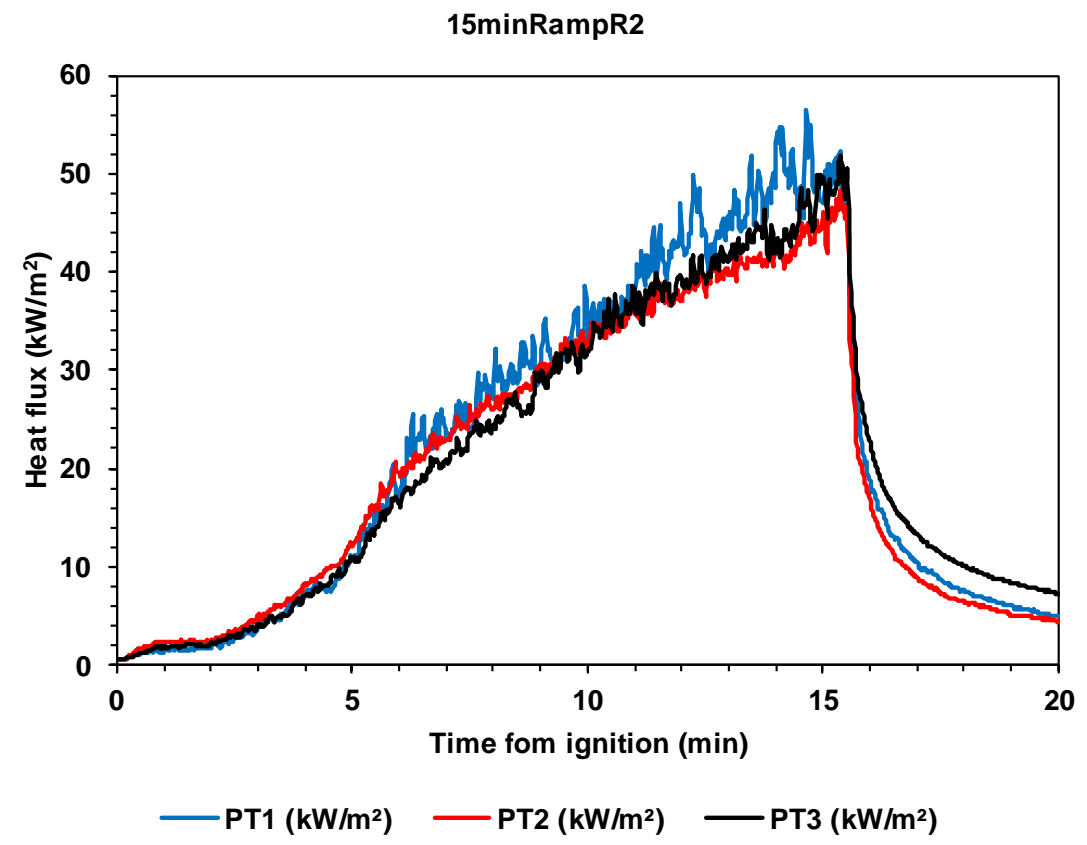

(b)

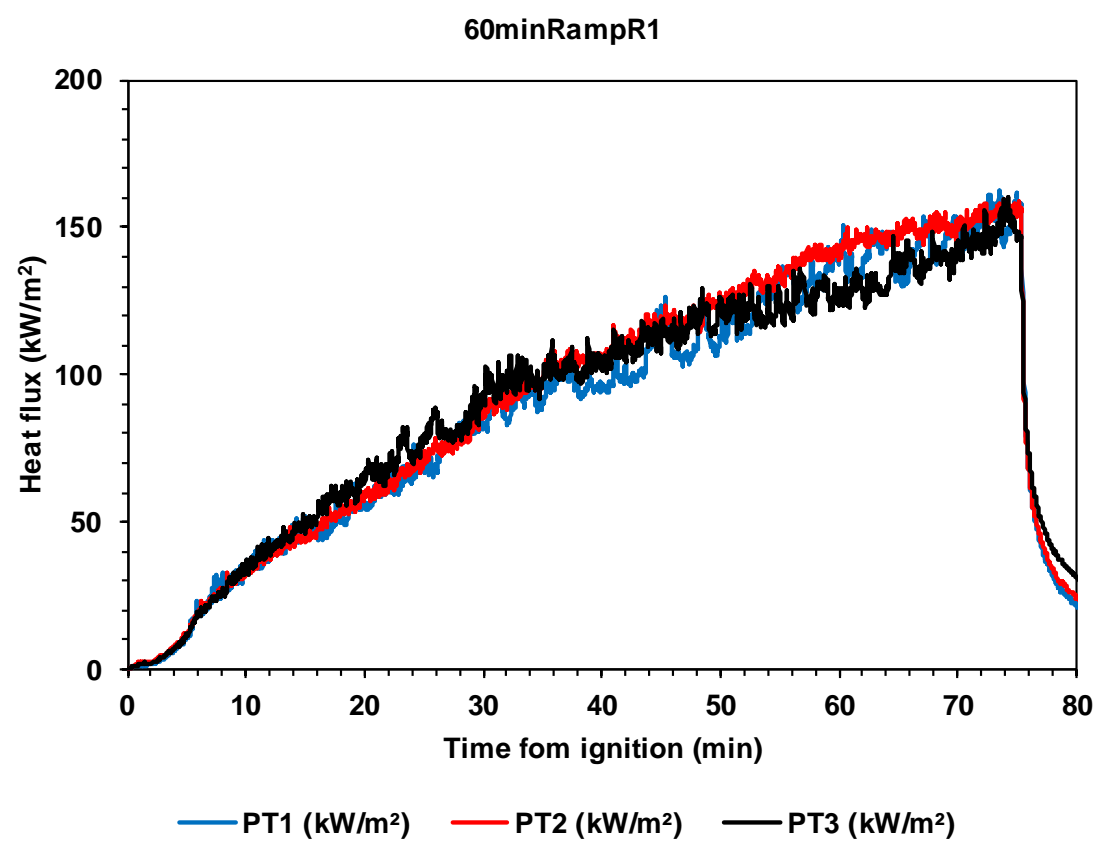

Figure 22. Incident fluxes for (a) 15minRampR1, (b) 15minRampR2, and (c) 60minRampR1.

\section{(ii) Measured Radiant and Convective Heat Flux}

Gardon gauges provided measurements of the heat flux at the north-west and south-east locations. Figure 23 shows the measured heat fluxes during the three tests. The peak heat fluxes for 
15minRampR1, 15minRampR2 and 60minRampR1 were $50 \mathrm{~kW} / \mathrm{m}^{2}, 50 \mathrm{~kW} / \mathrm{m}^{2}$ and $180 \mathrm{~kW} / \mathrm{m}^{2}$. The measured temperatures of the Gardon gauges are presented in the Appendix section.

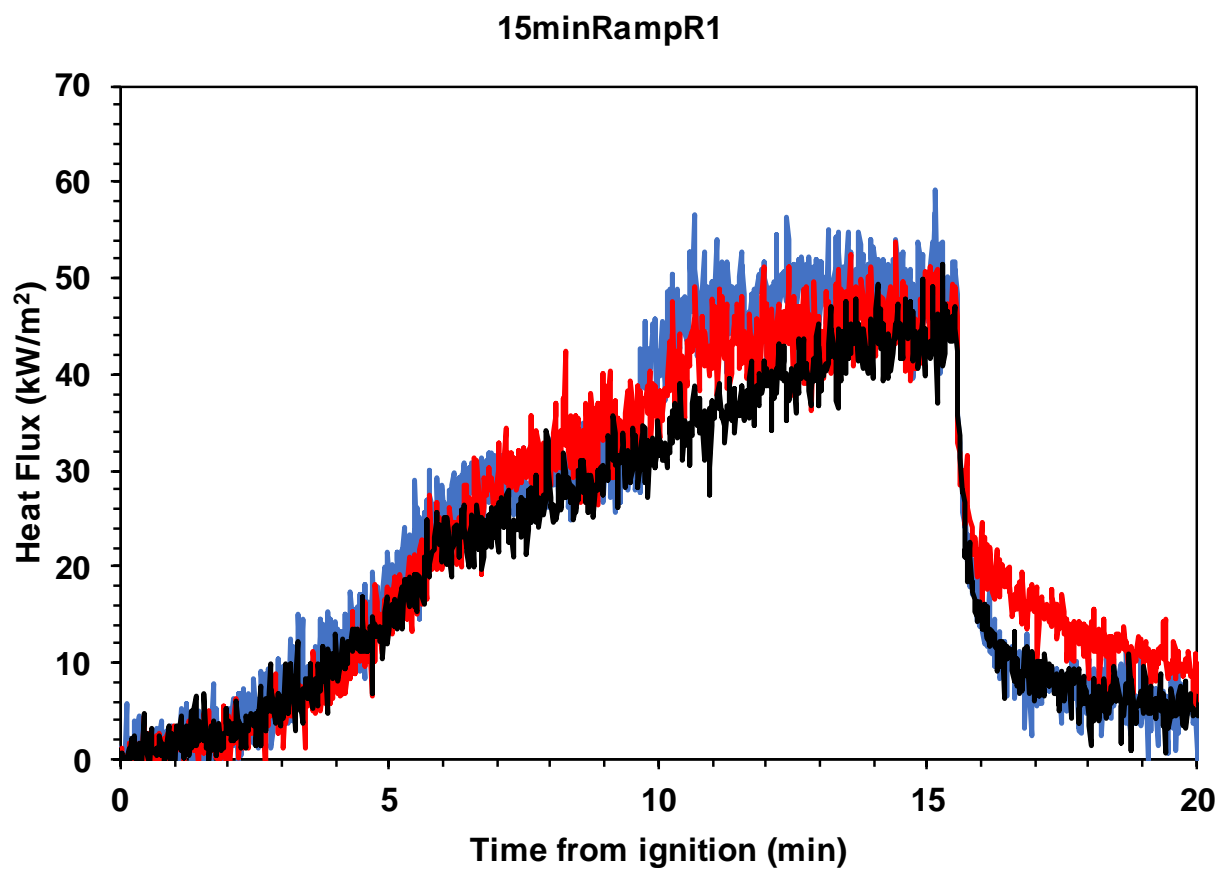

(a)
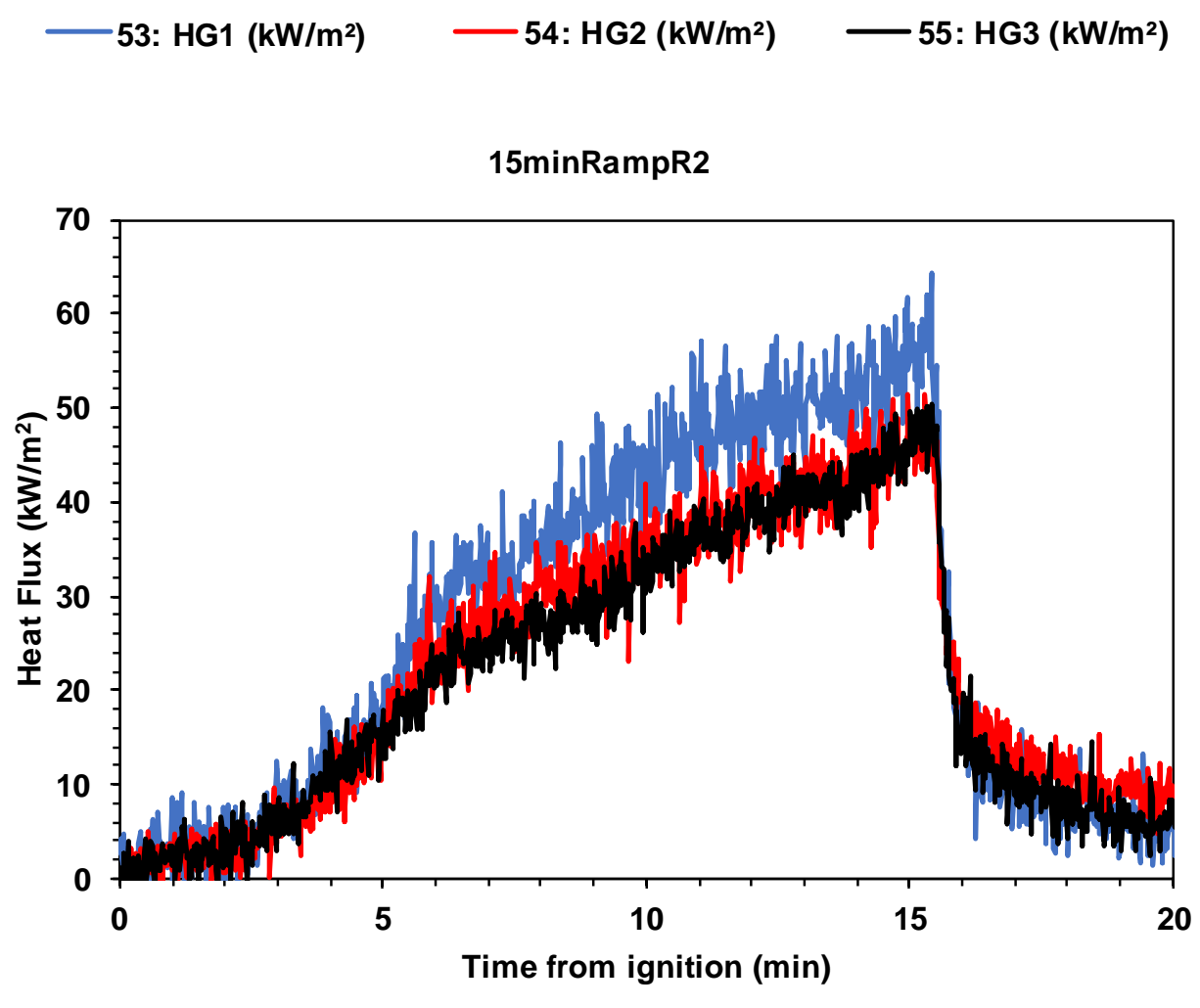

(b)

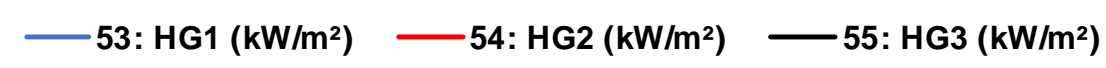




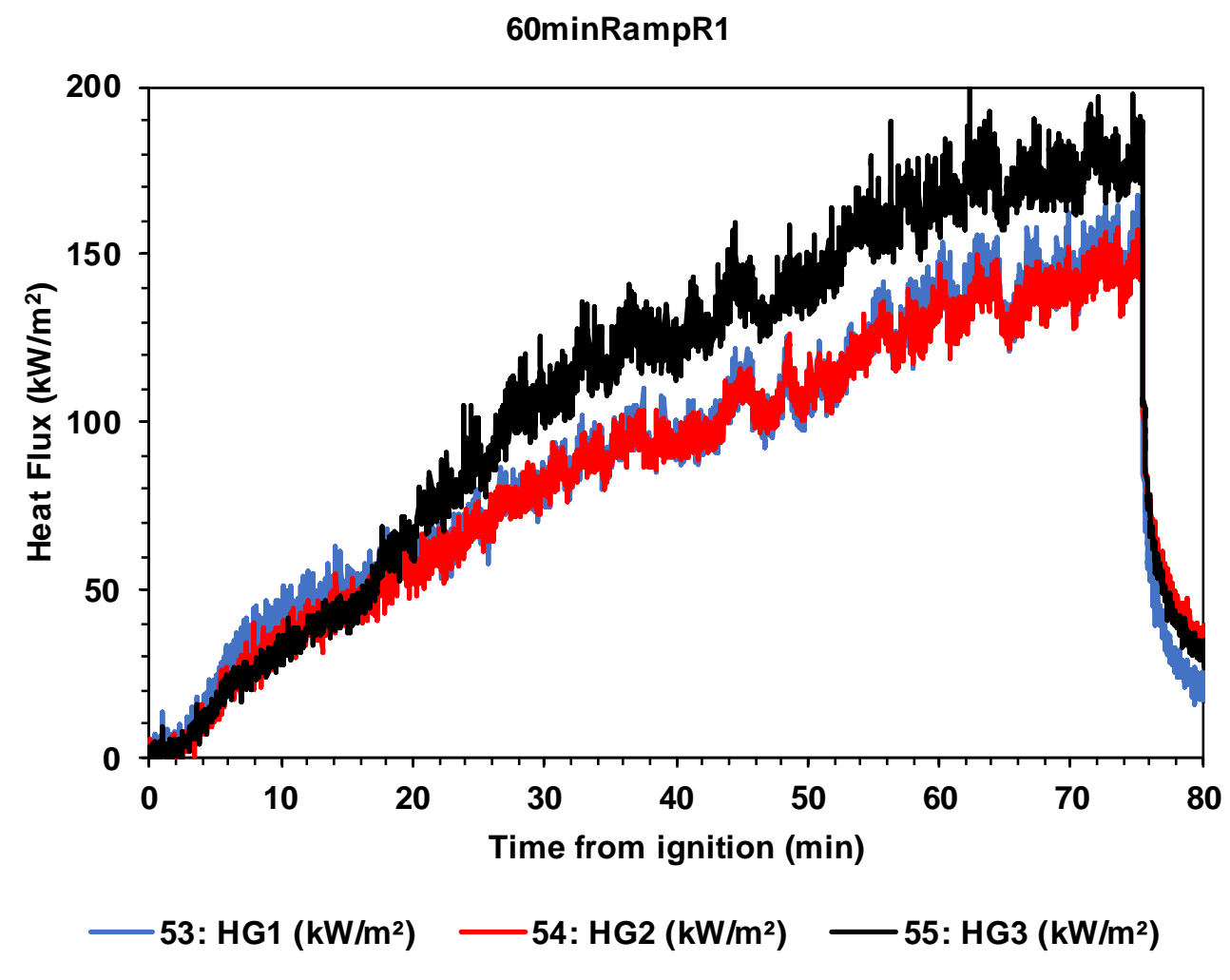

Figure 23. Measured heat fluxes for (a) 15minRampR1, (b) 15minRampR2, and (c) 60minRampR1.

\subsubsection{Repeatability of the 15minRampR1 and 15minRampR2 tests}

Figure 24, Figure 25 and Figure 26 show a comparison of the average temperature of the upper layer gas, the heat release rate and the measured heat flux values obtained from $15 \mathrm{minRampR} 1$ and 15 minRampR2 experiments. The plotted values are recorded at every second after the ignition of fire.

The following conclusions can be made based on the linear regression analysis:

- The average temperature of the upper layer gas measured in $15 \mathrm{minRampR} 1$ test was $3 \%$ higher than $15 \mathrm{minRampR} 2$ test.

- The burner HRR measured in 15 minRampR1 test was $1 \%$ lower than 15 minRampR2 test.

- The measured heat flux using the Gardon gauge HG1 in 15 minRampR1 test was $1 \%$ lower than $15 \mathrm{minRampR} 2$ test. When using the Gardon gauges HG2 and HG3, the measured heat flux in 15 minRampR1 test was $11 \%$ and $2 \%$ higher than 15 minRampR2 test.

These plots confirm the repeatability of the experiments for the ASTM-E119 curve. 


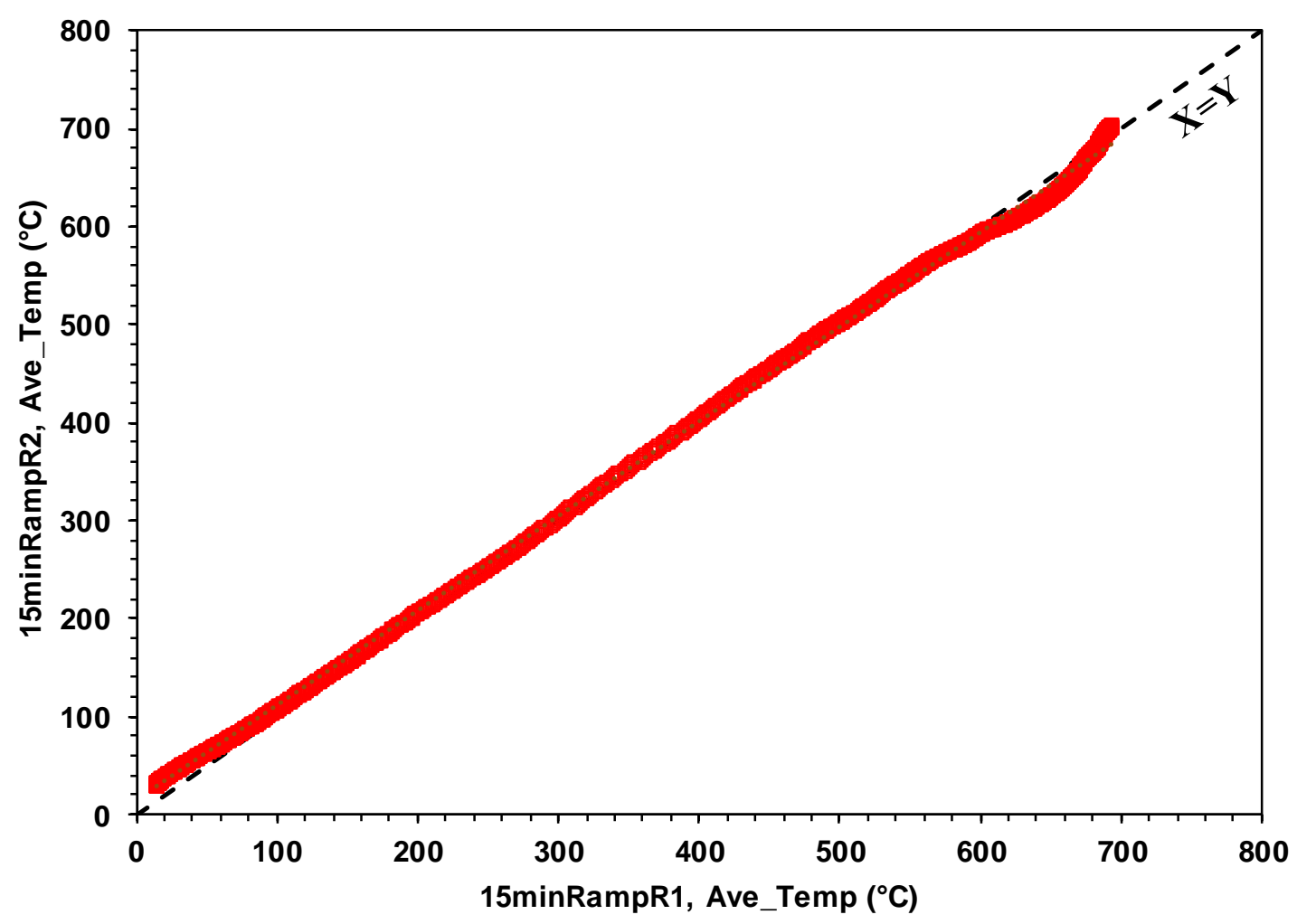

Figure 24. Reproducibility of the average upper layer gas temperature.

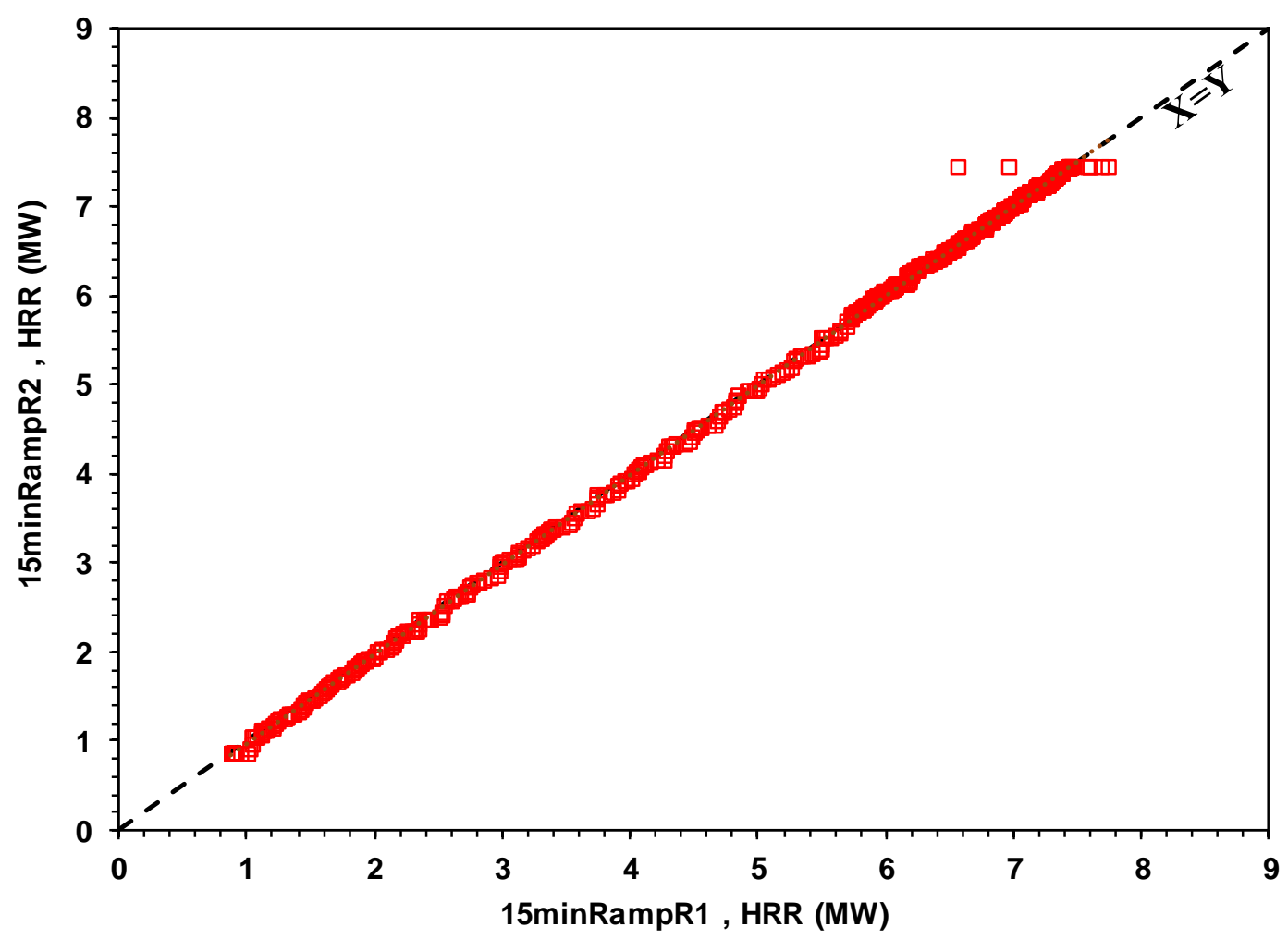

Figure 25. Reproducibility of the heat release rate (HRR) of the burner. 


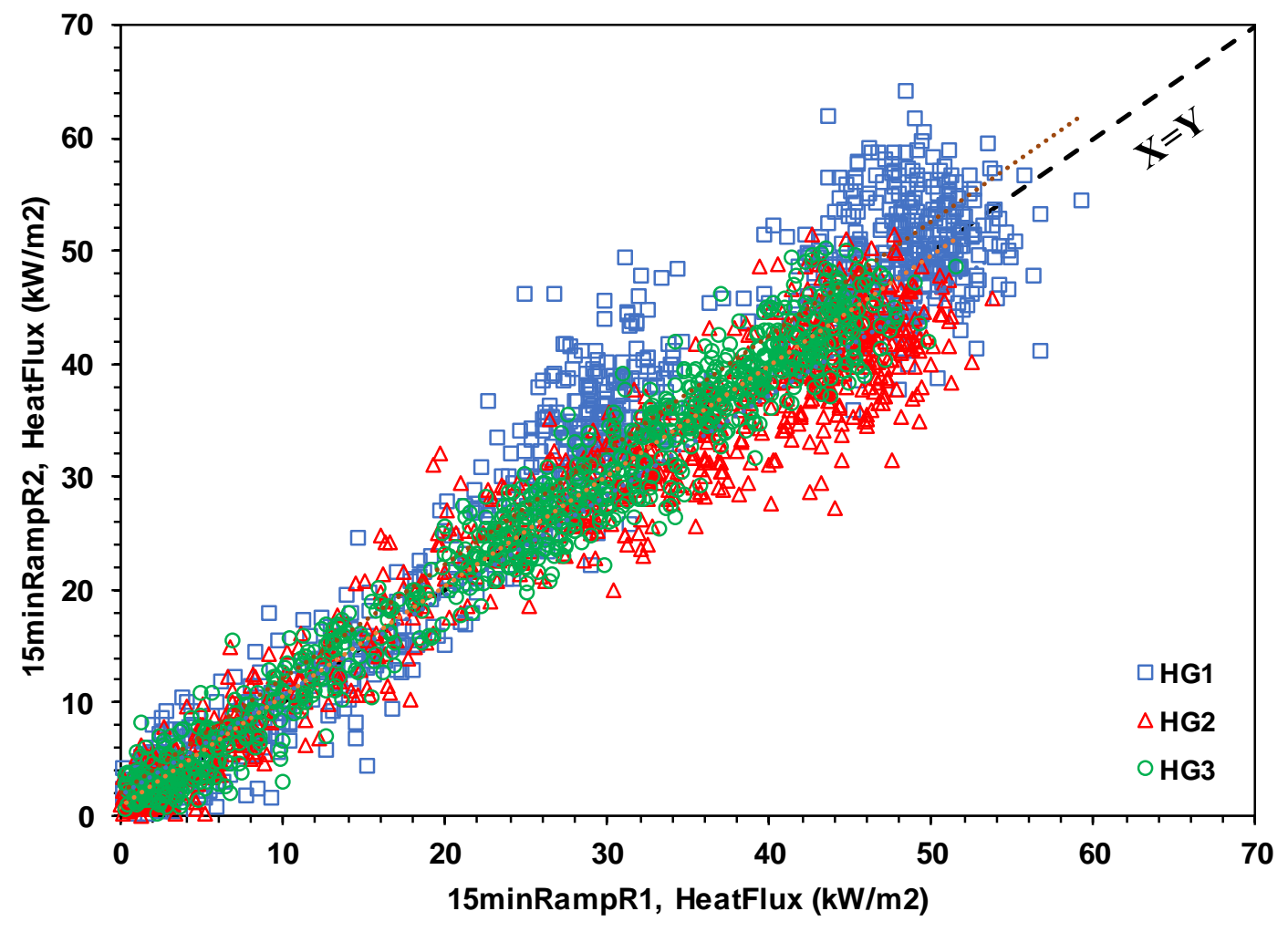

Figure 26. Reproducibility of the heat flux. 


\section{Chapter 4 \\ SUMMARY AND CONCLUSIONS}

This report presents a design basis for test fires used for the experimental assessment of the structural integrity and behavior of concrete-steel composite floor systems joined to a full-scale multi-bay steel frame. The compartment fire is produced with a $10 \mathrm{~m}$ wide, $7 \mathrm{~m}$ deep and $3.8 \mathrm{~m}$ high bay within a two-story steel structure constructed in the National Fire Research Laboratory. Design objectives of test fires are: (1) to produce realistic yet extreme conditions to study fire design limit states of the structure, and (2) to experimentally simulate the thermal environment to which such a system would be exposed when rated using the ASTM E119 standard test method without furnaces. The results from a full-scale experiment in a mock-up of the test bay allow comparison of the simulated upper layer gas temperatures to experimentally measured values. The study indicates that by proper design and control, the time-temperature curve for the standard fire test may be attained in a real compartment within about $7 \%$ temperature difference toward the end of the test. The coefficient of variation for the upper layer gas temperatures (measured by twelve steel sheathed thermocouples) toward the end of the test was around $2 \%$. The area under time-temperature curve, obtained by averaging the results from the readings, is within $2 \%$ of the corresponding area under the standard ASTM E119 time-temperature curve. Heat fluxes of maximum $175 \mathrm{KW} / \mathrm{m}^{2}$ were measured. No damage of the fire compartment was observed. 


\section{REFERENCES}

ASTM E119 (2018). Standard test methods for fire tests of building construction and materials. Standard, ASTM International.

Bailey, C.G., \& Toh, W., S. (2007). Behaviour of concrete floor slabs at ambient and elevated temperatures. Fire Saf. J., 42, 425-436.

Building Research Establishment Ltd (BRE). (2004). Results and Observations from Full-Scale Fire Test at BRE Cardington, 16 Jan 2013, Client Report 215-741.

BRE (2004). Results and observation from full-scale fire test at BRE Cardington, Client report number 215-741.

British Steel. (1999). The behaviour of multi-storey steel framed buildings in fire. British Steel, Rotherham, UK

Bryant, R.A. et al., (2004). The NIST 3 Megawatt Quantitative Heat Release Rate Facility - Description and Procedures, National Institute of Standards and Technology, NIST TN 7052, 2004.

BSI. (2002). Eurocode 1: Actions on structures - Part 1-2: General rules - Actions on structures exposed to fire. British Standard.

Bundy, M.F., Hamins, A., Johnsson, E.L., Kim, S.C., Ko, G.H. and Lenhert, D.B. (2007). Measurements of Heat and Combustion Products in Reduced-Scale Ventilation-Limited Compartment Fires, National Institute of Standards and Technology, NIST TN 1483, 2007.

Bundy, M., Hamins, A., Gross, J., Grosshandler, W., and Choe, L. (2016). "Structural fire experimental capabilities at the NIST National Fire Research Laboratory," Fire Technology, 52(4), 959-966.

Choe, L., Ramesh, S., Hoehler, M., Seif, M., Gross, J., Zhang, C. and Bundy, M. (2018). National Fire Research Laboratory Commissioning Project: Testing Steel Beams under Localized Fire Exposure. NIST Technical Note 1983.

Häggkvist, A., Sjöström, J. \& Wickström, U., (2013). Using plate thermometer measurements to calculate incident heat radiation. Journal of Fire Sciences, 31(2), pp.166-177.

Hamins, A. P., Maranghides, A., McGrattan, K. B., Ohlemiller, T.J., \& Anleitner, R. (2008). Experiments and Modeling of Multiple Workstations Burning in a Compartment. Federal Building and Fire Safety Investigation of the World Trade Center Disaster (NIST NCSTAR 15E), National Institute of Standards and Technology.

McAllister, T.P., Gross, J.L., Sadek, F., Kirkpatrick, S., MacNeil, R.A., Zarghamee, M. (2012). Structural Response of World Trade Center Buildings 1, 2, and 7 to Impact and Fire Damage. Fire Technology, 40(3):709-739. 
McCaffrey, B.J. and Heskestad, G. (1976). Robust Bidirectional Low-Velocity Probe for Flame and Fire Applications, Combustion and Flame 1125-127 (1976).

McGrattan, K., Hostikka, S., McDermott, R., Floyd, J., Weinschenk, C., \& Overholt, K. (2018). Fire Dynamics Simulator, User's Guide. National Institute of Standards and Technology, Gaithersburg, Maryland, USA, and VTT Technical Research Centre of Finland, Espoo, Finland, sixth edition.

MEDTHERM Corporation (2002). Heat Flux Transducers and Infrared Radiometers for the direct measurement of heat transfer rates.

Peacock, R.D., Reneke, P.A., \& Forney, G.P. (2017). CFAST-consolidated model of fire growth and smoke transport (version 7), volume 2: user's guide. National Institute of Standards and Technology.

Vassart, O., \& Zhao, B. (2011). FRACOF Engineering Background. Report developed for the Leonardo Da Vinci Programme: Fire Resistance Assessment of Partially Protected Composite Floors (FRACOF). European Commission, Education and Culture DG, Bordeaux, France

Vassart, O. (2014). EN1991-1-2. Basic design methods and worked examples, Chapter 1 in Eurocodes: Background \& Applications Structural Fire Design, Report EUR 26698 EN.

Wald, F., Simões da Silva, L., Moore, D.B., Lennon, T., Chaldna, M., Santiago, M., Borges, L. (2006). Experimental behaviour of a steel structure under natural fire. Fire Safety Journal 41(7):509-522.

Zhang, C., Choe, L., Gross, J., Ramesh, S., Bundy M. (2017). Engineering approach for designing a thermal test of real-scale steel beam exposed to localized fire. Fire Technology. 53, 1535-1554

Zhang, C., Usmani, A. (2015). Heat transfer principles in thermal calculation of structures in fire. Fire Safety Journal. Vol. 78, pp. 85-95. 


\section{APPENDIX A: 15MINRAMPR1}

\section{Compartment Heat Fluxes}

\section{Gardon gauges temperature}

Figure 27 presents the gas temperature close to the Gardon gauges. The maximum mean value is around $30{ }^{\circ} \mathrm{C}$ and the maximum standard deviation is $5{ }^{\circ} \mathrm{C}$. The higher temperatures are registered for the Gardon gauge installed on the north wall.

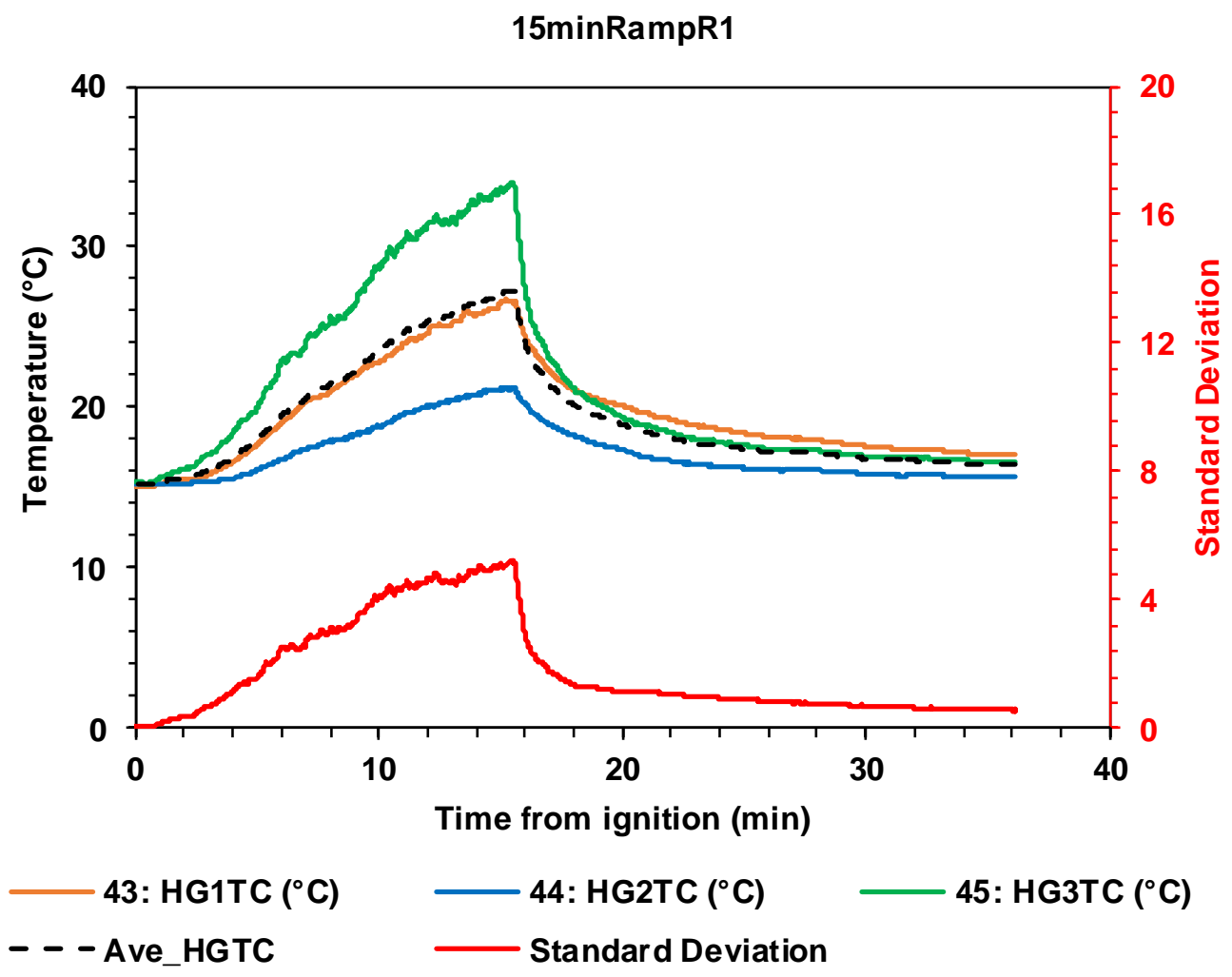

Figure 27. Gardon gauges temperature for 15minRampR1 test.

\section{Vent conditions}

\section{Openings temperature}

Figure 28 presents the temperatures measured by the thermocouples mounted at the north and south opening (see Figure 12 (c) and (d)). The measured temperatures at the north and south opening are similar, reaching peak values of around $500{ }^{\circ} \mathrm{C}$. The temperature measured at the east bottom opening of the south wall is much smaller, reaching the peak value of around $190{ }^{\circ} \mathrm{C}$. 

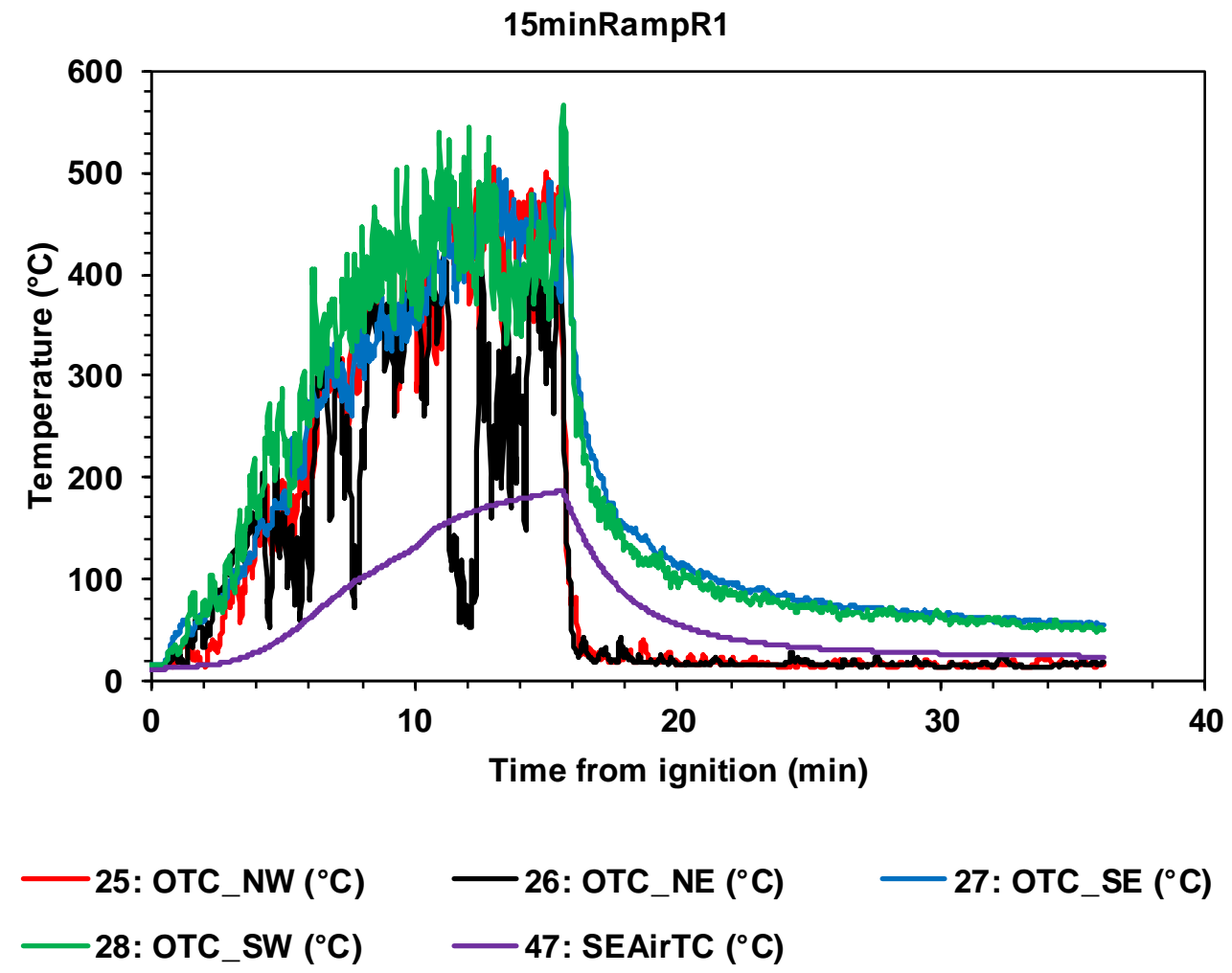

Figure 28. Openings temperature for $15 \mathrm{minRampR} 1$ test. 


\section{APPENDIX B: 15MINRAMPR2}

\section{Compartment Heat Fluxes}

\section{Gardon gauges temperature}

Figure 29 presents the gas temperature close to the Gardon gauges. The maximum mean value is $35{ }^{\circ} \mathrm{C}$ and the maximum standard deviation is $6{ }^{\circ} \mathrm{C}$. The higher temperatures are registered for the Gardon gauge installed on the north wall.

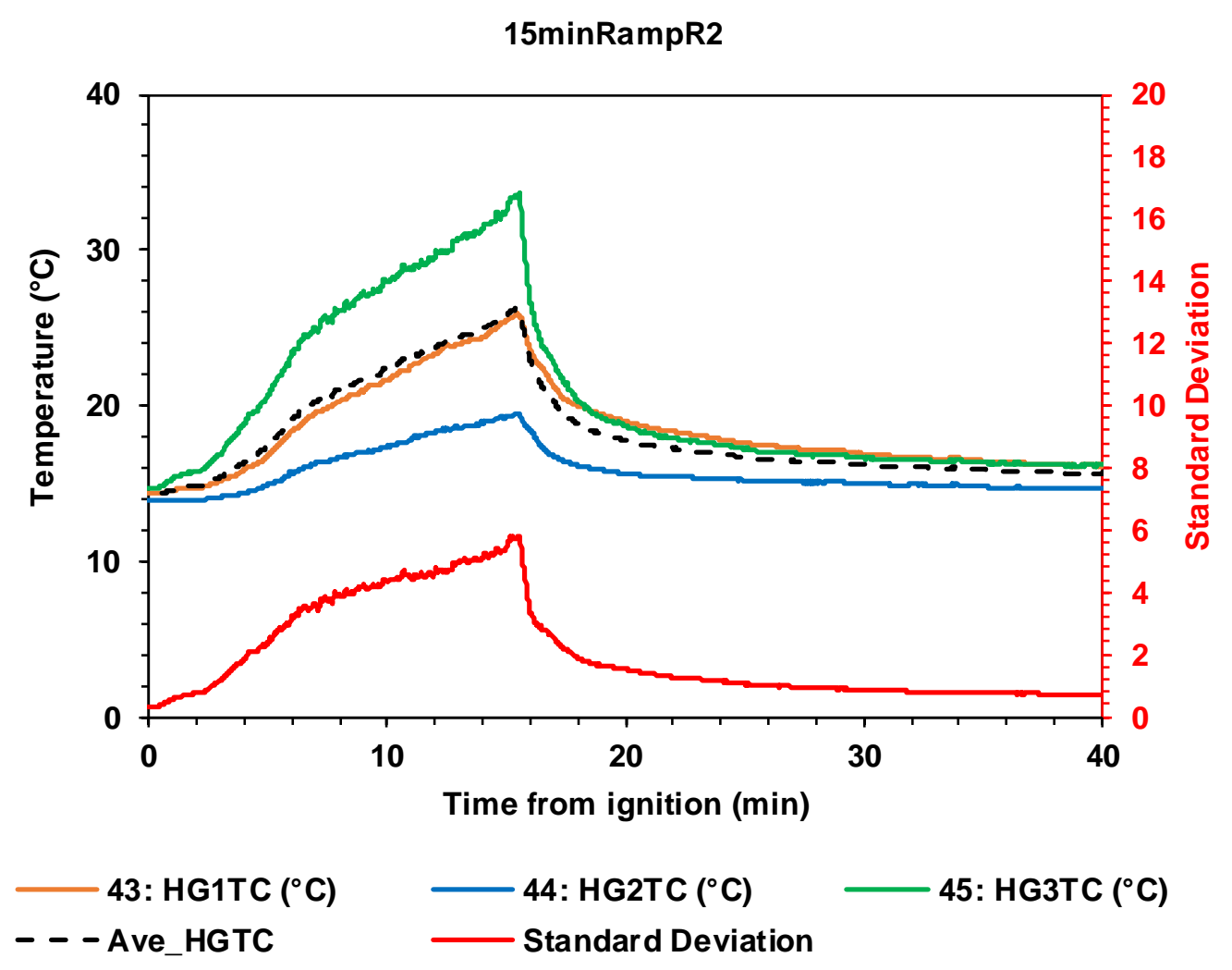

Figure 29. Gardon gauges temperature for 15minRampR2 test.

\section{Vent conditions}

\section{Openings temperature}

Figure 30 presents the temperatures measured by the thermocouples mounted at the north and south opening (see Figure 12 (c) and (d)). Higher temperatures were registered at the top part of the south opening, reaching peak values of around $570{ }^{\circ} \mathrm{C}$. The temperature measured at the east bottom of the south wall is much smaller, reaching the peak value of $210{ }^{\circ} \mathrm{C}$. 


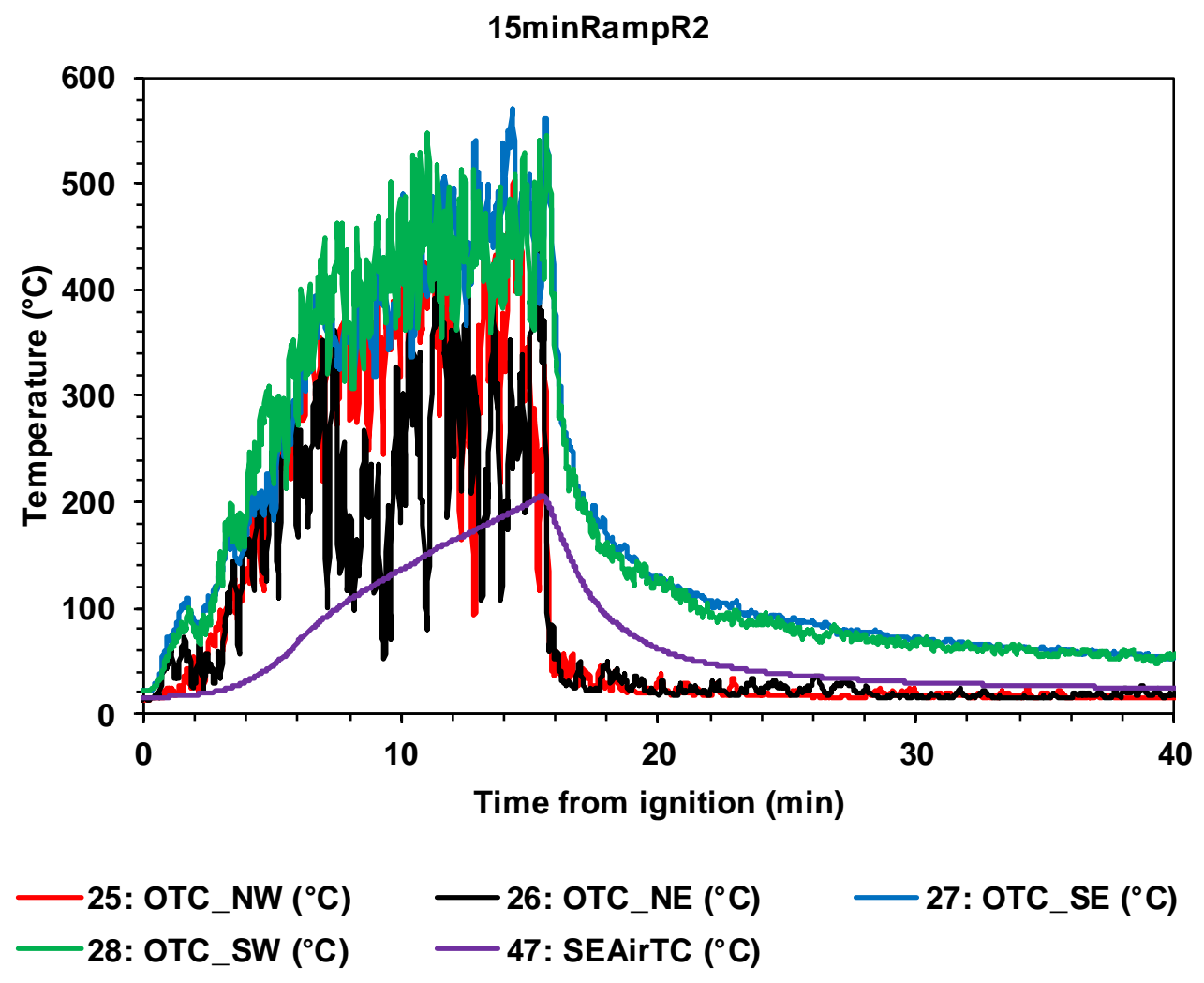

Figure 30. Openings temperature for 15 minRampR2 test.

Note:

During the $15 \mathrm{minRampR} 2$ test the registered temperatures were slightly higher than in the $15 \mathrm{minRampR} 1$ test. Both tests were performed in the same day and the compartment was not left to cool down completely before the start of the second test. 


\section{APPENDIX C: 60MINRAMPR1}

\section{Compartment Heat Fluxes}

\section{Gardon gauges temperature}

Figure 31 presents the gas temperature close to the Gardon gauges. The maximum mean value is $60{ }^{\circ} \mathrm{C}$ and the maximum standard deviation is $10^{\circ} \mathrm{C}$. The higher temperatures are registered for the Gardon gauge installed on the north wall.

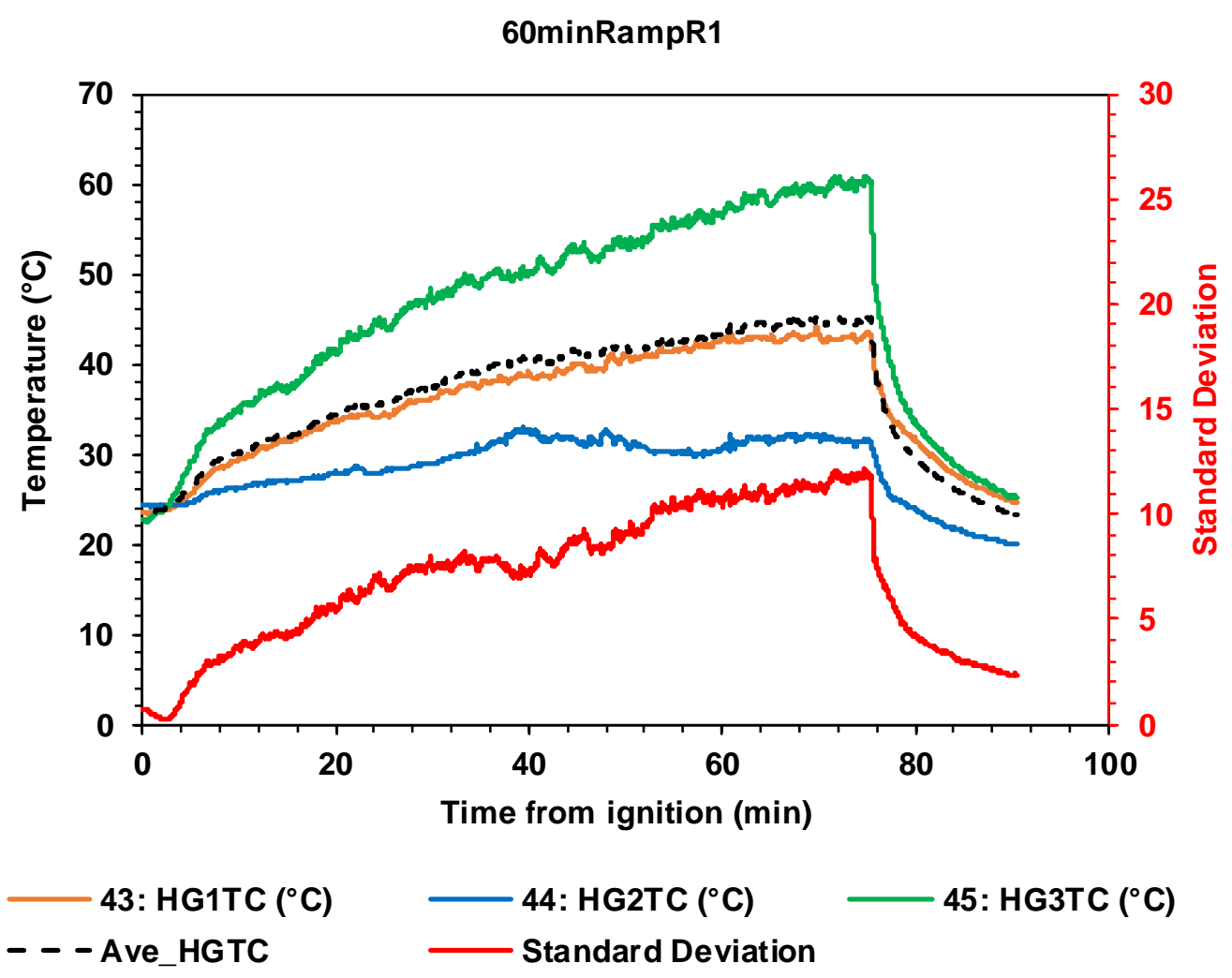

\section{Vent conditions}

Figure 31. Gardon gauges temperature for 60minRampR1 test.

\section{Openings temperature}

Figure 32 presents the temperatures measured by the thermocouples mounted at the north and south opening (see Figure 12 (c) and (d)). Higher temperatures were registered at the top part of the south-west opening, reaching peak values of around $900{ }^{\circ} \mathrm{C}$. 


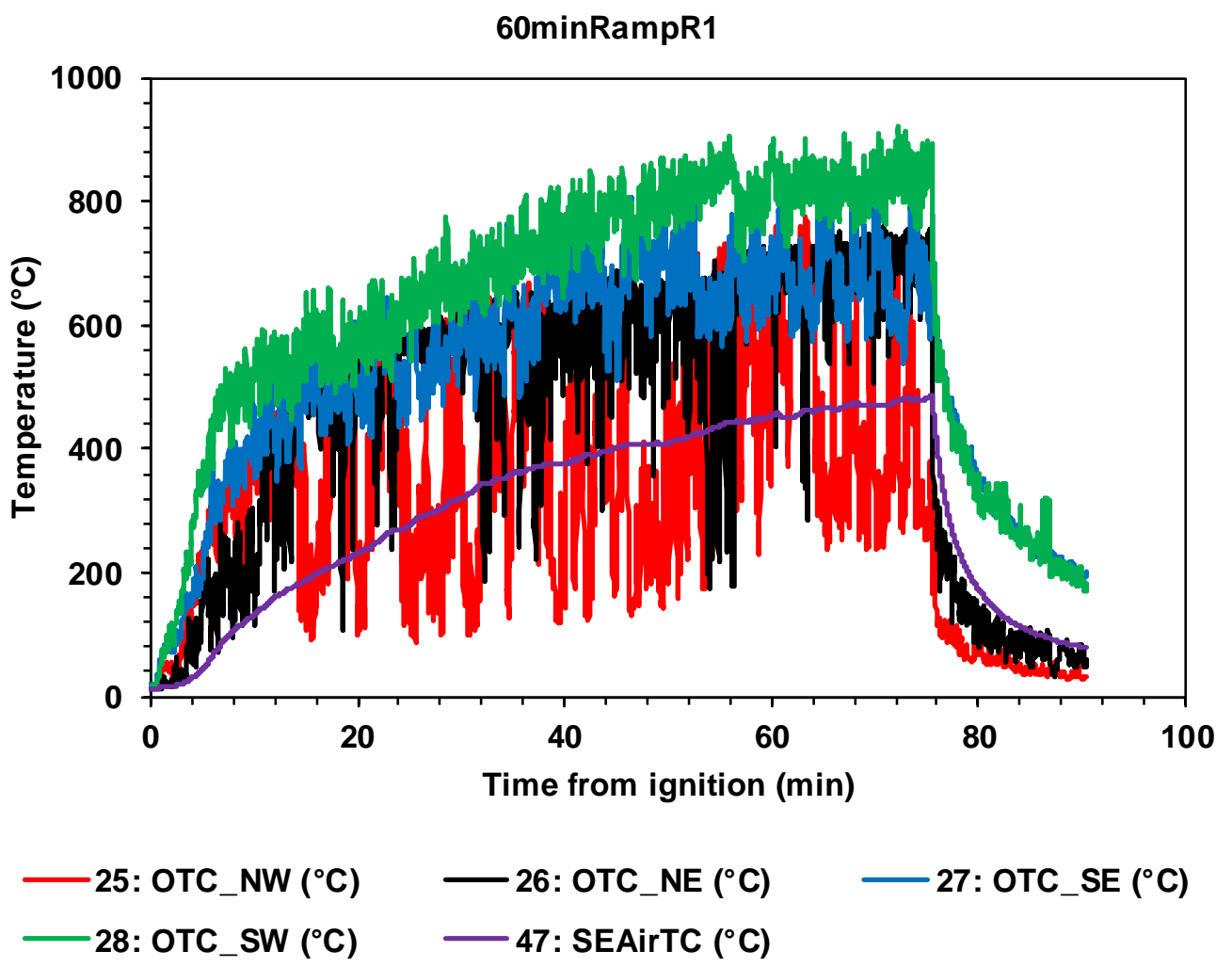

Figure 32. Openings temperature for 60minRampR1 test. 


\section{APPENDIX D: POST-TEST SIMULATIONS}

\section{Upper layer gas temperatures}

Figure 33 to Figure 35 present the comparisons between the predicted and measured thermocouple temperatures at $30.5 \mathrm{~cm}$ beneath the ceiling. The predicted data are from post-test simulations on the full compartment. Measured heat release rates of the burners are used in the FDS models. The FDS input files can be found at:

$\underline{15 \operatorname{minRampR} 1}$

https://github.com/firemodels/fds/blob/master/Validation/NIST_E119_Compartment/FDS_Input _Files/E119_Compartment_Test_1.fds

$\underline{15 \operatorname{minRampR} 2}$

https://github.com/firemodels/fds/blob/master/Validation/NIST_E119_Compartment/FDS_Input _Files/E119_Compartment_Test_2.fds

$\underline{60 \mathrm{minRampR} 1}$

https://github.com/firemodels/fds/blob/master/Validation/NIST_E119_Compartment/FDS_Input _Files/E119_Compartment_Test_3.fds 
(a)
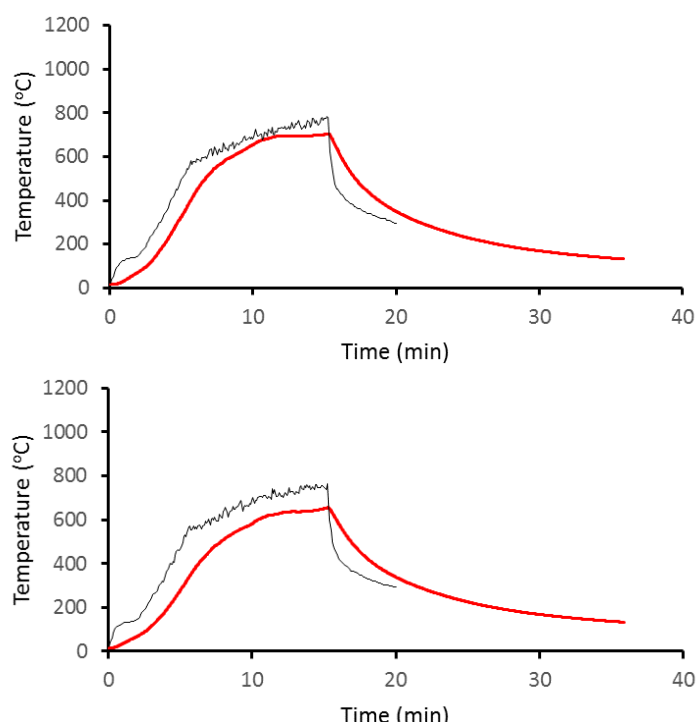

(c)

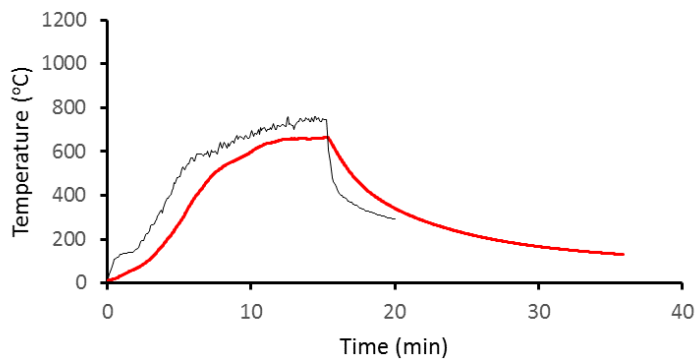

(e)

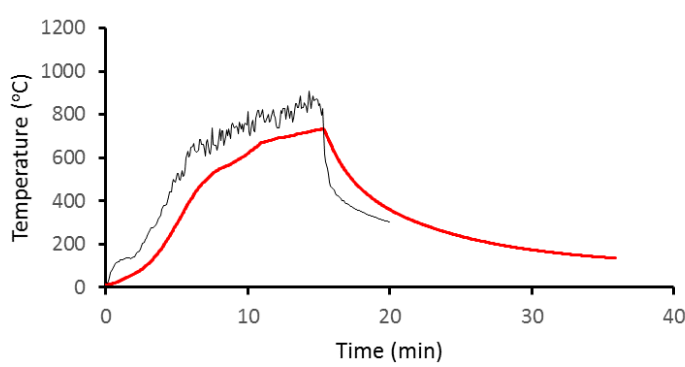

(g)

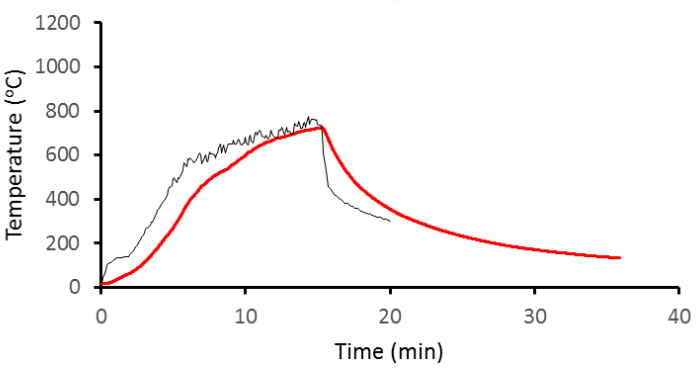

(i)

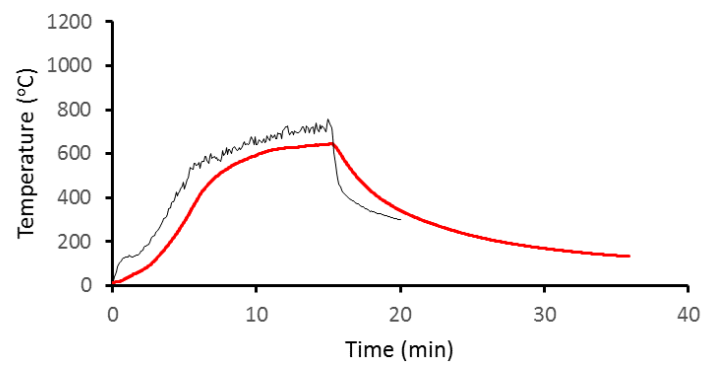

(k)

Figure 33. 15minRampR1. (a)-(I) are TC1-TC12. Bold red line - test data; black line - FDS data

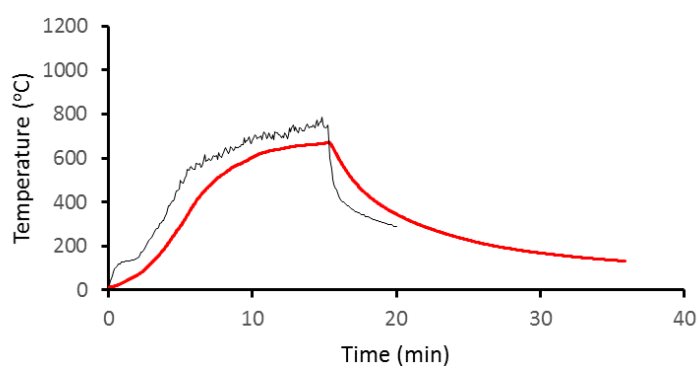

(d)

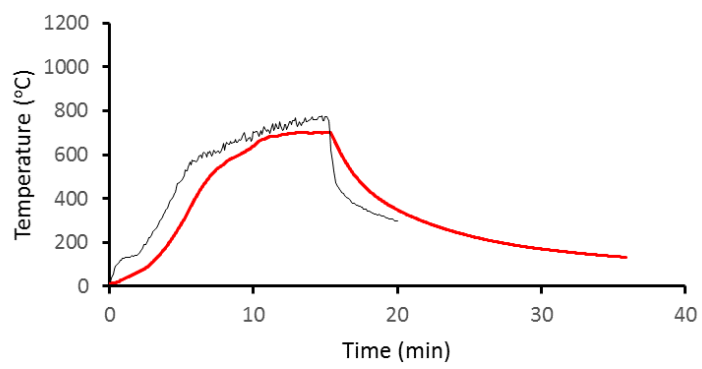

(f)

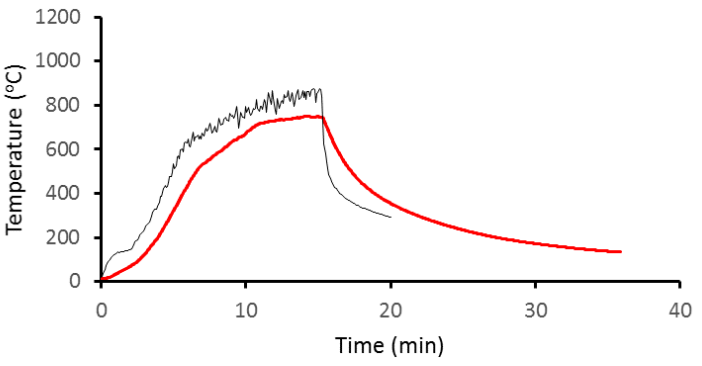

(h)

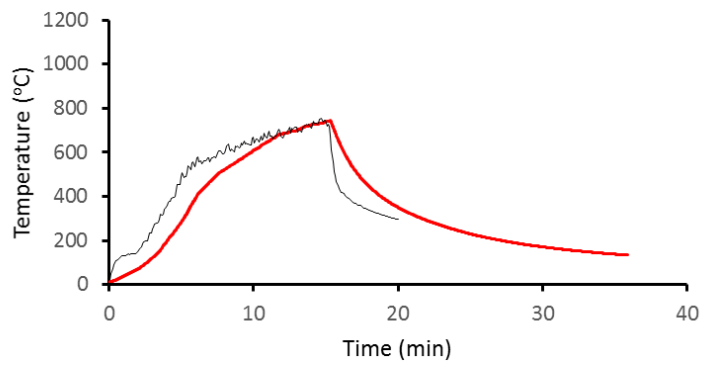

(j)
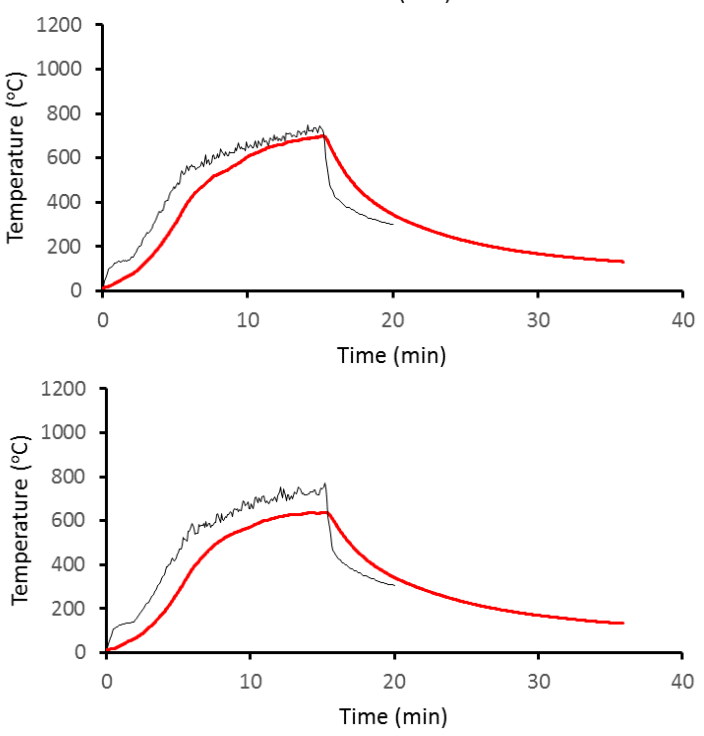
(a)
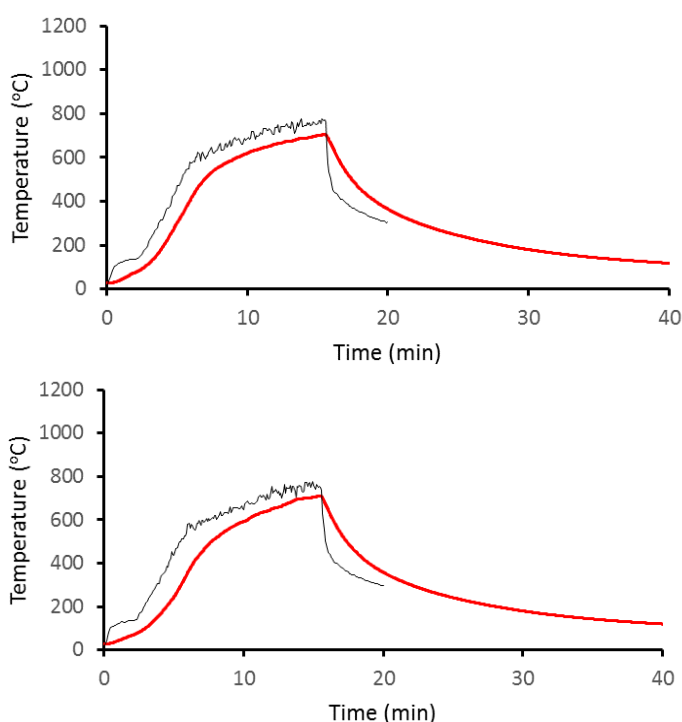

(c)

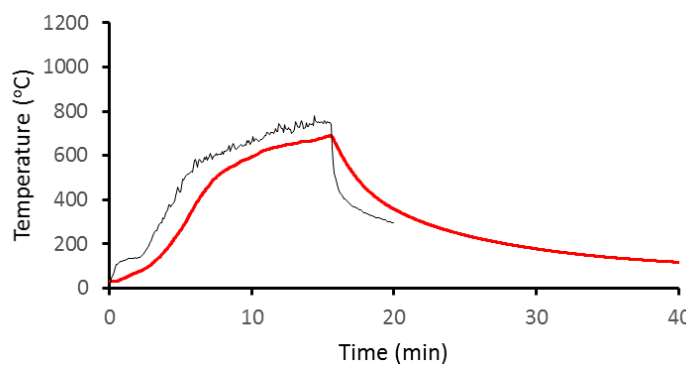

(e)

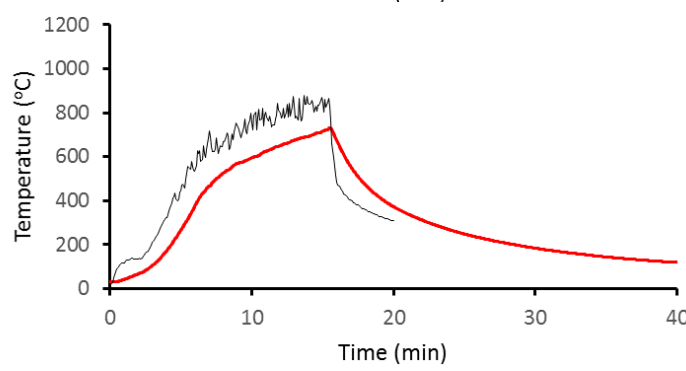

(g)

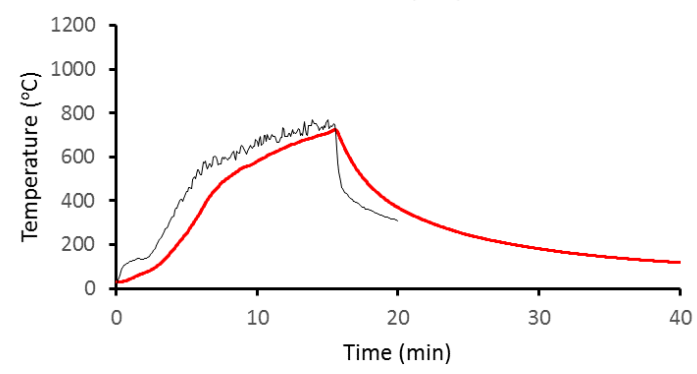

(i)

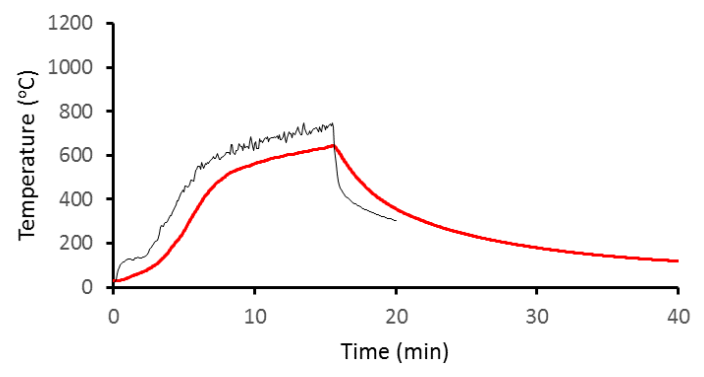

(b)

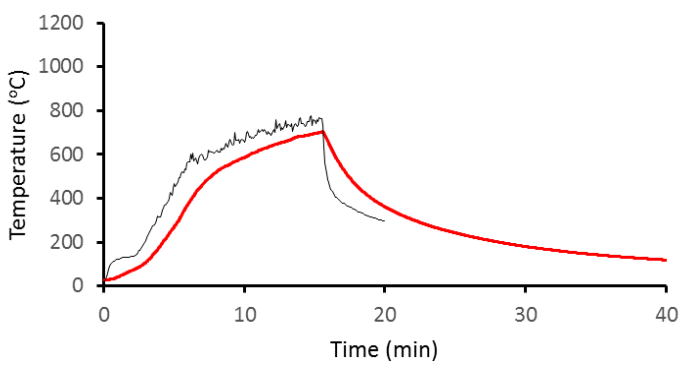

(d)
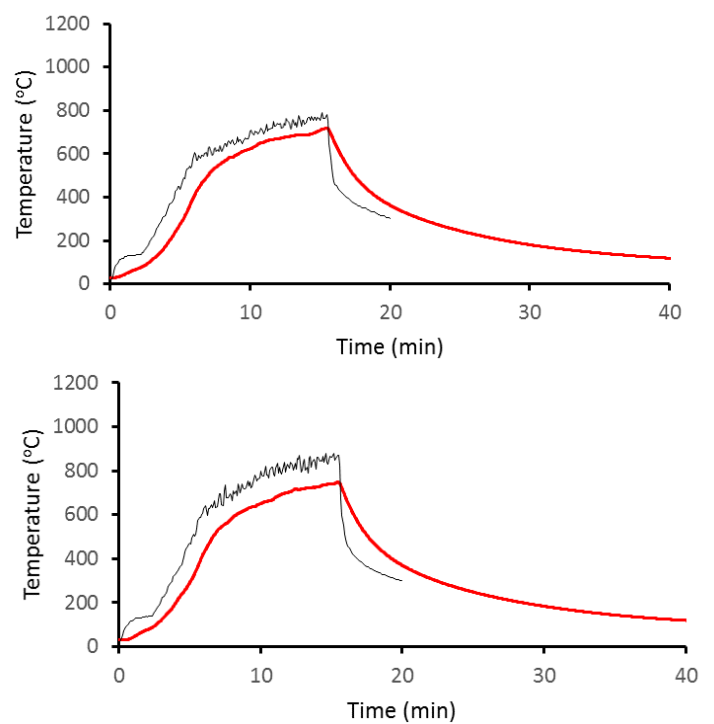

(f)

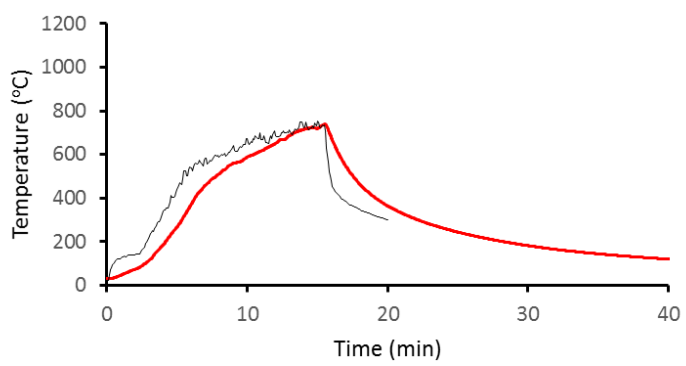

(h)

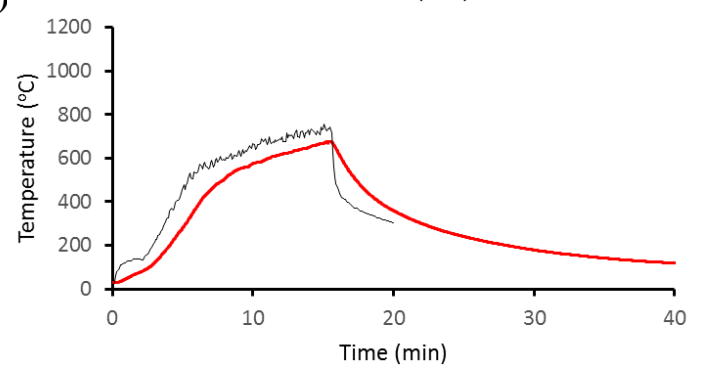

(j)

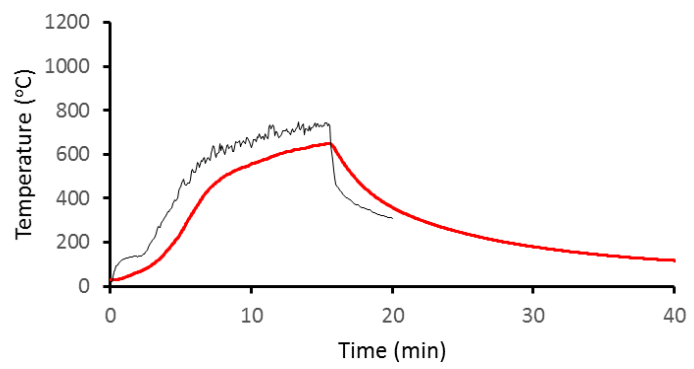

Figure 34. 15minRampR2. (a)-(1) are TC1-TC12. Bold red line - test data; black line - FDS data 


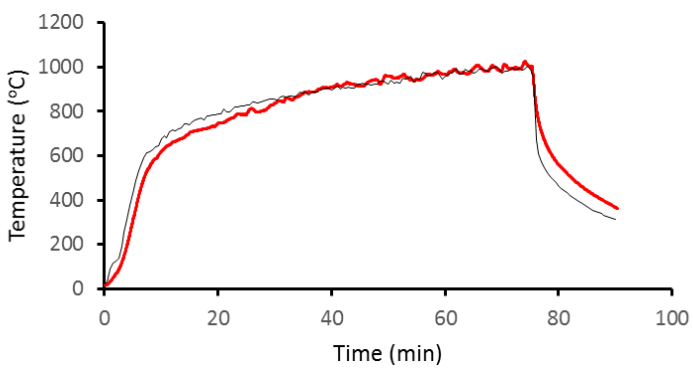

(b)
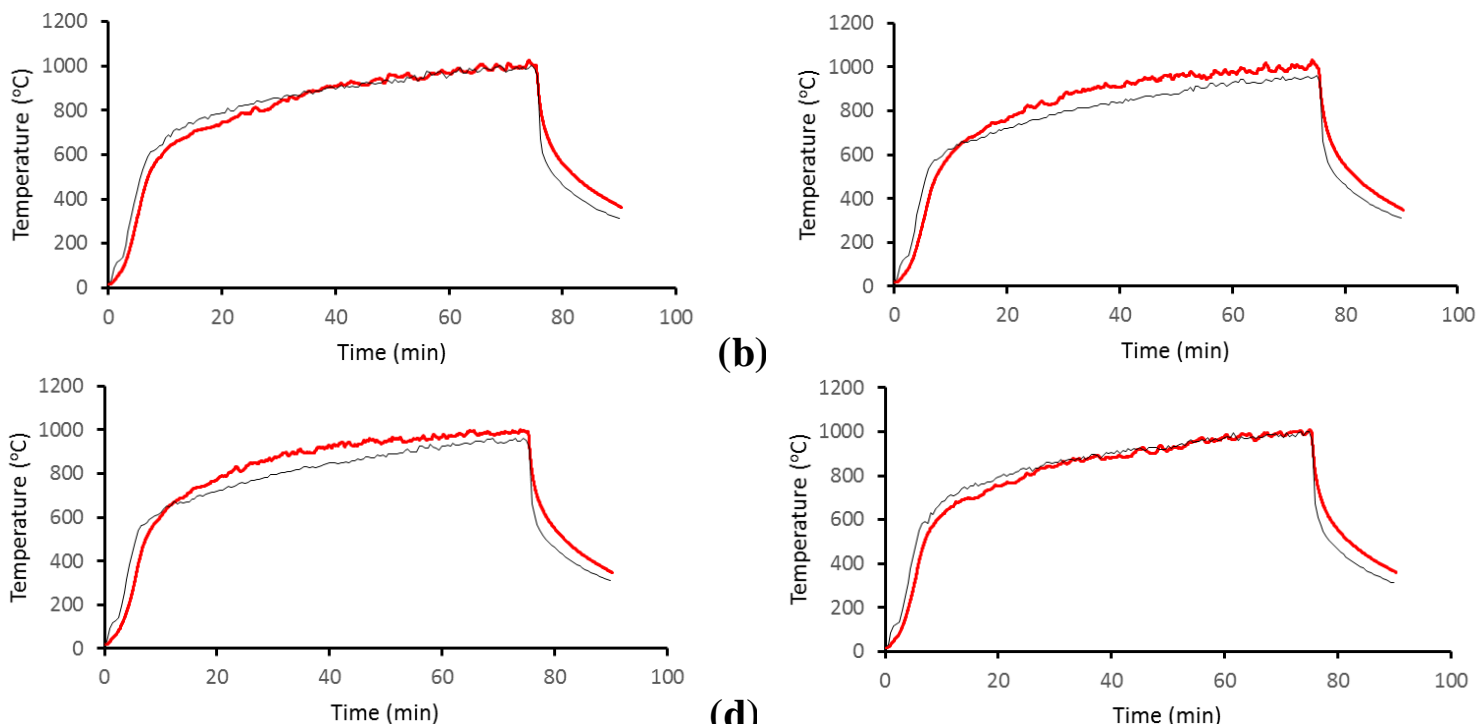

(c)

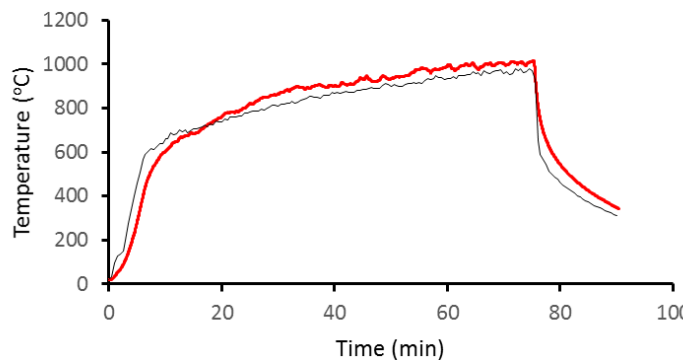

(e)

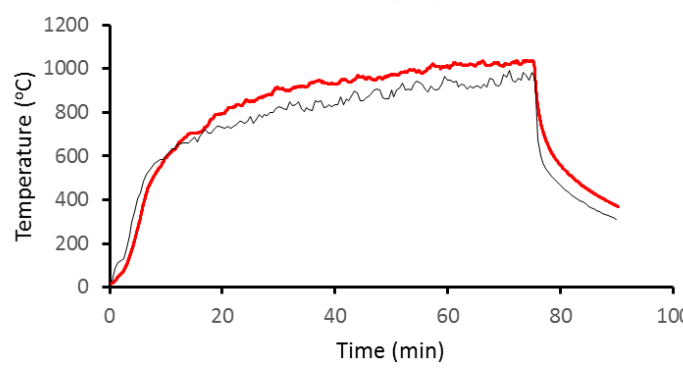

(d)
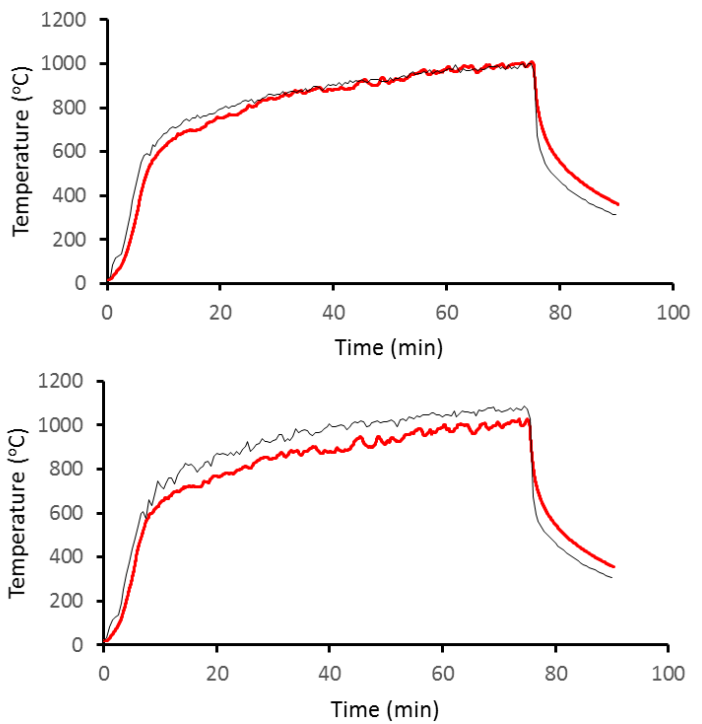

(f)

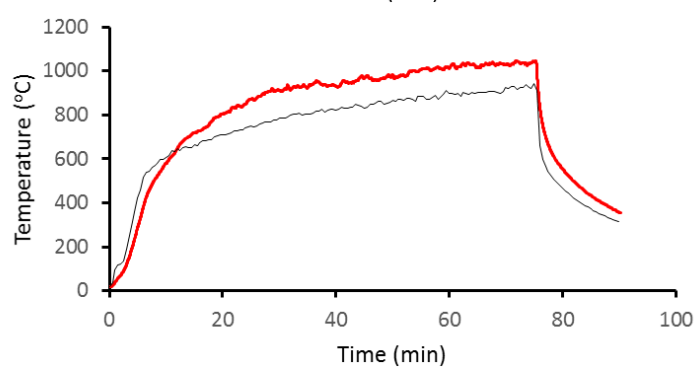

(g)

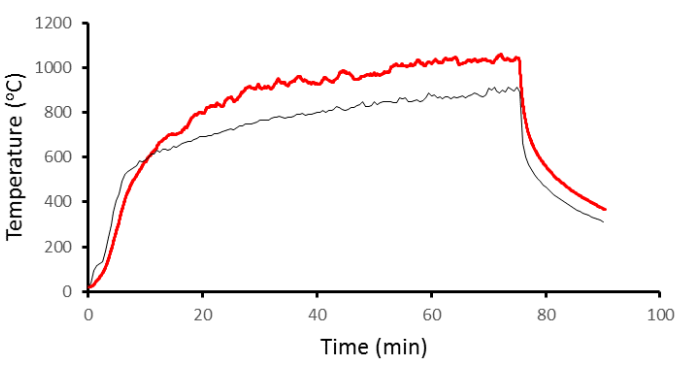

(i)

(h)

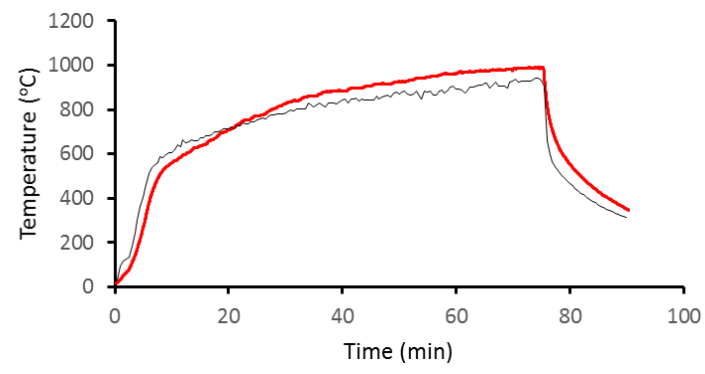

(j)

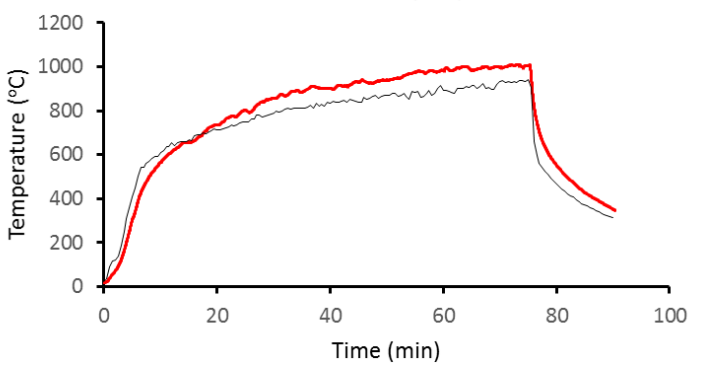

$(\mathbf{k})$

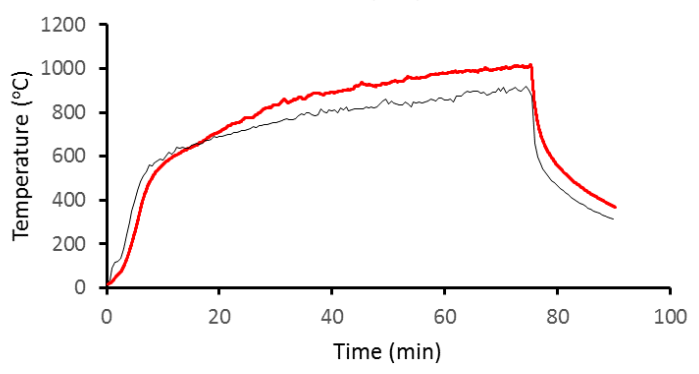

Figure 35. 60minRampR1. (a)-(1) are TC1-TC12. Bold red line - test data; black line - FDS data 


\section{ApPendix E: ChANGe Log}

\section{Revision - April 9, 2020}

- Corrected the equation of incident heat flux, $\left[\dot{q}_{i n c}^{\prime \prime}\right]^{i}$, in Section 3.3.3. 